\title{
molecules
}

ISSN 1420-3049

www.mdpi.com/journal/molecules

Review

\section{Photochemistry of Flavonoids}

Miroslav Sisa ${ }^{1}$, Susan L. Bonnet ${ }^{1}$, Daneel Ferreira ${ }^{2}$ and Jan H. Van der Westhuizen ${ }^{1, *}$

1 Department of Chemistry, University of the Free State, Nelson Mandela Avenue, Bloemfontein, 9301, South Africa; E-Mails: sisa.miroslav@gmail.com (M.S.); bonnets1@ufs.ac.za (S.L.B.)

2 Department of Pharmacognosy, Research Institute of Pharmaceutical Sciences, School of Pharmacy, The University of Mississippi, University, MS 38677, USA;

E-Mail: dferreir@olemiss.edu (D.F.)

* Author to whom correspondence should be addressed; E-Mail: vdwestjh@ufs.ac.za; Tel.: +27-(0)51 4012782; Fax: +27-(0)51 4446384.

Received: 19 May 2010; in revised form: 15 July 2010 / Accepted: 29 July 2010 /

Published: 2 August 2010

Abstract: Flavonoids and their photochemical transformations play an important role in biological processes in nature. Synthetic photochemistry allows access to molecules that cannot be obtained via more conventional methods. This review covers all published synthetic photochemical transformations of the different classes of flavonoids. It is first comprehensive review on the photochemistry of flavonoids.

Keywords: photochemistry; photoinduction; phototransformation; UV radiation; flavonoids; polyphenols; tannins; chalcones; photooxygenation

\section{Introduction}

Flavonoids are polyphenolic compounds based on a $\mathrm{C}_{15}\left(\mathrm{C}_{6} \mathrm{C}_{3} \mathrm{C}_{6}\right)$ framework. They contain a chroman ring (C-ring) with a second aromatic ring (B-ring) at the $\mathrm{C}-2, \mathrm{C}-3$, or C-4 position. The heterocyclic six-membered C-ring is sometimes replaced by a five-membered ring (e.g., aurones) or the acyclic form (chalcones). The oxidation state of the C-ring is used to classify flavonoids into different categories, of which typical examples are flavan-3-ols, flavanones, flavones and flavonols. The term flavonoid can be ambiguous as it may refer either to the class of all $\mathrm{C}_{6} \mathrm{C}_{3} \mathrm{C}_{6}$ compounds, or its meaning may be restricted to 2-arylchromans with a carbonyl group at C-4 (C-ring) [1]. Flavonoids 
occur widely as glycosylated monomers or as flavan-3-ol oligomers (proanthocyanidins $=$ condensed tannins).

Epidemiological studies suggest that the regular consumption of flavonoids protects humans against diseases associated with oxidative stress such as Alzheimer's disease [2], arteriosclerosis [3], cancer [4,5], and ageing [6]. The polyphenolic nature of flavonoids equates with ready oxidation and the formation of stable radicals and it is widely believed that flavonoids protect against free radical damage (caused by photolytically generated singlet oxygen and metabolic processes in living organisms) and act as antioxidants [7]. Other biological effects include improved blood flow [8], the inhibition of cholesterol absorption [9] and protection from damage by ultraviolet B radiation [10]. These have stimulated renewed interest in flavonoid synthesis and photochemical transformations that give access to molecules that are not available via conventional chemistry. The increasing use of flavonoids as food additives for health purposes has also contributed towards the growing interest in flavonoid photostability and photochemistry. Flavonoids are commercially important constituents of red wine [11], adhesives [12], and black tea [13].

The reason for the ubiquitous existence of flavonoid monomers and their oligomers as secondary metabolites in plants is controversial. Their polyphenolic nature allows complexation with proteins, as is evident in the widespread use of tannin extracts to tan leather, hence the name tannin [14]. This property renders protein in food indigestible and supports their putative anti-feeding role that provides protection against insect predation. Certain flavonoids are toxic to insects and other organisms. Bark that contains rotenoids is used by tribal communities to poison and harvest fish from rivers [15].

The light absorption properties of flavonoids and anthocyanidins in the visible ultraviolet light region are responsible for the colours associated with flowers and this plays an important role in pollination by insects and thus plant reproduction.

It has been shown that light is important in flavonoid biosynthesis [16,17], and that light is essential for anthocyanidin synthesis [18-21]. Flavonoids play important roles as development regulators and can regulate auxin transport in vivo [22]. Their role as antioxidants in plants [23], in stress protection [17] and in photoprotection [24] has been discussed. The influence of light on plant defence against pest and pathogens has been reviewed [25].

The postulate that flavonoids protect plants against ultraviolet light damage is supported not only by the fact that flavonoids absorb UV radiation and may act as sunscreens, but also by observations that exposure to UV radiation induces higher levels of flavonoids in plants. Caldwell [26] demonstrated a correlation between flavonoid content in plants and ambient UV conditions. Alpine plants at high altitudes and tropical plants from regions exposed to intense UV radiation have higher flavonoid content than plants from other regions. Plants exposed to sunlight have short internodes and smaller thicker leaves than plants that grow in shade [17].

It was observed that the biosynthesis of flavonoids with antioxidant properties (e.g., orthodihydroxy or catechol B-ring substitution) in plants is stimulated by UV light at the expense of flavonoids that are not considered as antioxidant (e.g., monohydroxy B-ring substitution) and flavonoids with good sunscreen properties (e.g., hydrocinnamic acid derivatives). This suggested that flavonoids' photoprotection may also involve the removal of reactive oxygen species that form as a result of exposure to strong UV light. 
Apart from the photochemical transformations that flavonoids may undergo due to their long daily exposure to sunlight, these compounds may also transfer or accept light energy to or from other molecules, i.e. act as sensitizers or quenchers.

A photochemical transformation requires excitation of an electron from a ground state orbital to an excited state orbital. This is usually achieved via the absorption of ultraviolet light (UV) by a chromophore. All flavonoids have aromatic chromophores, as indicated by UV absorptions in the $250 \mathrm{~nm}$ region of their UV spectra. These compounds may undergo $\pi, \pi^{*}$ excitation and react from $\pi, \pi^{*}$ excited states. Certain flavonoids contain carbonyl chromophores and absorb light in the $300 \mathrm{~nm}$ region. They may undergo $n, \pi^{*}$ excitation to react from $n, \pi^{*}$ excited states. Carbonyl chromophores that are conjugated with the aromatic ring (e.g., acetophenones and chalcones) absorb UV light in the $350 \mathrm{~nm}$ region. The $\mathrm{n}, \pi^{*}$ and $\pi, \pi^{*}$ excited states of these compounds are almost degenerate and the state from which their reactions originates is sometimes controversial. Polyphenolic chalcones may absorb light in the visible region as is evident by their colours. Molecules that have no chromophores and cannot absorb light energy may be excited indirectly via sensitisation. This involves the transfer of mostly triplet energy.

The excited states may be in the triplet or singlet form. The triplet excited $n, \pi^{*}$ state $\left[3\left(n, \pi^{*}\right)\right.$ state $]$ is associated with radical reaction type products and the singlet excited $\pi, \pi^{*}$ state $\left[{ }^{1}\left(\pi, \pi^{*}\right)\right.$ state] with ionic reaction type products. Solvent polarity is important and ionic type products are encouraged by polar solvents. Triplet excited states are formed indirectly from the initially formed singlet states via intersystem crossing [27]. Triplet excited states usually have much longer lifetimes than the corresponding singlet states, permitting photochemical transformations to compete more effectively with relaxation of the excited state to the photochemical inert ground state.

Much of the older photochemistry work in flavonoid chemistry was on compounds with unsubstituted aromatic rings and high yields were reported (see the review by Gupta et al. [28]). Polyphenolic flavonoids are more representative of naturally occurring molecules and have more interesting biological properties. These compounds generally afford lower yields and require special conditions to react due to deactivation by phenolic hydroxy and methoxy groups [29].

\section{Flavone and Flavonol Photochemistry}

Flavones and flavonols are characterized by fully unsaturated C-rings that connect the A and Brings in a single conjugated system. They are generally photochemically inert as indicated by their reported use as photosensitisers, photoquenchers and ultraviolet absorption filters [30]. Their inertness prompted and allowed investigation into the potential of photochemically generated singlet oxygen to afford chemical transformations.

Waiss and Corse (1965) [31] investigated per-O-methylflavonols. Photoxidative cyclisation of quercetin penta- $O$-methyl ether (1) afforded the tetra- $O$-methyl ether of $\beta$-photomethylquercetin (2) in $32 \%$ yield in deoxygenated methanol under dry nitrogen (low pressure mercury lamps, $350 \mathrm{~nm}$ ) (Scheme 1). This result led the authors to speculate that photochemistry was involved in the biosynthesis of peltogynol (3) and the rotenoids [e.g., dolichone (4) and $\alpha$-toxicarol (5) (Figure 1], which co-occur with 2-methoxyisoflavonoids. 
Scheme 1. Photo-oxidative cyclization of quercetin pentamethyl ether.<smiles>COc1cc(OC)c2c(=O)c(OC)c(-c3ccc(OC)c(OC)c3)oc2c1</smiles>

Figure 1. Structure of peltogynol and the naturally occurring rotenoids.<smiles>Oc1ccc2c(c1)O[C@H]1c3cc(O)c(O)cc3CO[C@@H]1[C@H]2O</smiles><smiles>O=C1c2cc3ccoc3cc2O[C@H]2COc3cc4c(cc3[C@H]12)OCO4</smiles><smiles>COc1cc2c(cc1OC)[C@H]1C(=O)c3ccc4c(c3O[C@H]1CO2)C=CC(C)(C)O4</smiles>

In a subsequent paper Waiss and co-workers (1967) [32] described the isolation under similar conditions of $\beta$-photomethylquercetin (2, 31\%), $\alpha$-lumimethylquercetin (6, 16\%), $\alpha$-photomethylquercetin $(7,5 \%)$, and traces of methoxy $\beta$-photomethylquercetin $(\mathbf{8}, 1 \%)$ (Scheme 2). No $\beta$-lumimethylquercetin (9, Figure 2 ) was detected. Repetition of the reaction in oxygen-free benzene yielded only photo-oxidised $\beta$-photomethylquercetin, and $\alpha$-photomethylquercetin, at twice the rate of reaction. Rigorous efforts to exclude oxygen failed to yield $\alpha$-and $\beta$-lumimethylquercetins. Yields in benzene were not reported. Failure to inhibit the reaction with triplet quenchers (anthracene or $\mathrm{O}_{2}$ ) and low intensity of phosphorescence as compared to fluorescence led to postulation of a ${ }^{1}\left(\pi, \pi^{\star}\right)$ primary reactive intermediate.

Scheme 2. Photochemistry of quercetin pentamethyl ether.

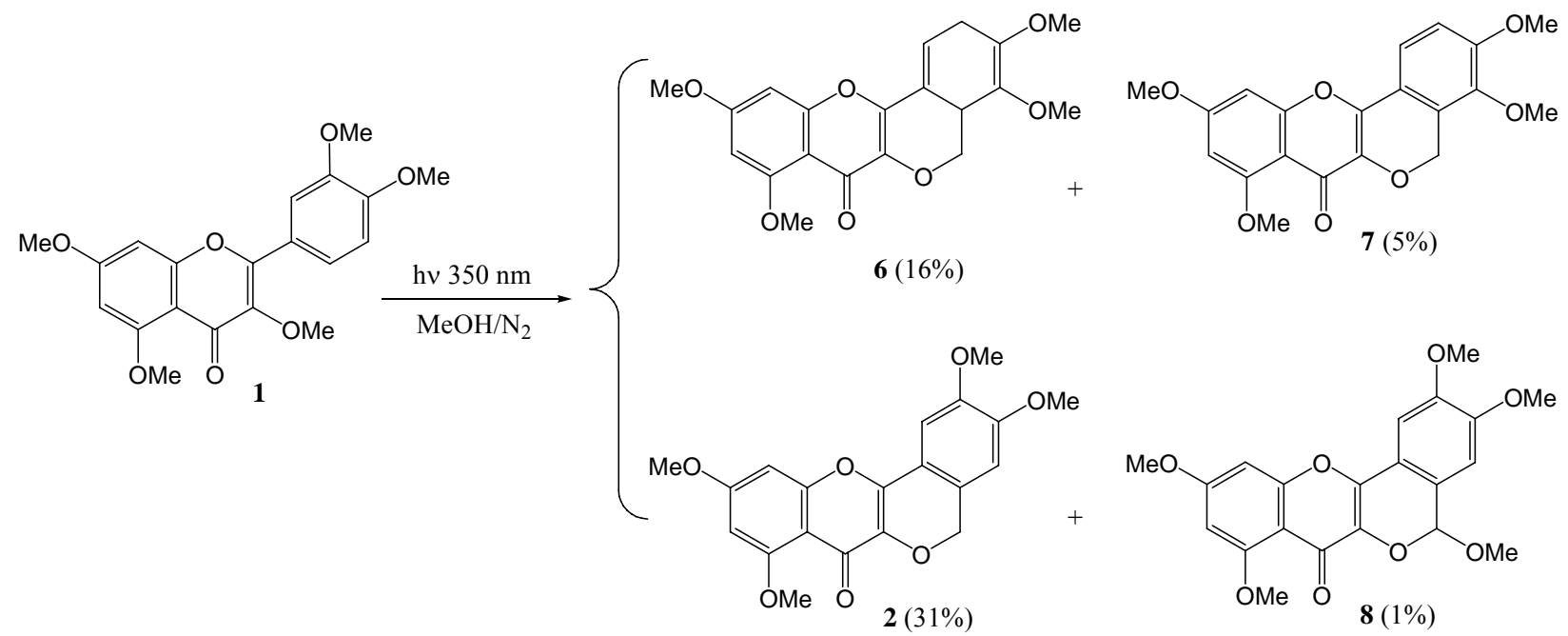


Figure 2. Structure of $\beta$-lumimethylquercetin.<smiles>COC1=CC2COc3cc4oc(OC)cc(OC)c-4c(=O)c3C2=CC1OC</smiles>

9

Matsuura and Matsushima [33] studied flavonols where the 3-hydroxy group had not been methylated. Photolysis of quercetin 5,7,3',4'-tetra-O-methyl ether (10b) in pyridine in the presence of rose bengal under bubbling oxygen ( $300 \mathrm{~W}$ tungsten lamp) followed by diazomethane methylation of the reaction mixture afforded depside (11b, 77\%), methyl 2-hydroxy-4,6-di-O-methylbenzoate (12b, 2\%) and methyl 3,4-di-O-methylveratrate (13b, 11\%) (Scheme 3). Enzymatic oxygenation also yielded depside and there seemed to be a resemblance between enzymatic and photosensitised oxygenation. Liberated carbon monoxide (31\%) and carbon dioxide (17\%) were determined. Similar results were obtained with 3-hydroxyflavone (10c). In a later publication Matsuura and co-workers [34] irradiated (100 W high-pressure lamp) free phenolic quercetin (10d) in methanol in the presence of rose bengal to get 12b. In the absence of an oxygen sensitiser no reaction took place. No reaction was observed with quercetin 3,7,3',4'-tetra-O-methyl ether. It was suggested that the 3-hydroxy group was essential for photo-oxygenation. The mechanism for the reaction is given in Scheme 4.

Scheme 3. Photosensitized oxygenation of 3-hydroxyflavones.

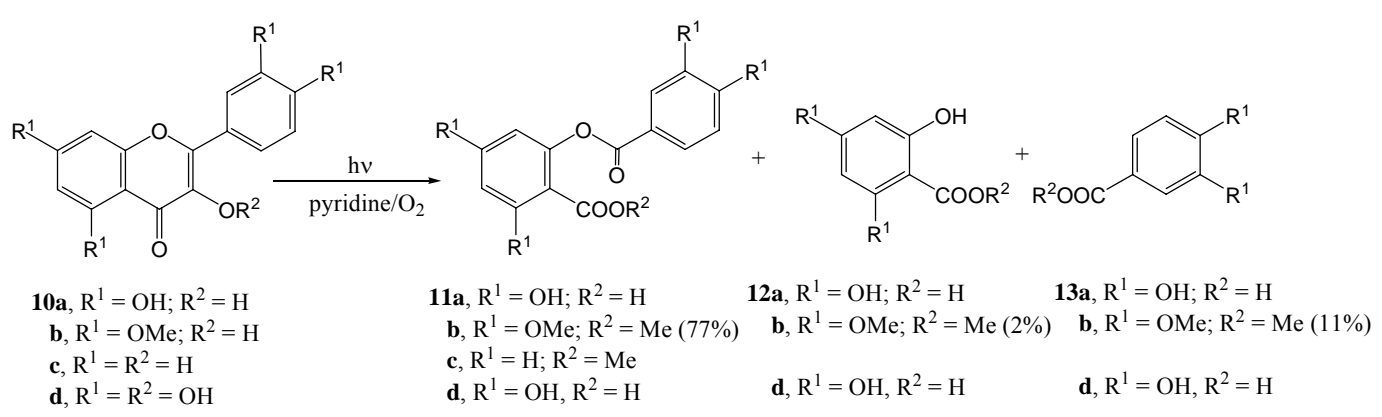

Scheme 4. Suggested mechanism of photosensitized oxygenation of 3-hydroxyflavones.

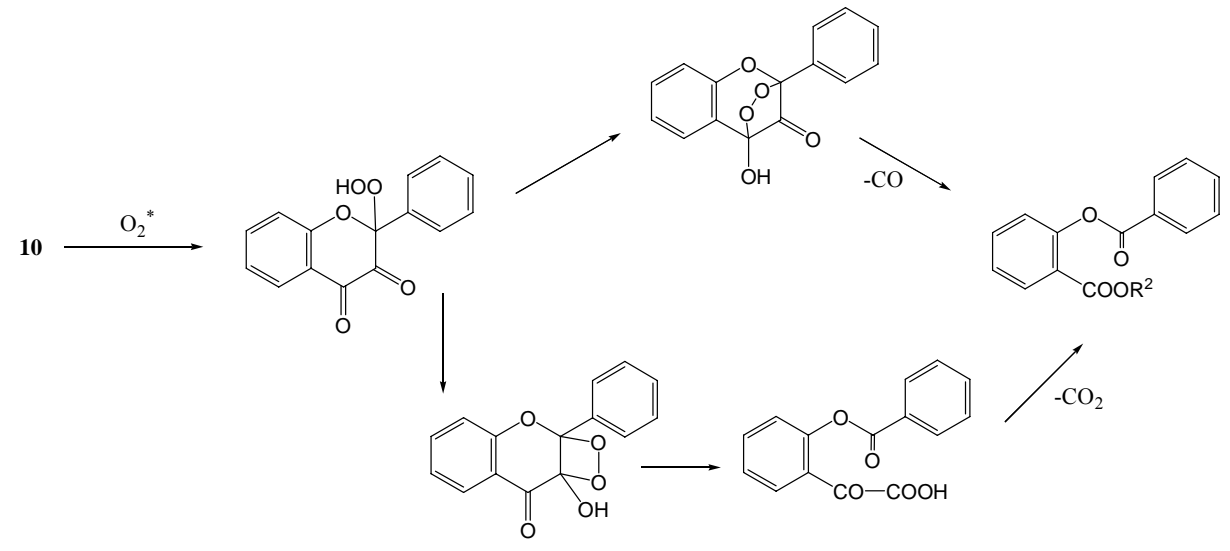


Matsuura and Matsushima [35] postulated that, despite rigorous efforts by Waiss and co-workers $[31,32]$ to work under oxygen-free conditions, oxygen must be involved in the transformation of intermediary lumimethylquercetin to photomethylquercetin. Photolysis of 3,7-dimethoxyflavone (14) under oxygen in pyridine (high-pressure mercury lamp with a Pyrex filter) yielded at least seven compounds. Only the photomethyl analogue $(\mathbf{1 5}, 4 \%)$ and the lactone $(\mathbf{1 6}, 11 \%)$ were isolated. 3Methoxyflavanone (17) yielded only the lactone (19, also 11\%) (Scheme 5).

Scheme 5. Photo-oxidative cyclization of 3-methoxyflavones.<smiles>[R]c1ccc2c(=O)c(OC)c(-c3ccccc3)oc2c1</smiles>

14, $\mathrm{R}=\mathrm{OMe}$

$17, \mathrm{R}=\mathrm{H}$
15, $\mathrm{R}=\mathrm{OMe}(4 \%)$

18, $R=H$ (not isolated)
16, $\mathrm{R}=\mathrm{OMe}(11 \%)$

19, $\mathrm{R}=\mathrm{H}(11 \%$, rose bengal presence $-14 \%)$<smiles>COc1cc(O)c2c(=O)c(OC)c(-c3ccc(OC)c(OC)c3)oc2c1</smiles>

The mechanism of the formation of the lactone is given in Scheme 6. Quercetin 3,7,3',4'-tetra-Omethyl ether (20) and 5-hydro-3,7-dimethoxyflavone (21) did not undergo photocyclisation and were recovered unchanged. This was attributed to hydrogen bonding between the 4-carbonyl and 5-hydroxyl group that interferes with the $n, \pi^{*}$ excitation of the carbonyl chromophore. This conclusion is supported by the fact that $o$-hydroxybenzophenone does not undergo photoreduction and is used as a photostabiliser (Scheme 7).

Scheme 6. Mechanism of the formation of the lactone.

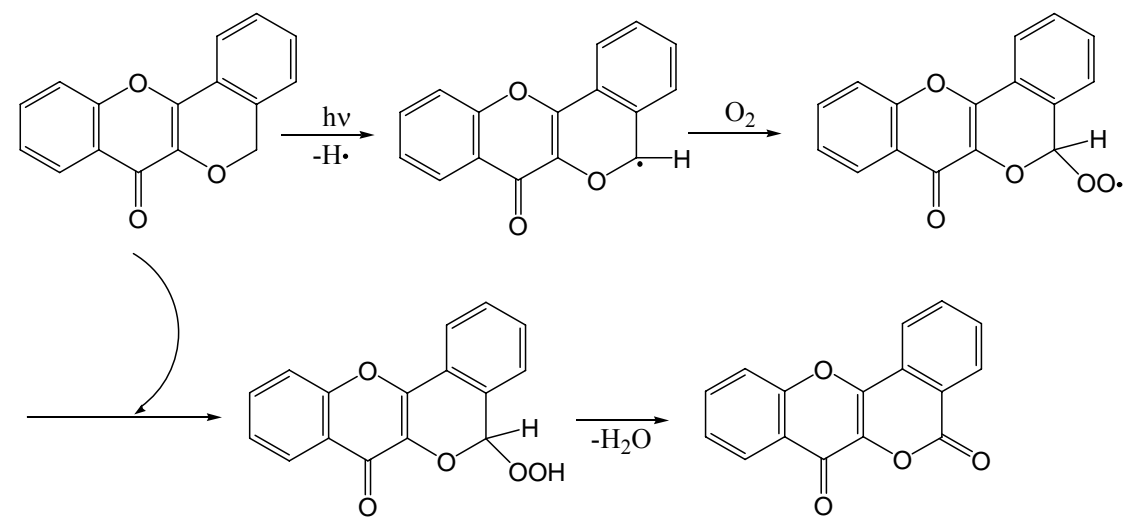


Scheme 7. Photostabilization of o-hydroxybenzophenone.<smiles></smiles><smiles>COc1cc2c3c(c1O)OC(c1ccccc1)=C(O2)O3</smiles>

21

Suginome and co-workers [36] studied photo-oxygenation of dehydrorotenoids. Irradiation of dehydrorotenone (22c) with a $150 \mathrm{~W}$ high-pressure mercury lamp in a dioxane-ethanol mixture containing sodium borohydride yielded rotenonone (23c, 40\%) (Scheme 8). In the absence of sodium borohydride no isolable product was formed. It was postulated that sodium borohydride converted intermediary hydroperoxides (the product of singlet oxygen attack on the methylene moiety) into hemiacetals that converted to the lactone carbonyl in the product. Sodium borohydride may also destroy free radical initiators and prevent unwanted side reactions. Table 1 gives yields obtained with analogues of dehydrorotenones 23a-d. Rotenone and isorotenone were inert under the reaction conditions.

Scheme 8. Photoinduced oxygenation of dehydrorotenones.

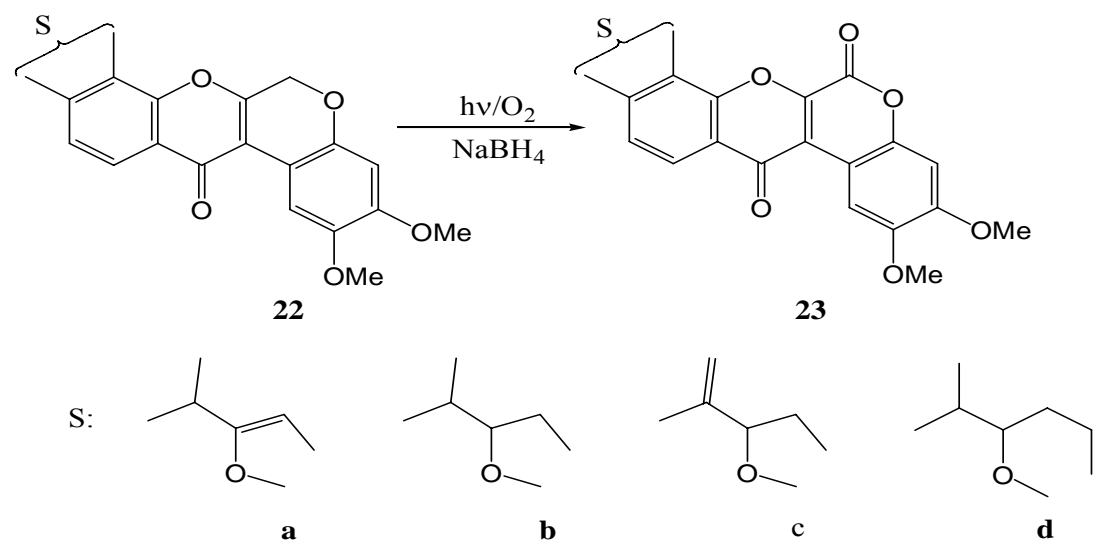

Table 1. Photoinduced oxygenation of dehydrorotenones.

\begin{tabular}{cccc}
\hline $\begin{array}{c}\text { Irradiated compound } \\
\text { 22 }\end{array}$ & $\begin{array}{c}\text { Product 23 (time of } \\
\text { irrad./h) }\end{array}$ & $\begin{array}{c}\text { Yield (\%) } \\
\text { with } \mathbf{~ N a B H}_{\mathbf{4}}\end{array}$ & $\begin{array}{c}\text { Yield (\%) } \\
\text { without } \mathbf{N a B H}_{\mathbf{4}}\end{array}$ \\
\hline $\mathbf{a}$ & $\mathbf{a}(44)$ & 40 & trace \\
$\mathbf{b}$ & $\mathbf{b}(24)$ & 9 & trace \\
$\mathbf{c}$ & $\mathbf{c}(24)$ & 10 & trace \\
$\mathbf{d}$ & $\mathbf{d}(94) *$ & 16 & trace \\
Rotenone (22c: & $($ 23c: 6a,12a-dihydro-) & 0 & 0 \\
6a,12a-dihydro-) & & & 0 \\
Isorotenone (22a: & (23a: 6a,12a-dihydro-) & 0 & 0 \\
6a,12a-dihydro-) & & & \\
\hline
\end{tabular}

* benzene-dioxane $(2: 1)$ as the solvent. 
Thakur and co-workers [37] investigated the photochemistry of 3-O-propargylflavonol (24). Irradiation with Pyrex filtered light from a $125 \mathrm{~W} \mathrm{Hg}$ lamp in dry benzene furnished cyclized products 25a (20\%), 25b (16\%), 26a (35\%) and 26b (30\%), as shown in Scheme 9.

Scheme 9. Phototransformations of 3-O-propargylflavonol.<smiles>[R]c1ccc(-c2oc3ccc(Cl)cc3c(=O)c2OCC#C)cc1</smiles><smiles>[R]C1=CC2C(=CC1)c1oc3ccc(Cl)cc3c(=O)c1OC2C#C</smiles><smiles>[R]c1ccc2c(c1)C(C#C)Oc1c-2oc2ccc(Cl)cc2c1=O</smiles>

a, $\mathrm{R}=\mathrm{H}$ b, $\mathrm{R}=\mathrm{OMe}$

The mechanism was rationalised in terms of $\gamma$-hydrogen abstraction from the propargyl group by the excited carbonyl group followed by cyclisation of the 1,4-biradical (Scheme 10).

Scheme 10. 1,4-Hydrogen abstraction in propargylethers.

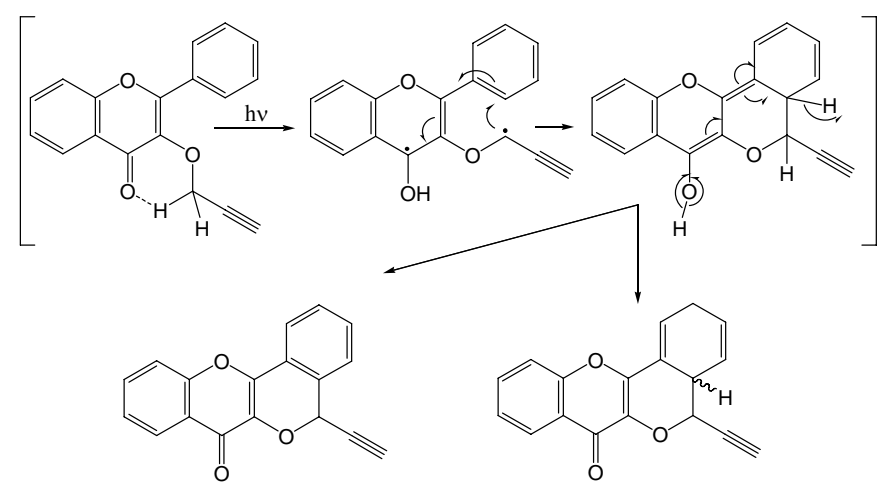

Matsuura and co-workers [38] irradiated flavonol 27b in isopropyl alcohol-benzene with a high pressure mercury lamp through Pyrex and obtained 3-aryl-3-hydroxy-1,2-inandione (28b) in almost quantitative yield. Irradiation of 2'-methoxyflavonol 27a yielded 28a. A 2,3-epoxy-2-hydroxy-1inandone intermediate $\mathbf{2 9}$, formed via a formal $\left[{ }_{\sigma} 2+{ }_{\pi} 2\right]$ cycloaddition, was postulated (Scheme 11).

Scheme 11. Photorearrangement of 3-hydroxyflavones.

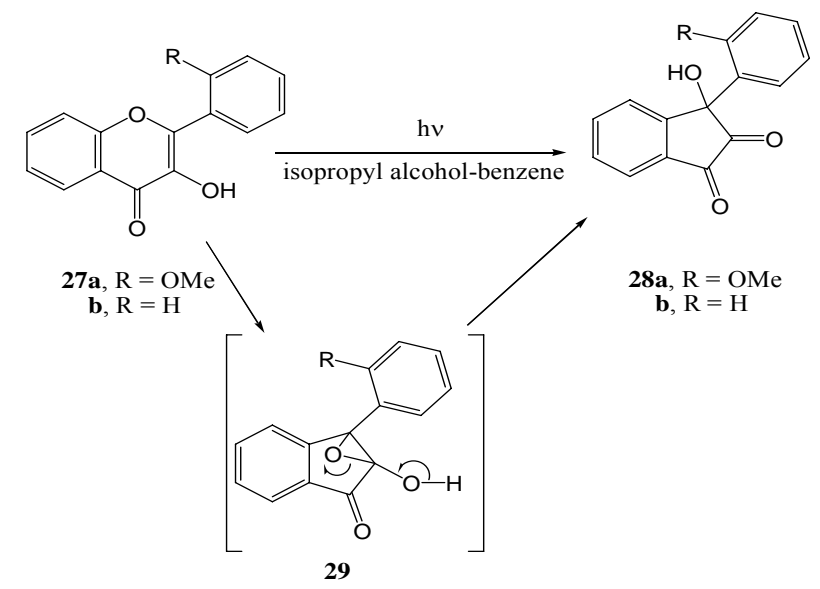


Subsequently Matsuura and co-workers [39] expanded the range of photolysed flavonols (Scheme 12). Table 2 includes previous results of Matsuura et al. [38] and the yields. Free phenolic quercetin (30e) resisted photo-transformation. This could be due to tautomerisation at the 4-CO and 5-OH (cf. photo-enolisation of $o$-hydroxyacetophenone [40,41]), internal quenching via the hydrogen bond between 4-CO and 5-OH, or deprotonation from the excited state (cf. resistance of 3-hydroxybenzophenone to photoreduction [42]). Irradiation of the 3-O-methoxyflavonol 32 yielded a tetracyclic product 33. The replacement of the 3-OH group (i.e. 30) with a 3-OMe group (compound 32) prevents the rearrangement to an inandione (compound 31) (Scheme 13).

Scheme 12. Photorearrangement of 3-hydroxyflavones to 3-aryl-3-hydroxy-1,2-indandiones.<smiles>[R]c1cc([R])c2c(=O)c(O)c(-c3ccc([R])c([R1])c3[R])oc2c1</smiles>

30

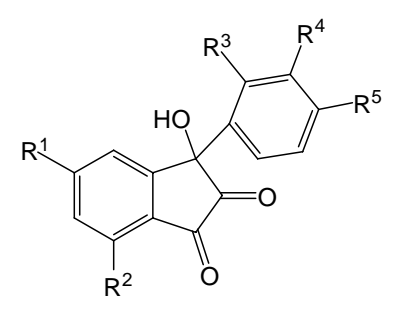

31

Table 2. Yields of indandiones obtained by photorearrangement of 3-hydroxyflavones.

\begin{tabular}{cccccccc}
\hline $\mathbf{3 0}$ & $\mathbf{R}^{\mathbf{1}}$ & $\mathbf{R}^{\mathbf{2}}$ & $\mathbf{R}^{\mathbf{3}}$ & $\mathbf{R}^{\mathbf{4}}$ & $\mathbf{R}^{\mathbf{5}}$ & $\mathbf{3 1}$ & Yield (\%) \\
\hline $\mathbf{a}$ & $\mathrm{H}$ & $\mathrm{H}$ & $\mathrm{OMe}$ & $\mathrm{H}$ & $\mathrm{J}$ & $\mathbf{a}$ & Quant. \\
$\mathbf{b}$ & $\mathrm{H}$ & $\mathrm{H}$ & $\mathrm{H}$ & $\mathrm{H}$ & $\mathrm{H}$ & $\mathbf{b}$ & 84 \\
$\mathbf{c}$ & $\mathrm{H}$ & $\mathrm{H}$ & $\mathrm{H}$ & $\mathrm{H}$ & $\mathrm{OMe}$ & $\mathbf{c}$ & 71 \\
$\mathbf{d}$ & $\mathrm{OMe}$ & $\mathrm{OMe}$ & $\mathrm{H}$ & $\mathrm{OMe}$ & $\mathrm{OMe}$ & $\mathbf{d}$ & 69 \\
$\mathbf{e}$ & $\mathrm{OH}$ & $\mathrm{OH}$ & $\mathrm{H}$ & $\mathrm{OH}$ & $\mathrm{OH}$ & $\mathbf{e}$ & - \\
\hline
\end{tabular}

Scheme 13. 3-OMe-group prevention of the rearrangement to an inandione.<smiles></smiles><smiles>CC=CC(C)C</smiles>

32<smiles>O=c1c2c(oc3ccccc13)-c1ccccc1CO2</smiles>

33

Yokoe and co-workers [43] irradiated flavonol 34a in methanol with a high-pressure mercury lamp and obtained, in addition to the 3-aryl-3-hydroxy-1,2-inandione (35a, 8\%) [38], a phthalide 37a (0.7\%) (Scheme 14).

Scheme 14. Photorearrangement of flavonols.<smiles>[R]c1ccc2oc(-c3ccc([R])c([R])c3)c(O)c(=O)c2c1</smiles>

34<smiles>[R]c1ccc(C2(O)C(=O)C(=O)c3c([R])cccc32)cc1[R]</smiles>

35

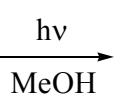<smiles>CC(=O)C(=O)C(C)C</smiles>

36<smiles>[R20]c1ccc2c(c1)C(=O)OC2c1ccc([R])c([R])c1</smiles>

37 
The formation of phthalide 37a was explained in terms of a photoinduced carbon monoxide loss from C-4 via a repeated Norrish type I process ( $\alpha$-fission) of the aliphatic carbonyl group (Scheme 15). The reaction was repeated with a range of substituted flavonols (Scheme 14 and Table 3) and in some cases an aromatic $\alpha$-ketoacid, of type 36 was isolated. It was concluded that the formation of phthalides was, despite the poor yields, a general photoreaction of flavonols. In some cases a benzoic acid degradation product was also isolated. The presence of metal ions such as $\mathrm{Cu}^{2+}, \mathrm{Ni}^{2+}, \mathrm{Fe}^{3+}, \mathrm{Co}^{2+}$, and $\mathrm{Be}^{2+}$ prevented the photochemical rearrangement of flavonols. In contrast to these ions, $\mathrm{Ca}^{2+}$, $\mathrm{Mg}^{2+}$, and $\mathrm{Hg}^{2+}$ had no effects on the photochemical reactivities of flavonols.

Table 3. Products obtained by the irradiation of flavonol in methanol.

\begin{tabular}{|c|c|c|c|}
\hline \multicolumn{4}{|c|}{ Yields (\%) } \\
\hline 34 & 35 & 36 & 37 \\
\hline a, $\mathrm{R}^{1}=\mathrm{H}, \mathrm{R}^{2}=\mathrm{H}, \mathrm{R}^{3}=\mathrm{H}$ & 8 & & 0.7 \\
\hline $\mathbf{b}, \mathrm{R}^{1}=\mathrm{H}, \mathrm{R}^{2}=\mathrm{Me}, \mathrm{R}^{3}=\mathrm{H}$ & 44 & & 2 \\
\hline c, $\mathrm{R}^{1}=\mathrm{H}, \mathrm{R}^{2}=\mathrm{OMe}, \mathrm{R}^{3}=\mathrm{H}$ & & 6 & 12 \\
\hline $\mathbf{d}, \mathrm{R}^{1}=\mathrm{H}, \mathrm{R}^{2}=\mathrm{O}-\mathrm{CH}_{2}-\mathrm{O}=\mathrm{R}^{3}$ & & 14 & 6 \\
\hline e, $\mathrm{R}^{1}=\mathrm{Me}, \mathrm{R}^{2}=\mathrm{H}, \mathrm{R}^{3}=\mathrm{H}$ & 15 & & 2 \\
\hline $\mathbf{f}, \mathrm{R}^{1}=\mathrm{Me}, \mathrm{R}^{2}=\mathrm{Me}, \mathrm{R}^{3}=\mathrm{H}$ & & & 3 \\
\hline g, $\mathrm{R}^{1}=\mathrm{Me}, \mathrm{R}^{2}=\mathrm{OMe}, \mathrm{R}^{3}=\mathrm{H}$ & & 1 & 0.2 \\
\hline $\mathbf{h}, \mathrm{R}^{1}=\mathrm{Me}, \mathrm{R}^{2}=\mathrm{O}-\mathrm{CH}_{2}-\mathrm{O}=\mathrm{R}^{3}$ & & 4 & \\
\hline
\end{tabular}

Scheme 15. Mechanism of Norrish type I formation of phthalide.

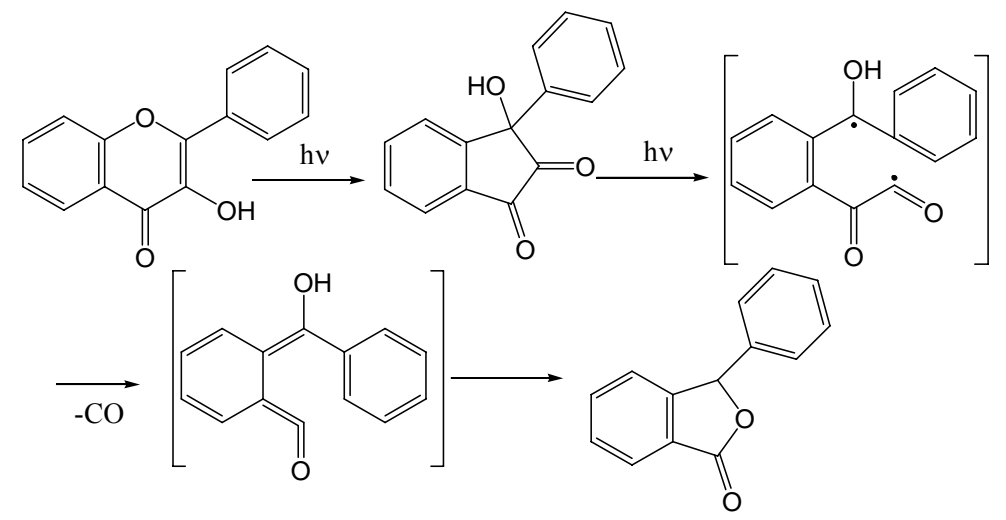

Ficarra and co-workers [44] obtained only the indandione 35a upon irradiation of flavonol 34a in aerated or oxygen-free acetonitrile and dichloromehane solutions (high pressure mercury lamp with Bausch Lamb monochromator) (Scheme 16). No indication of the formation of photo-oxygenated products was found. This contrasts with the results of Yokoe and co-workers [43], where the oxygenated product dominated. They concluded that photo-rearrangement takes place from a singlet excited phototautomer $\left({ }^{1} \mathrm{PT}\right)$ and photo-oxygenation from a triplet phototautomer $\left({ }^{3} \mathrm{PT}\right)$. Alcoholic solvents (protic polar solvents) slow down rearrangements from $\left({ }^{1} \mathrm{PT}\right)$ and inhibit photo-rearrangement at the expense of photo-oxygenation from $\left({ }^{3} \mathrm{PT}\right)$. Aprotic polar solvents have the opposite effect and do not interfere with photo-rearrangement of $\left({ }^{1} \mathrm{PT}\right)$. Their formation of only the oxygenated product in heptane and other non-polar solvents was explained by a rapid conversion of $\left({ }^{1} \mathrm{PT}\right)$ to $\left({ }^{3} \mathrm{PT}\right)$ in non- 
polar solvents. They thus concluded that molecular oxygen affects photochemical reactions of flavones in alcoholic (protic-polar) and hydrocarbon (non-polar) solutions and does not participate in acetonitrile and dichloromethane (aprotic-polar) (Figure 3).

Scheme 16. Irradiation of flavonol oxygen-free acetonitrile and dichloromehane solutions.

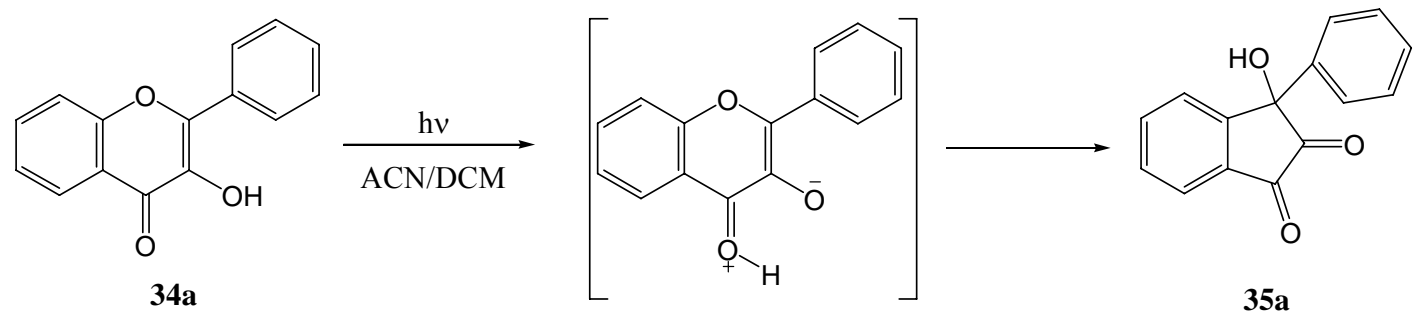

Figure 3. Proposed flavonol excited states: (GS ground state (singlet), ${ }^{1}$ ES excited state (singlet), PT ground state of phototautomer (singlet), its singlet excited state $\left({ }^{1} \mathrm{PT}\right)$ and triplet excited state $\left({ }^{3} \mathrm{PT}\right) \mathrm{a}=$ light absorbtion; $\mathrm{b}=$ intersystem crossing; $\mathrm{c}$ and $\mathrm{d}=$ photochemical reaction; $\mathrm{e}=$ light energy emission).

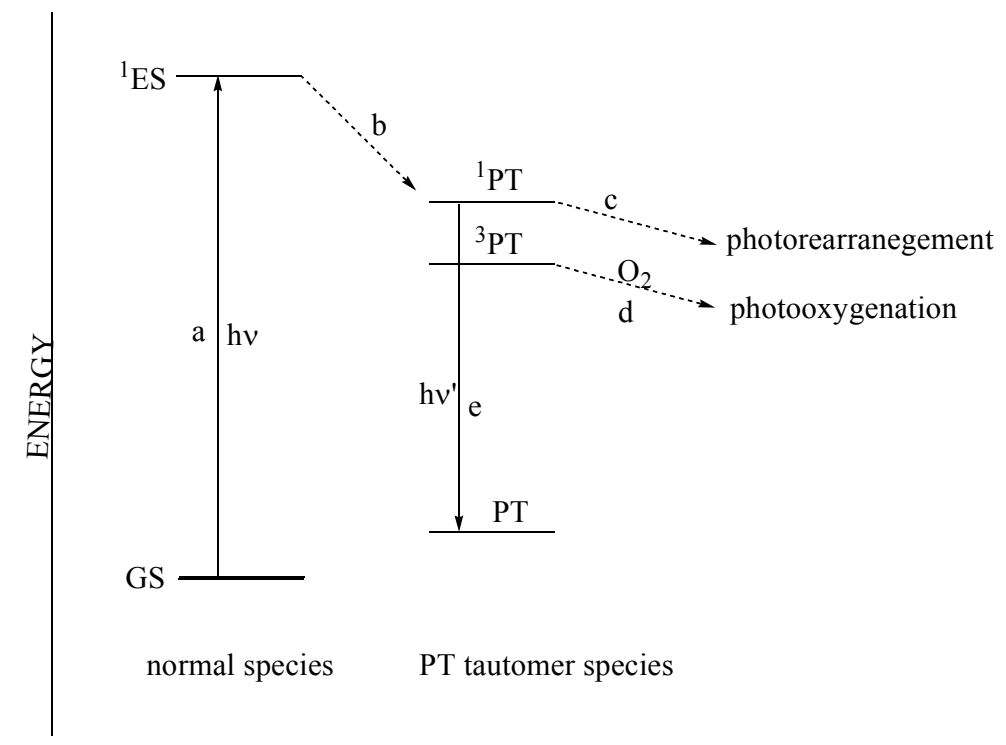

Chen and co-workers [45] investigated the photoinduced electron transfer reactions of flavones with amines. Irradiation of flavone 38 with $0.1 \mathrm{M}$ triethylamine in acetonitrile under argon at $>300 \mathrm{~nm}$ yielded meso-2,2'-biflavanone 39, ( \pm )-meso-2,2'-biflavanone 40 and flavone [I-4,II-2]-flavanol 41 (Scheme 17). Different amines were used (TEA, DMBA, DMAE, DMA) in acetonitrile and benzene to afford yields, based on consumed flavone 38, as shown in Table 4. These products resulted from radical addition of 4-ketyl 43 and/or its isomeric 1,2-ketyl anion to flavones, respectively (Scheme 19). Single electron transfer (SET) [46] is a well-known photoreaction between amines and $\alpha, \beta$-unsaturated carbonyl compounds. The amine donates an electron to form an exciplex or a contact ion radical pair [47] (CIP) that undergoes hydrogen transfer to yield the radical responsible for dimerisation. 
Scheme 17. Photoinduced electron transfer reactions of flavone with amines.

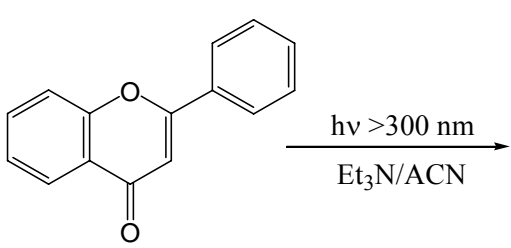

38

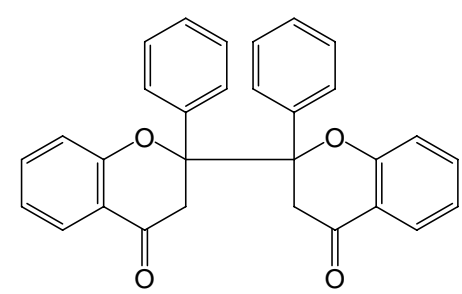

39 meso-, 40 (+/-)-meso

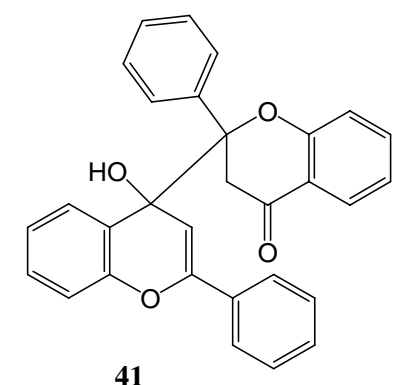

41

Table 4. Photoinduced reactions of flavone with amines.

\begin{tabular}{ccccc}
\hline Amine & Solvent & Irrad. Time/h & Conversion (\%) & Products (yield, \%) \\
\hline TEA & ACN & 14 & 100 & $\mathbf{3 8}(38), \mathbf{3 9}(14), \mathbf{4 0}(25)$ \\
TEA & benzene & 25 & 100 & $\mathbf{3 8}(51), \mathbf{4 0}(45)$ \\
DMBA & ACN & 18 & 100 & $\mathbf{3 8}(53), \mathbf{4 0}(22)$ \\
DMAE & benzene & 12 & 89 & $\mathbf{3 8}(7), \mathbf{3 9}(50), \mathbf{4 0}(16)$ \\
DMA & ACN & 14 & 100 & $\mathbf{3 8}(41), \mathbf{3}(35), \mathbf{4 1}(18)$ \\
DMA & benzene & 12 & 68 & $\mathbf{3 8}(19), \mathbf{3 9}(10), \mathbf{4 0}(15), \mathbf{4 1}(30)$ \\
\hline
\end{tabular}

Chen and co-workers [47] reinvestigated the photoinduced electron transfer reactions of flavone 38 with amines that was studied by his namesake in 1995. They used triethylamine or 2-(N,Ndimethylamino)ethanol at 250 and $300 \mathrm{~nm}$ in benzene, dichloromethane or acetonitrile, respectively, and isolated meso-2,2'-biflavone 39, (+/-)-meso-2,2'-biflavone 40 and flavanone 42 (Scheme 18).

Scheme 18. Photochemical synthesis of 2,2'-biflavanones from flavone.<smiles>O=c1cc(-c2ccccc2)oc2ccccc12</smiles>

38

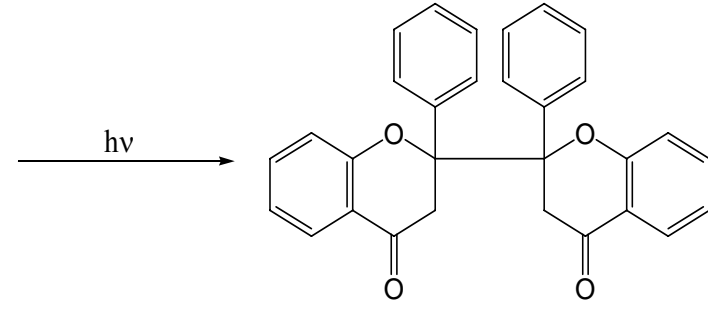

39 meso, 40 (+/-)-meso<smiles>O=C1CC(c2ccccc2)Oc2ccccc21</smiles>

The mechanism of photolysis was proposed as shown in Scheme 19. The yields and the ratio between $\mathbf{3 9}$ and $\mathbf{4 0}$ depended on the molar ratio of flavone to amine, the type of amine, and the solvent and the light source (Sankyo $254 \mathrm{~nm}$ Germicidal lamp or $306 \mathrm{UV}-\mathrm{B}$ lamp) (Table 5). The combined yield of meso-39 and (+/-)-meso-40 varied beween 17.3 and 50.9\%. They also isolated flavanone 42 , resulting from photo-reduction, in yields of between 8.9 and $16.9 \%$, depending on the reaction conditions (Table 5). The absence of flavone [I-4,II-2]-flavan-4-ol $\mathbf{4 1}$ as described by Chen and co workers [45] above, was attributed to the use of light with a wavelength longer than $300 \mathrm{~nm}$. 
Scheme 19. Proposed mechanism of photoinduced biflavanone formation with amines.

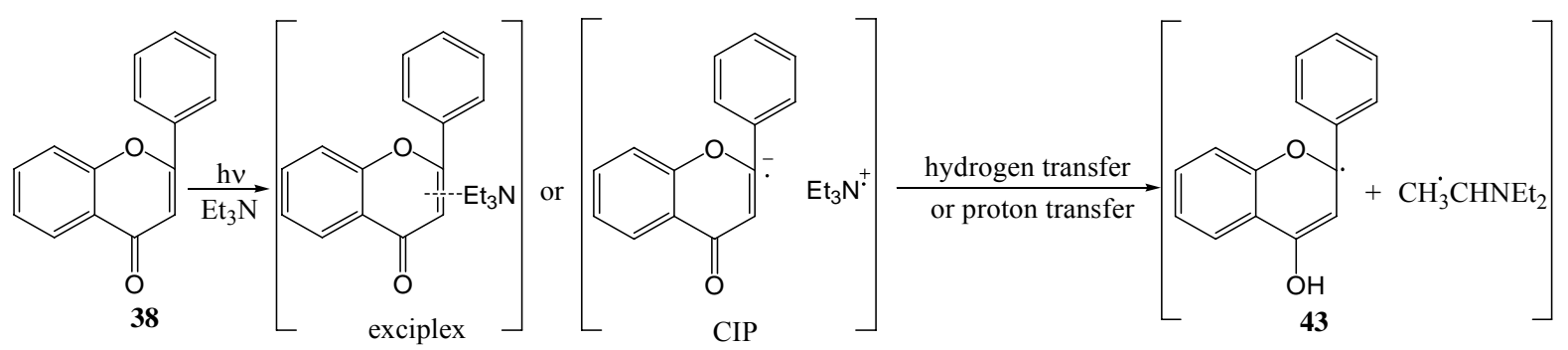

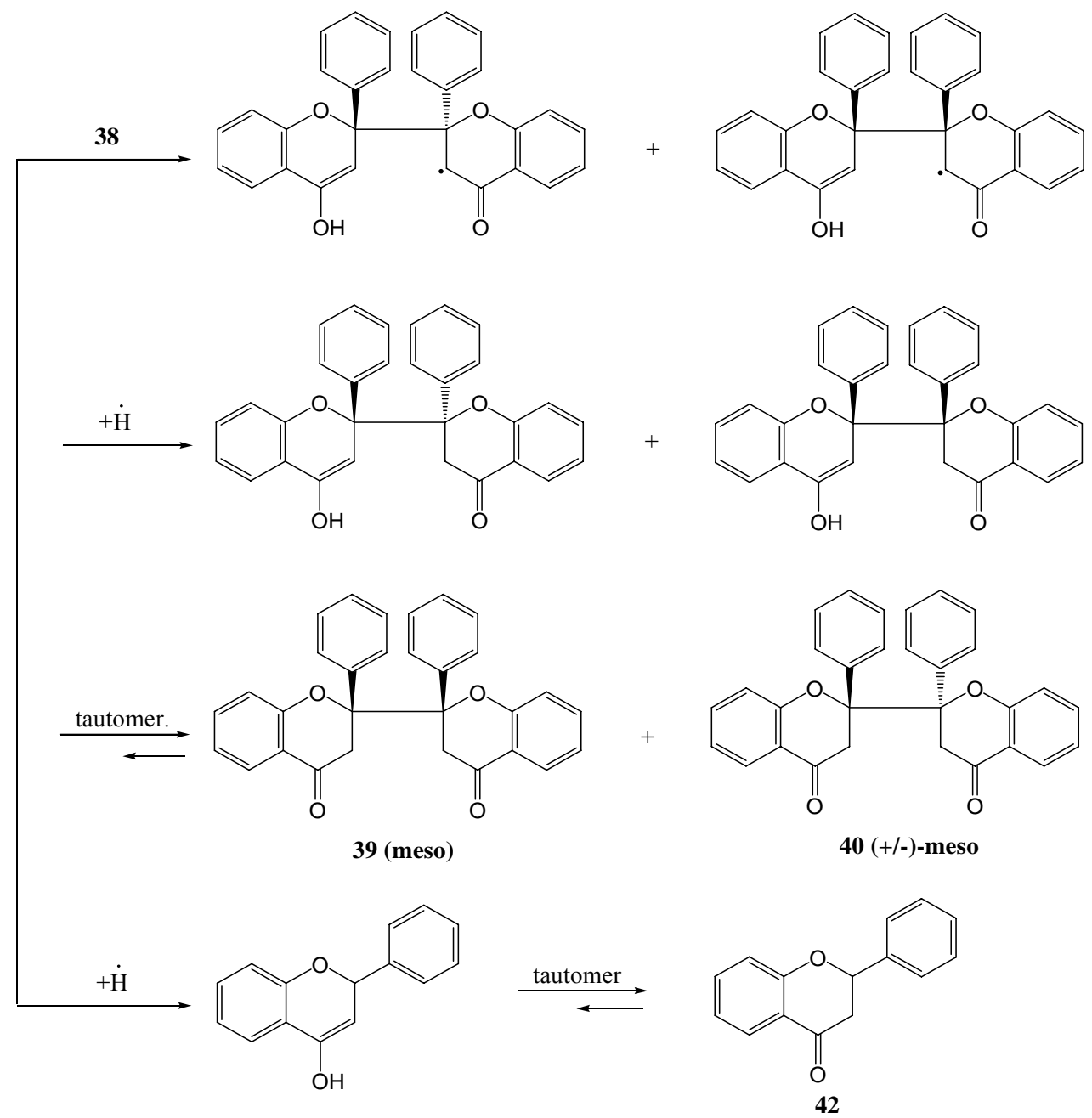

Table 5. Yields and conditions of photoinduced biflavanone formation with amines.

\begin{tabular}{|c|c|c|c|c|}
\hline \multirow{2}{*}{$\begin{array}{c}\text { Reaction Conditions } \\
\text { Molar ratios* }{ }^{*^{1}} \text {, Amines }{ }^{*^{2}} \text {, Solvents, Irradiation } \\
\text { Time, Irradiation Source }{ }^{*^{3}}\end{array}$} & \multirow{2}{*}{$\begin{array}{c}\text { Conversion } \\
(\%)\end{array}$} & \multicolumn{3}{|c|}{ Yields $(\%)^{* 4}$} \\
\hline & & 39 & 40 & 41 \\
\hline $1 / 2$, TEA, benzene, $25 \mathrm{hrs}, \mathrm{A}$ & 75.0 & 22.0 & 22.3 & 13.0 \\
\hline 1/4, TEA, ACN, 25 hrs, A & 78.4 & 15.9 & 26.1 & 10.2 \\
\hline 1/1, TEA, ACN, $14 \mathrm{hrs,} \mathrm{A}$ & 88.5 & 12.2 & 9.7 & 11.6 \\
\hline 1/2, TEA, ACN, $14 \mathrm{hrs,} \mathrm{A}$ & 78.0 & 20.9 & 30.0 & 15.8 \\
\hline 1/4, TEA, ACN, 14 hrs, A & 85.4 & 16.7 & 14.6 & 14.4 \\
\hline 1/10, TEA, ACN, 14 hrs, A & 82.6 & 29.7 & 13.5 & 15.8 \\
\hline
\end{tabular}


Table 5. Cont.

\begin{tabular}{ccccc}
\hline 1/2, DMAE, benzene, $12 \mathrm{hrs,} \mathrm{A}$ & 88.8 & 15.2 & 22.8 & 13.7 \\
1/2, TEA, DCM, 16 hrs, A & 71.1 & 17.4 & 7.9 & 16.9 \\
1/2, TEA, benzene, 25 hrs, B & 78.7 & 17.6 & 7.5 & 8.9 \\
1/2, TEA, ACN, 14 hrs, B & 75.8 & 12.5 & 4.8 & 11.9 \\
1/2, DMAE, benzene, 14 hrs, A & 79.1 & 9.6 & 19.3 & 11.2 \\
\hline$*^{1}$ Molar ratio of substrate to amine; $*^{2}$ Amine: TEA: & triethylamine, DMAE: $2-(N, N-$ \\
dimethylamino)ethanol. ${ }^{3}$ Irradiation Source: A (Sankyo 254 nm Germicidal Lamp), B (Sankyo \\
306 nm UV-B Lamp), ${ }^{4}$ Yield based on consumed flavone 1.
\end{tabular}

Yokoe and co-workers [48] obtained similar results. Photolysis (450 W high pressure mercury lamp, Pyrex filter) of flavone $\mathbf{4 4}$ in a methanol-water solution in the presence of sodium sulphite yielded meso-2,2'-biflavanone 45 and (+/-)-meso-2,2'-biflavanone 46.

Scheme 20. Photoinduced formation of biflavanones with sodium sulphite.

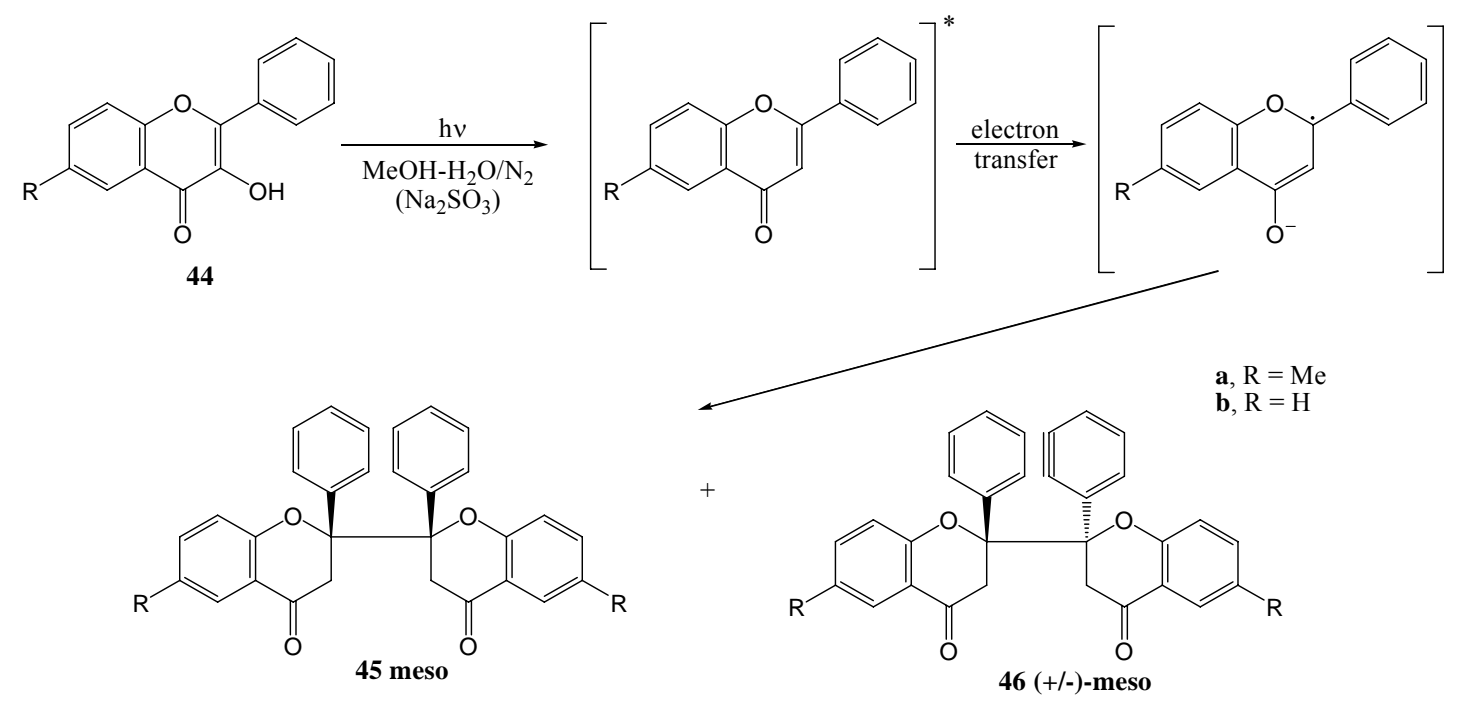

Schönberg and Khandelwahl [49] studied 1,2-cycloaddition to flavones. Irradiation of flavones 47a and $\mathbf{4 7 b}$, respectively, -and diphenylacetylene in benzene with a Hanau quartz lamp in a quartz or Pyrex vessel yielded the corresponding cyclobutabenzopyrans 48a and 48b, respectively. Products 50, 52 and 54, respectively, were isolated upon irradiation of isoflavone 49, 7,8-benzoflavone 51 and 1thioflavone 53, respectively. Yields were almost quantitative.

Scheme 21. 1,2-Cycloadition of diphenylacetylene and flavone.<smiles>[R]c1ccc2oc(-c3ccccc3)cc(=O)c2c1</smiles>

b, $\mathrm{R}=\mathrm{Me}$<smiles>C(#Cc1ccccc1)c1ccccc1</smiles><smiles>CCCCC</smiles><smiles>[R][R]([R16])=Cc1ccc2c(c1)C(=O)C1C(c3ccccc3)=C(c3ccccc3)C1(c1ccccc1)O2</smiles> 
Scheme 21. Cont.<smiles>O=c1c(-c2ccccc2)coc2ccccc12</smiles><smiles>Cc1ccc(C#Cc2ccccc2)cc1</smiles><smiles>O=c1cc(-c2ccccc2)oc2c1ccc1ccccc12</smiles><smiles>Cc1ccc(C#Cc2ccccc2)cc1</smiles>
51<smiles>O=c1cc(-c2ccccc2)sc2ccccc12</smiles>

53

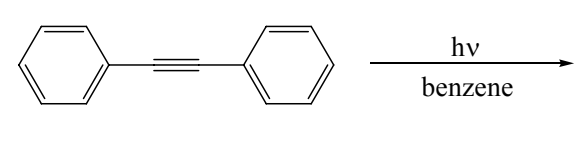

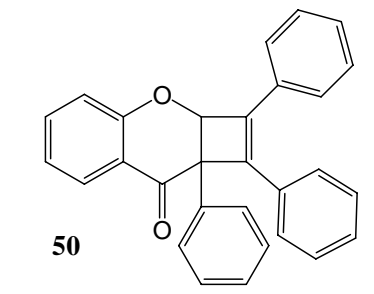<smiles>O=C1c2ccc3ccccc3c2OC1(c1ccccc1)c1ccccc1</smiles><smiles>O=C1c2ccccc2SC2(c3ccccc3)C(c3ccccc3)=C(c3ccccc3)C12</smiles>

54

Gerard and co-workers [50] described 1,3-dipolar cycloaddition between methyl cinnamate (55) and flavonol 56 to obtain products 57 to 60 (rocaglamides) via photochemical generation of an oxidopyrylium species in acetonitrile with a Hanovia UV lamp uranium filter (Scheme 22).

Scheme 22. Photochemical synthesis of rocaglamide.

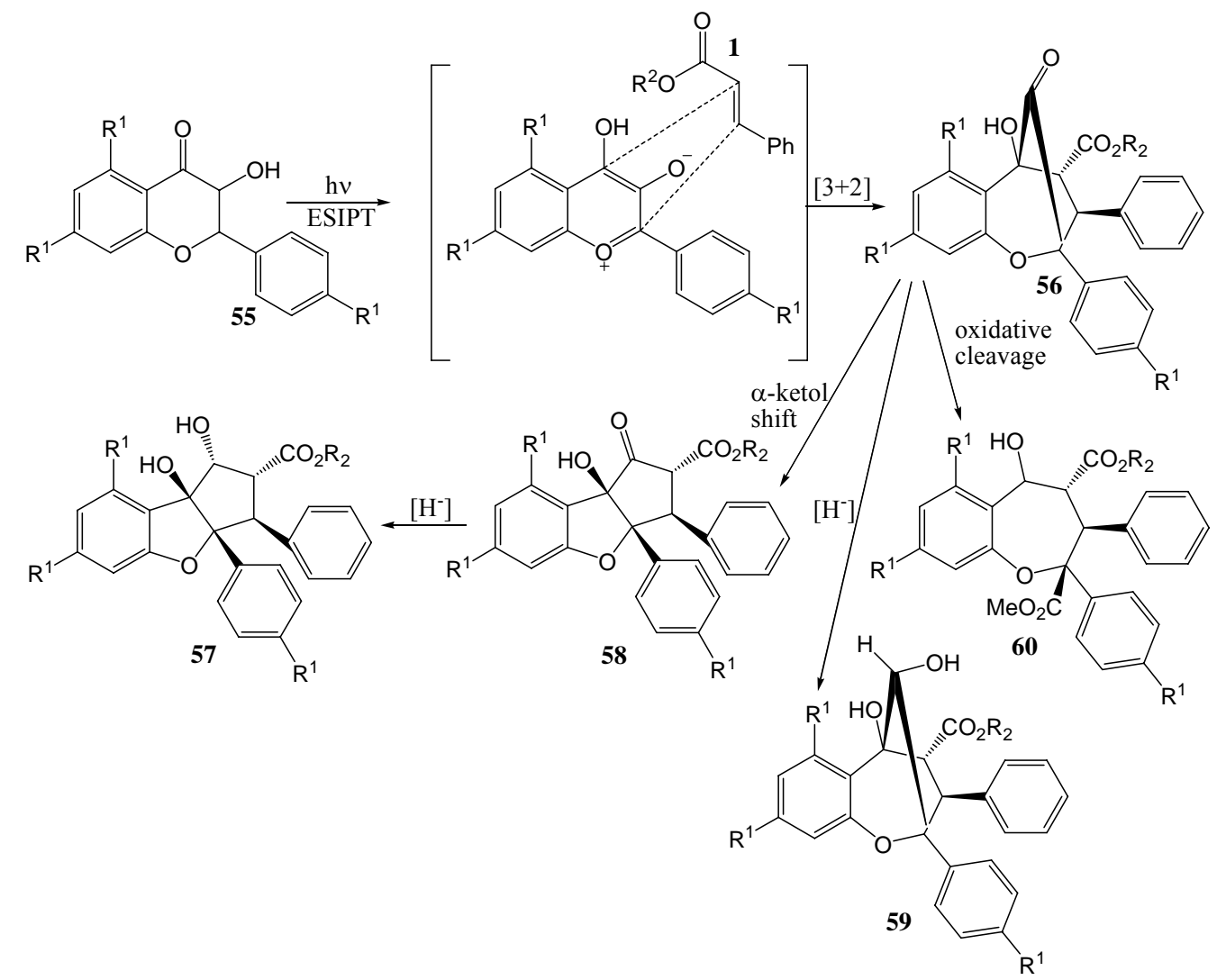


Gerard and co-workers [51] repeated the reaction in the presence of chiral Brønsted acids to obtain chiral rocaglamide derivatives. $\mathrm{R}^{1}$ and $\mathrm{R}^{2}$ are identical or different and selected from the group consisting of hydrogen, halogen, hydroxyl, alkoxy, aryloxy, heteoaryloxy, thioalkyl, thioaryl, and next variety of protecting groups.

Bhatacharyya and co-workers [52] studied the photophysics of flavones. They concluded that flavone almost instantaneously forms a triplet state with a $90 \%$ intersystem crossing (ISC) yield after absorption of UV light. Polar solvents enhanced yields indicating a $\pi, \pi^{*}$-character for the lowest triplet excited state. The flavone's triplet is quenched by several typical triplet quenchers like hydrogen donors [53], including amines [54].

Christoff and co-workers [55] investigated the photophysics of 3-methoxy-and 7-methoxyflavone. A 7-methoxy substituent increases the $\pi, \pi^{*}$-character of the excited state further but does not change the energy level or known flavone deactivation pathways. In contrast, a 3-methoxy substituent leads to a strong geometric constraint which interferes with planar $\pi$-orbital conjugation between the carbonyl group and the aromatic ring. This reduces the $\pi, \pi^{*}$-character and increases the $n, \pi^{*}$-character and the triplet state energy. The methoxy group becomes an intramolecular hydrogen donor to the excited carbonyl $n, \pi^{*}$-triplet. The spectroscopic properties of the transient species are compatible with a 1,4biradical structure. Conventional photolysis indicates that the biradical is transformed into an ethereal ethylene group. The mechanism for the photocyclisation is given in Scheme 23.

Scheme 23. Mechanism of photocyclisation of the 3-methoxyflavone.

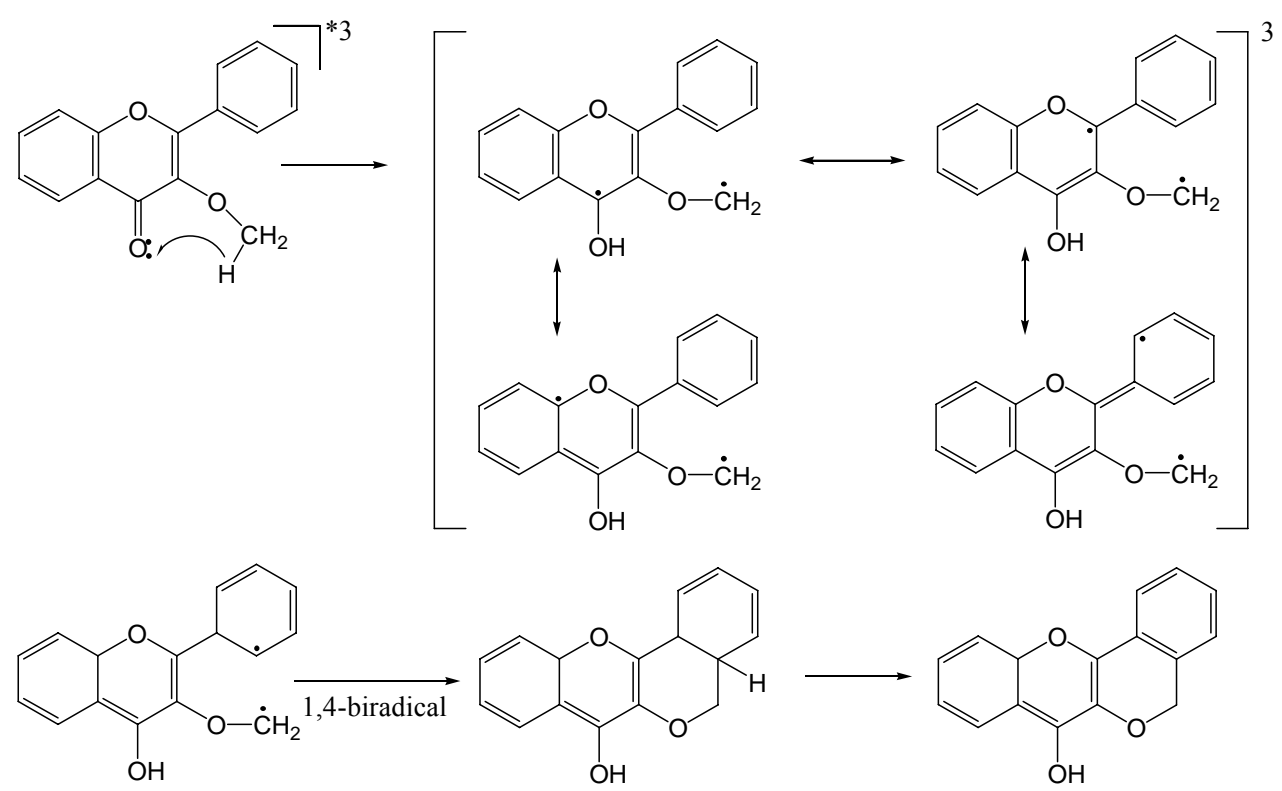

\section{Chalcone and Flavanone Photochemistry}

Chalcones and $\alpha$-hydroxychalcones are key intermediates in flavonoid synthesis and biosynthesis and the photochemistry of these compounds has attracted much early interest. Of major interest is cistrans isomerisation of the olefinic bond and reversible interconversion of 2'-hydroxychalcones and flavanes. Lutz and Jordan [56] obtained a photo-stationary mixture of $74 \%$ cis- and $26 \%$ transchalcone upon leaving the chalcone in benzene in sunlight. The trans-isomer absorbs light more efficiently and is depleted compared to the cis-isomer under the reversible reaction conditions. 
Volsteedt and co-workers (1973) [57] isomerised trans- $\alpha, 2^{\prime}, 4,4^{\prime}, 6^{\prime}$-pentamethoxychalcone (61) to the cis form 62 in methanol at $350 \mathrm{~nm}$ (Scheme 24).

Scheme 24. Trans-cis - photoinduced isomerisation of $\alpha$-methoxychalcone.<smiles>CO/C(=C\c1ccc(OC)cc1)C(=O)c1c(OC)cc(OC)cc1OC</smiles>

61<smiles>CO/C(=C/c1ccc(OC)cc1)C(=O)c1c(OC)cc(OC)cc1OC</smiles>

Ferreira and Roux [58] found that a trans-chalcone with a free hydroxy group (e.g., 2'-hydroxy4,4',6'-trimethoxy- and 4-hydroxy-2',4',6'-trimethoxy-trans-chalcone 63a, 63b and 63c) did not undergo cis-trans isomerisation in methanol at 300 or $350 \mathrm{~nm}$. Their $O$-methoxymethyl derivatives 63d and 63e did undergo the desired isomerisations to a mixture of $60 \%$ trans (compound 64d) and $40 \%$ cis (compound 64e) (Scheme 25). The products were, however, metastable and spontaneously reverted to the trans isomer (half-life of about six months). Removal of the $O$-methoxymethyl protecting group of the cis chalcones $64 \mathbf{d}$ and $64 \mathbf{e}$ with acid, yielded the corresponding trans isomers 63b and 63c. In contrast 2'-hydroxy- $\alpha$-methoxy-cis-chalcones $64 f$ and $64 g$ are relatively stable (Figure 4).

Scheme 25. Trans-cis - photoinduced isomerisation of $\alpha$-methoxychalcones.

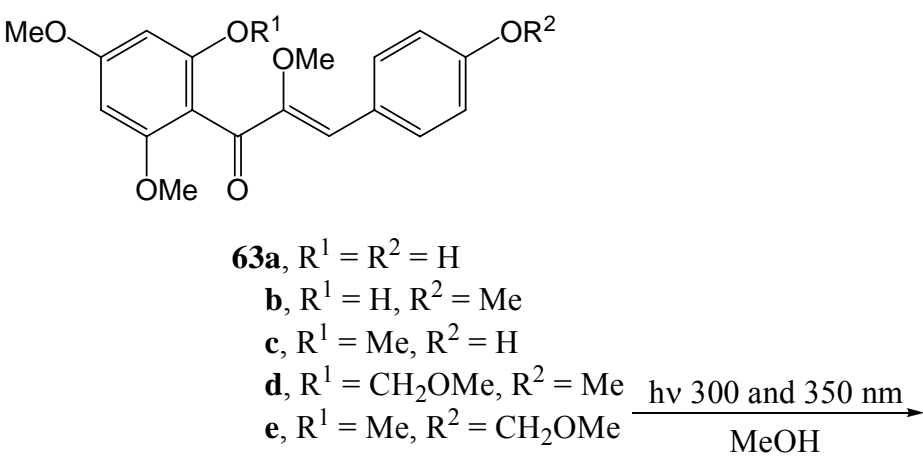

63a, $\mathrm{R}^{1}=\mathrm{R}^{2}=\mathrm{H}$

d, $\mathrm{R}^{1}=\mathrm{CH}_{2} \mathrm{OMe}, \mathrm{R}^{2}=\mathrm{Me} \mathrm{h} v 300$ and $350 \mathrm{~nm}$

e, $\mathrm{R}^{1}=\mathrm{Me}, \mathrm{R}^{2}=\mathrm{CH}_{2} \mathrm{OMe} \frac{\mathrm{MeOH}}{\mathrm{N}}$<smiles>CCO/C(=C\c1ccc(O)cc1)C(=O)c1c(OC)cc(OC)cc1OC</smiles>

d, $\mathrm{R}^{1}=\mathrm{CH}_{2} \mathrm{OMe}, \mathrm{R}^{2}=\mathrm{Me}$

e, $\mathrm{R}^{1}=\mathrm{Me}, \mathrm{R}^{2}=\mathrm{CH}_{2} \mathrm{OMe}$

Figure 4. Structures of photochemical relatively stable 2'-hydroxy- $\alpha$-methoxy-cis-chalcones<smiles>[R1]Oc1cc(OC)cc(OC)c1C(=O)/C(=C/c1ccc(O)cc1)OCC</smiles>

Dewar and Sutherland [59] transformed 2"-hydroxychalcone 65 into 2-ethoxy- or 2-methoxyflav-3ene (compounds 66a or b) (96\%), and trace amounts of flavones (1\%), upon irradiation at $350 \mathrm{~nm}$ in 
ethanol or methanol (Scheme 26). The product (67a or b) was smoothly converted to a flavylium salt with acid.

Scheme 26. The photochemistry of 2"-hydroxychalcone.

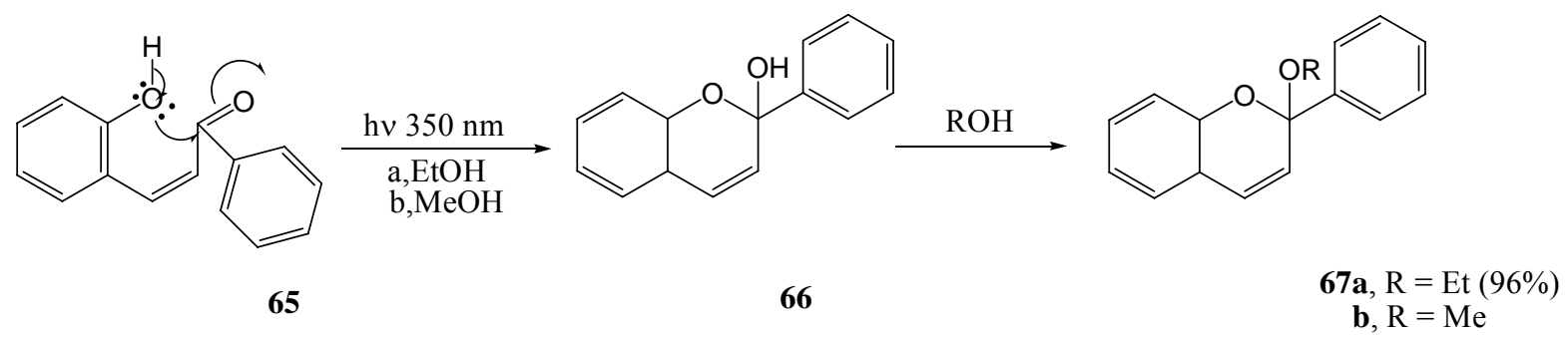

Mack and Pinhey [60] transformed flavanone 68, via fragmentation of the heterocyclic benzylic O$\mathrm{C}$ bond, into 2'-hydroxychalcone 70 (20\%) in benzene at $250 \mathrm{~nm}$. They also isolated salicylic acid (73, $4 \%$ ) via the subsequent fragmentation of the $\mathrm{C} 2-\mathrm{C} 3$ bond to form a ketene 72 that can be trapped with water or methanol. The 4-phenyldihydrocoumarin (74, 13\%) was formed via attack of the aromatic Aring on the benzylic radical intermediate 69 to yield the intermediate dienone 71 (Scheme 27). This reaction is related to the photo-Fries rearrangement of benzylic ethers.

Scheme 27. Photochemistry of flavanone.

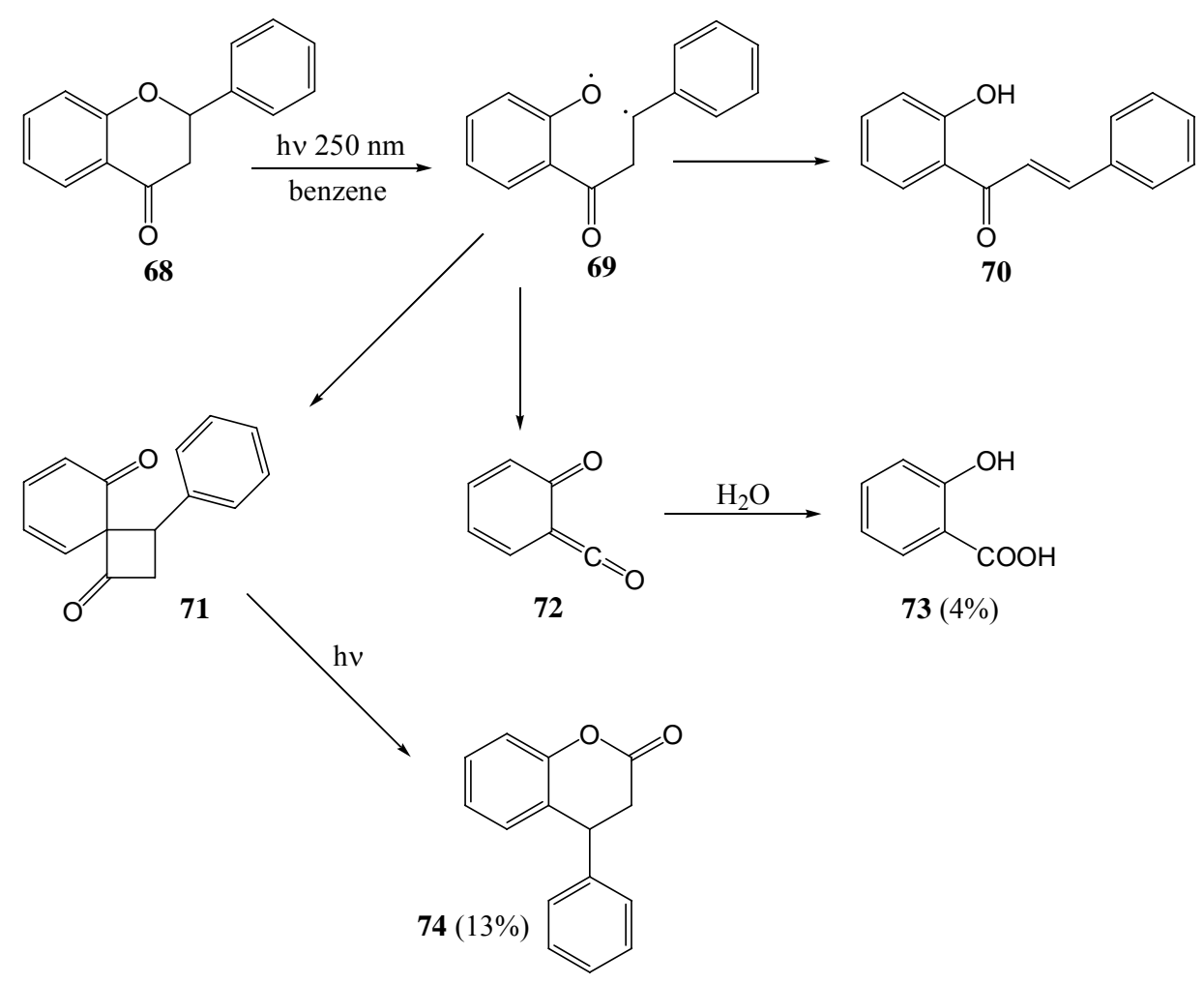

Stermitz and co-workers [61] transformed 2'-hydroxychalcone 70 to flavanone 68 (53\%) upon irradiation with a Hanovia $450 \mathrm{~W}$ lamp with a Pyrex filter in benzene. It is known that the pKa values of phenols increase in the excited state [62] and, thus, the reaction could have been acid self-catalyzed (Scheme 28). 
Scheme 28. Photochemical transformation of 2'-hydroxychalcone to flavanone.<smiles>O=C(/C=C/c1ccccc1)c1ccccc1O</smiles>

70<smiles>O=C1CC(c2ccccc2)Oc2ccccc21</smiles>

$68(53 \%)$

Matsushima and co-workers [63] photolysed (100 W high pressure mercury lamp) flavanone 68 in benzene and obtained 2'-hydroxychalcone 70 (14\%) via cleavage of the pyrone ring. Repetition of the reaction in 2-propanol gave the pinacols 75 (39\%) and solvent adducts 76 (8\%) (Scheme 29). Photolysis of 7,8-benzoflavanone 77 in 2-propanol gave no coupling products $\mathbf{7 9}$ and $\mathbf{8 0}$, but rather the ring-cleaved chalcone 78 (33\%) (Scheme 30). The lack of photo-reduction (coupling products) suggested that the lowest triplet state of 7,8-benzoflavanone was ${ }^{3}\left(\pi, \pi^{*}\right)$ and that of the flavanones that had undergone photo-reduction to pinacols were ${ }^{3}\left(\mathrm{n}, \pi^{*}\right)$. Methoxylated flavanones are assumed to have considerable $\pi, \pi^{*}$ character in their lowest triplet state. This is supported by conversion of 4'methoxyflavan to 2'-hydroxy-4-methoxyflavanone in yields of $69 \%$ in benzene (compared to the $14 \%$ conversion of flavanone), $66 \%$ in pyridine, $48 \%$ in acetonitrile and $31 \%$ in carbon tetrachloride.

Scheme 29. Photolysis of flavanone in 2-propanol and benzene.

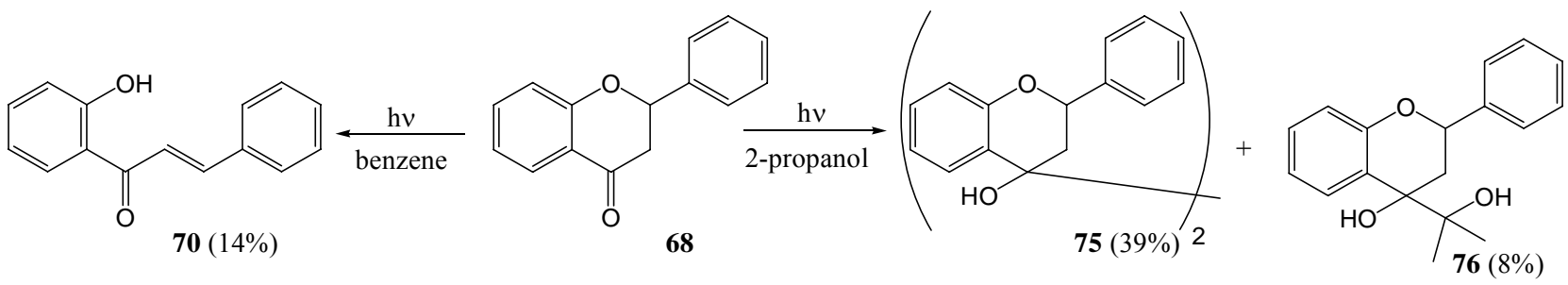

Scheme 30. Photolysis of 7,8-benzoflavanone.
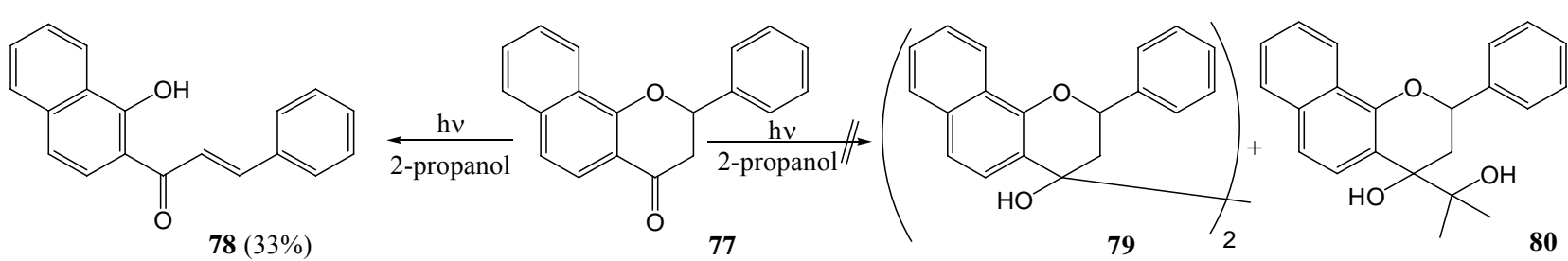

Nakashima and co-workers [64] investigated the photochemistry of 4'-methoxyflavanone (81). They obtained chalcone 82 (14\%), and a mixture of pinacols 83 (23\%) upon irradiation of 81 with a high pressure Pyrex lamp in benzene or 2-propanol. 5,7,4'-Trimethoxyflavanone was inert in benzene and gave a complex mixture of at least six products that was not identified. 5,7-Dimethyl-4'methoxyflavanone (84) yielded bis-flavanone 85, probably via intramolecular hydrogen abstraction by an $n, \pi^{*}$-excited carbonyl from the 5-methyl group (Scheme 31 ). 
Scheme 31. Photochemistry of 4'-methoxy- and 5,7-dimethyl-4'-methoxyflavanone.

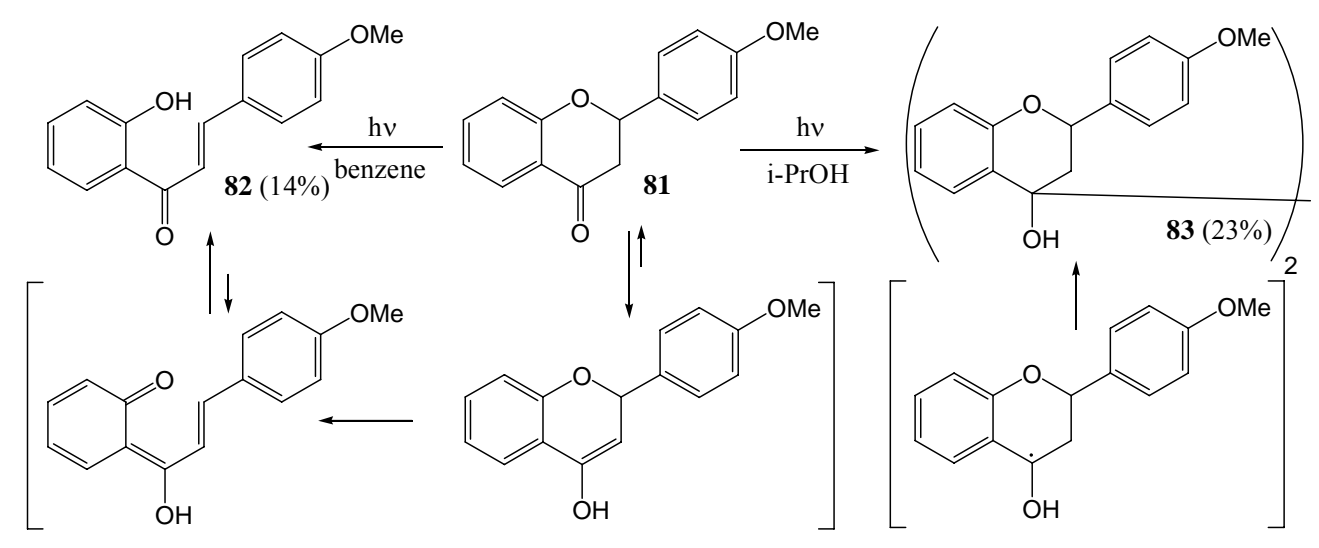<smiles>CCc1cc(C)c2c(c1)OC(c1ccc(OC)cc1)CC2Oc1ccc(OC)cc1C1CC(O)c2c(C)cc(C)cc2O1</smiles>

Matsushima and Kageyama [65] studied the influence of the solvent and wavelength on the reactivity, reaction rate, and yield of photocyclisation of a series of 2'-hydroxychalcones 86a-e to flavanones 87a-e (Scheme 32, Table 6). They also investigated the effect of triplet quenchers and radical scavengers. All the chalcones were inert in chloroform and $t$-butyl alcohol and all were reactive in benzene, ethyl acetate, and 1,4-dioxane (Table 7). Light of a shorter wavelength gave slower reaction rates and more side reactions. The best results were obtained with wavelengths above $365 \mathrm{~nm}$ (Table 8). Rates were highest in ethyl acetate and dioxane and low in benzene. The yields were the highest in ethyl acetate [e.g., $86 \%$ conversion of $\mathbf{8 6 b}$ ] (Table 9). Triplet quenchers and radical scavengers had no effect, suggesting that photocyclisation of 2'-hydroxychalcones is an ionic or polar reaction. Solvent effects are ambiguous, but it seems that polar aprotic (basic) solvents gave the best results, supporting the polar mechanism. Photo-enolization of 3-chromanones as described by Padwa et al [66], followed by cis-trans isomerisation that may require a second photon, seems to best explain the experimental results (Scheme 33).

Scheme 32. Photocyclization of 2'-hydroxychalcones to flavanones.<smiles>O=C(/C=C/c1ccccc1)c1ccccc1O</smiles> 
Table 6. Photocyclization of 2'-hydroxychalcones to flavanones.

\begin{tabular}{ccc|ccc}
\hline $\begin{array}{c}\text { 2'-Hydroxychalcone } \\
\mathbf{8 6}\end{array}$ & $\mathrm{R}^{1}$ & $\mathrm{R}^{2}$ & Flavanone 87 & $\mathrm{R}^{1}$ & $\mathrm{R}^{2}$ \\
\hline $\mathbf{a}$ & $\mathrm{H}$ & $\mathrm{H}$ & $\mathbf{a}$ & $\mathrm{H}$ & $\mathrm{H}$ \\
$\mathbf{b}$ & $\mathrm{H}$ & $2-\mathrm{OMe}$ & $\mathbf{b}$ & $\mathrm{H}$ & $2^{\prime}-\mathrm{OMe}$ \\
$\mathbf{c}$ & $4^{\prime}-\mathrm{OMe}$ & $\mathrm{H}$ & $\mathbf{c}$ & $7-\mathrm{OMe}$ & $\mathrm{H}$ \\
$\mathbf{d}$ & $6^{\prime}-\mathrm{OMe}$ & $\mathrm{H}$ & $\mathbf{d}$ & $5-\mathrm{OMe}$ & $\mathrm{H}$ \\
$\mathbf{e}$ & $3^{\prime}, 4^{\prime}-\mathrm{Benzo}$ & $\mathrm{H}$ & $\mathbf{e}$ & 7,8 -Benzo & $\mathrm{H}$ \\
\hline
\end{tabular}

Table 7. Solvent effects on the photocyclization of 2'-hydroxychalcones to flavanones.

\begin{tabular}{c|ccccccccc}
\hline $\begin{array}{c}\text { 2'-Hydroxychalcone } \\
\text { 86 }\end{array}$ & Benzene & $\mathrm{CCl}_{4}$ & $\mathrm{CHCl}_{3}$ & $\mathrm{Et}_{2} \mathrm{O}$ & $\mathrm{EtOAc}$ & $\begin{array}{c}1,4- \\
\text { dioxane }\end{array}$ & $\mathrm{ACN}$ & $\mathrm{EtOH}$ & $t-\mathrm{BuOH}$ \\
\hline $\mathbf{a}$ & $\mathbf{8 7 a}$ & $\mathbf{8 7 a}$ & - & $\mathbf{8 7 a}$ & $\mathbf{8 7 a}$ & $\mathbf{8 7 a}$ & $\mathbf{8 7 a}$ & $\mathbf{8 7 a}$ & - \\
$\mathbf{b}$ & $\mathbf{8 7 b}$ & - & - & $\mathbf{8 7 b}$ & $\mathbf{8 7 b}$ & $\mathbf{8 7 b}$ & $\mathbf{8 7 b}$ & $\mathbf{8 7 b}$ & - \\
$\mathbf{c}$ & $\mathbf{8 7 c}$ & - & - & $\mathbf{8 7 c}$ & $\mathbf{8 7 c}$ & $\mathbf{8 7 c}$ & - & - & - \\
$\mathbf{d}$ & $\mathbf{8 7 d}$ & - & - & $\mathbf{8 7 d}$ & $\mathbf{8 7 d}$ & $\mathbf{8 7 d}$ & - & - & - \\
$\mathbf{e}$ & $\mathbf{8 7 e}$ & - & - & & $\mathbf{8 7 e}$ & $\mathbf{8 7 e}$ & - & - & - \\
\hline
\end{tabular}

Table 8. Effect of the solvent on the relative rates of photochemical flavanone formation from 2'-hydroxychalcones.

\begin{tabular}{cccc}
\hline \multirow{2}{*}{ 2'-Hydroxychalcone 86 } & \multicolumn{3}{c}{ Consumption of 2'-hydroxychalcone (\%) in } \\
& Benzene & 1,4-dioxane & EtOAc \\
\hline a & 8.2 & 94 & 95 \\
b & 10 & 97 & 91 \\
c & 14 & 35 & 63 \\
d & 30 & 30 & 84 \\
e & 7.4 & 1.4 & 1.3 \\
\hline
\end{tabular}

Table 9. Effect of irradiation time on the yield of photochemical flavanone $87 \mathbf{b}$ formation from 2'-hydroxychalcones.

\begin{tabular}{ccccc}
\hline Solvent & Irradiation time/h & $\begin{array}{c}\mathbf{8 6 b}(\mathbf{m M} \\
\text { Recovered) }^{\boldsymbol{a}}\end{array}$ & $\mathbf{8 7 b}^{(\mathbf{m M} \text { Formed) }}$ & Yield of 87b (\%) $^{\boldsymbol{b}}$ \\
\hline Benzene & 5 & 0.77 & 0.17 & 74 \\
& 10 & 0.66 & 0.24 & 71 \\
& 15 & 0.55 & 0.34 & 69 \\
1,4-dioxane & 20 & 0.52 & 0.40 & 83 \\
& 1 & 0.79 & 0.17 & 82 \\
& 2 & 0.57 & 0.48 & 700 \\
EtOAc & 3 & 0.31 & 0.55 & 58 \\
& 4 & 0.06 & 0.35 & 100 \\
& 2 & 0.57 & 0.45 & 91 \\
& 3 & 0.32 & 0.62 & 84 \\
& 4.5 & 0.23 & 0.65 & 100 \\
\hline
\end{tabular}

\footnotetext{
${ }^{a}$ Initial concentration of $\mathbf{8 6 \mathbf { b }}$ was $1 \mathrm{mM}$; ${ }^{\mathrm{b}}$ The yield of $\mathbf{8 7 \mathbf { b }}$ was based on the consumed amount of $\mathbf{8 6 \mathbf { b }}$.
} 
Scheme 33. Mechanism of photocyclization of 2'-hydroxychalcone to flavanone.

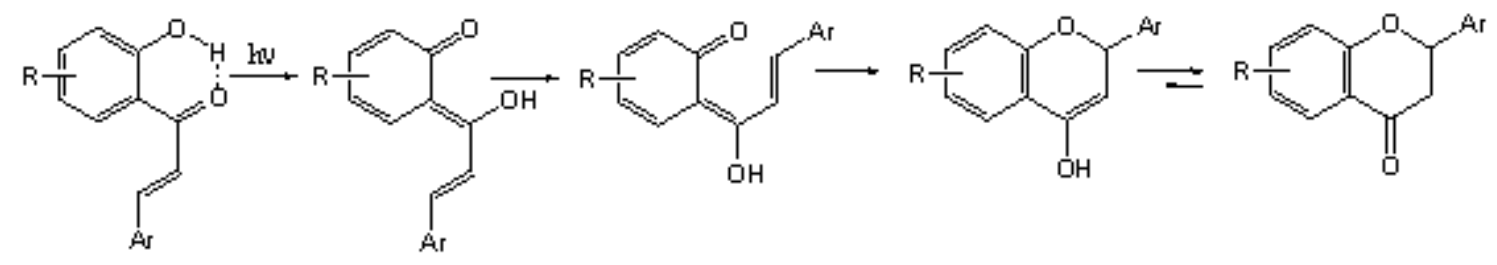

Matsushima and Kageyama [67] investigated the scope and mechanism of the photocyclisation of 2'-hydroxychalcones and photolysed a series of B-ring mono-substituted derivatives (Scheme 34). They concluded that visible light $(405 \mathrm{~nm})$ gives the best results via selective cyclisation, avoiding secondary reactions of the resulting flavanone such as hydrogen abstraction from the solvent or equilibration of the flavanone and chalcone. Methoxy and phenyl substituents on the B-ring enhanced the reaction rate while halogen atoms and a nitro group had little effect (Table 10). Solvent effects on the consumption rate of $\mathbf{8 8 a}$ are given in Table 11. Reaction rates are the highest in aprotic polar solvents, low in non-polar solvents and extremely low in hydroxylic solvents that interfere with intramolecular hydrogen bonding (except in t-butyl alcohol). Ethyl acetate gave superior results compared to benzene and THF. Free radical inhibitors (2,6-di-t-butylphenol, nitrosobenzene, or acrylonitrile) did not suppress the reaction, suggesting a non-radical mechanism as supported by increased reaction rates in polar solvents. Triplet quenchers ferrocene, cyclohexa-1,3-diene, anthracene, phenanthrene, or acenaphthylene had no effect, suggesting an excited singlet or very shortlived triplet state. Quantum yields were low. In $\pi, \pi^{\star}$ excited states phenolic groups become more acidic and carbonyl groups more basic [68-70] suggesting a charge transfer mechanism. 6-Methoxy-, 7-methoxy-, 4'-methoxy, 4'-carbomethoxy-, and 2-methyl-7-methoxyflavanones were also converted to the corresponding 2'-hydroxychalcones (no yields were reported).

Scheme 34. Photochemical cyclization of 2'-hydroxychalcones.<smiles>[R]c1ccc(C=CC(=O)c2ccccc2O)cc1</smiles>

a, $\mathrm{R}=\mathrm{H} ; \mathbf{b}, \mathrm{R}=4-\mathrm{Me}$

c, $\mathrm{R}=4$ - OMe; $\mathbf{d}, \mathrm{R}=4$ - F;<smiles>[R]c1ccc(C2CC(=O)c3ccccc3O2)cc1</smiles>

e, $\mathrm{R}=4-\mathrm{Cl} ; \mathbf{f}, \mathrm{R}=4-\mathrm{Br}$;

g, $\mathrm{R}=4-\mathrm{NO}_{2} ; \mathbf{h}, \mathrm{R}=2,4-(\mathrm{MeO})_{2}$

Table 10. Photocyclization of 2'-hydroxychalcones with visible light.

\begin{tabular}{|c|c|c|c|c|c|c|}
\hline \multicolumn{2}{|c|}{ Compound $^{\mathrm{a}}$} & \multirow[b]{2}{*}{ Solvent } & \multirow[b]{2}{*}{$\begin{array}{l}\text { Irrad. time } \\
\text { (h) }\end{array}$} & \multirow[b]{2}{*}{$\begin{array}{c}\text { Consumption of } 88 \\
\text { (mM) }\end{array}$} & \multirow[b]{2}{*}{$\begin{array}{c}\text { Formation of } 89 \\
(\mathrm{mM})\end{array}$} & \multirow[b]{2}{*}{$(\mathbf{8 9}) /-(\mathbf{8 8})^{b}$} \\
\hline 88 & & & & & & \\
\hline \multirow[t]{3}{*}{$\mathbf{a}$} & Phenyl & EtOAc & 10 & 0.79 & 0.72 & 0.91 \\
\hline & & Benzene & 10 & 0.24 & 0.12 & 0.50 \\
\hline & & THF & 5 & 0.30 & 0.25 & 0.83 \\
\hline
\end{tabular}


Table 10. Cont.

\begin{tabular}{|c|c|c|c|c|c|c|}
\hline \multirow[t]{3}{*}{ b } & 4-Tolyl & EtOAc & 10 & 0.67 & 0.64 & 0.93 \\
\hline & & Benzene & 10 & 0.18 & 0.14 & 0.77 \\
\hline & & THF & 5 & 0.34 & 0.22 & 0.63 \\
\hline \multirow[t]{3}{*}{ c } & 4-Methoxy- & EtOAc & 10 & 1.0 & 0.93 & 0.93 \\
\hline & & Benzene & 10 & 0.40 & 0.33 & 0.83 \\
\hline & & THF & 5 & $0 . .34$ & 0.32 & 0.94 \\
\hline d & 4-Fluorophenyl & EtOAc & 5 & 0.59 & $c$ & \\
\hline \multirow[t]{3}{*}{$\mathbf{e}$} & 4-Chlorophenyl & EtOAc & 10 & 0.93 & 0.82 & 0.88 \\
\hline & & Benzene & 10 & 0.17 & 0.18 & 1.0 \\
\hline & & THF & 5 & 0.49 & 0.37 & 0.75 \\
\hline \multirow[t]{3}{*}{ f } & 4-Bromophenyl & EtOAc & 10 & 1.0 & 0.74 & 0.74 \\
\hline & & Benzene & 10 & 0.17 & 0.16 & 0.94 \\
\hline & & THF & 5 & 0.24 & 0.18 & 0.75 \\
\hline g & 4-Nitrophenyl & EtOAc & 5 & 0.84 & $c$ & \\
\hline \multirow[t]{3}{*}{ h } & 2,4-Dimethoxy- & EtOAc & 10 & 1.0 & 0.96 & 0.96 \\
\hline & & Benzene & 10 & 0.62 & 0.50 & 0.81 \\
\hline & & THF & 10 & 0.77 & 0.70 & 0.91 \\
\hline \multirow[t]{3}{*}{$\mathbf{i}$} & $\alpha$-Naphthyl & EtOAc & 10 & 1.0 & 0.94 & 0.94 \\
\hline & & Benzene & 10 & 0.45 & 0.32 & 0.71 \\
\hline & & THF & 10 & 0.65 & 0.61 & 0.94 \\
\hline \multirow[t]{3}{*}{ j } & Styryl $^{d}$ & EtOAc & 10 & 0.45 & 0.31 & 0.69 \\
\hline & & Benzene & 10 & 0.15 & 0.06 & 0.40 \\
\hline & & THF & 10 & 0.15 & 0.09 & 0.60 \\
\hline
\end{tabular}

${ }^{\mathrm{a}}$ Initial concentration of each chalcone was $1 \mathrm{nM} .{ }^{\mathrm{b}}$ Yield of flavone $\mathbf{8 9}$ based on the consumption of chalcone 88. ${ }^{\mathrm{c}}$ Not determined. ${ }^{\mathrm{d}}$ 1-(2-Hydroxyphenyl)-5-phenylpenta-2,4-dien-1-one for comparison, although not a chalcone.

Table 11. Solvent effects on the consumption rate of 2'-hydroxychalcone 88a.

\begin{tabular}{|c|c|c|c|}
\hline Solvent ${ }^{\mathrm{a}}$ & Irrad. time (h) & Consumption (\%) & Rate $\left(\% \mathrm{~h}^{-1 b}\right)$ \\
\hline EtOAc & 0.5 & 7.0 & 14 \\
\hline Dioxane $^{c}$ & 2 & 14 & 7.0 \\
\hline Dioxane- $\mathrm{H}_{2} \mathrm{O}(95: 5)$ & 20 & 12 & 0.6 \\
\hline Dioxane- $\mathrm{D}_{2} \mathrm{O}(95: 5)$ & 20 & 13 & 0.65 \\
\hline $\mathrm{THF}^{c}$ & 2 & 11 & 5.4 \\
\hline THF- $\mathrm{H}_{2} \mathrm{O}(90: 10)$ & 5 & 6.4 & 1.3 \\
\hline THF- $\mathrm{H}_{2} \mathrm{O}(90: 10)$ & 5 & 7.0 & 1.4 \\
\hline$t$-Butyl alcohol & 2 & 4.7 & 2.4 \\
\hline DMF & 5 & 11 & 2.2 \\
\hline Cyclohexane & 3 & 6.1 & 2.0 \\
\hline $\mathrm{ACN}$ & 5 & 8.7 & 1.7 \\
\hline $\mathrm{ACN}-\mathrm{H}_{2} \mathrm{O}(95: 5)$ & 50 & 0.0 & 0.0 \\
\hline $\mathrm{ACN}-\mathrm{H}_{2} \mathrm{O}(40: 60)$ & 50 & 6.9 & 0.1 \\
\hline Benzene & 14 & 8.1 & 0.6 \\
\hline
\end{tabular}


Table 11. Cont.

\begin{tabular}{clll}
\hline Tetrachloromethane & 40 & 11 & 0.3 \\
EtOH & 90 & 9.8 & 0.1 \\
MeOH & 90 & 7.7 & 0.1 \\
Chloroform & 40 & 0.0 & 0.0 \\
\hline
\end{tabular}

${ }^{a}$ Initial concentration of 88a was $1 \mathrm{mM}$, on visible irradiation. Irradiation times were controlled so that conversions were close to or below $10 \%$. ${ }^{b}$ Relative rate for the consumption of $\mathbf{8 8 a}$. Solvent effects on the absorption at $\lambda \geq 400 \mathrm{~nm}$ were nil, hence the rate can be regarded as the relative quantum yield. ${ }^{c}$ Distilled over fresh sodium.

Jain [71] investigated the photochemistry of flavanones in alkaline medium. Flavanone 90a and 4chloroflavanone 90b rearranged in alkaline medium $(2 \mathrm{~mL} 10 \% \mathrm{NaOH}$ in $2 \mathrm{~mL}$ ethanol) upon irradiation with UV of an unspecified source to the corresponding products 91a and 91b (Scheme 35), but no yields were reported. A concerted mechanism was proposed (Scheme 36).

Scheme 35. Photochemistry of flavanone and 4'-chloroflavanone in alkaline medium.
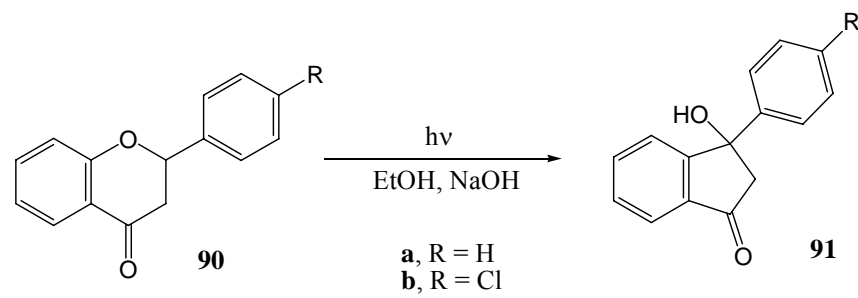

Scheme 36. Proposed mechanism of photochemical rearrangement of flavanone in alkaline medium.<smiles>Cc1ccccc1C(=O)CC(C)c1ccccc1</smiles><smiles>C=CC(CC(=O)c1ccccc1)c1ccccc1</smiles><smiles>O=C(CC(O)c1ccccc1)c1ccccc1</smiles><smiles>C=CC[CH+]C</smiles>

Photochemical Fries rearrangement of phenyl cinnamates represents a convenient method to prepare 2'-hydroxychalcones. Obara and Takahashi [72] irradiated phenyl cinnamate (92) in benzene under nitrogen with a high-pressure $450 \mathrm{~W}$ mercury arc and obtained 2'-hydroxychalcone 70 (10\%) and 4'-hydroxychalcone 93 (2\%) (Scheme 37).

Scheme 37. The photochemical Fries rearrangement of phenyl cinnamate to 2'-hydroxyand 4'-hydroxychalcone.<smiles>N#Cc1ccc(C(=O)/C=C/c2ccccc2)c(O)c1</smiles>

Obara and co-workers [73] repeated the reaction using a high-pressure $100 \mathrm{~W}$ mercury arc with 2-, 3-, and 4-hydroxyphenyl cinnamates 94a-c and obtained the corresponding 2',3'-, 2',4'-, and 2',5'dihydroxychalcones 95a-c in yields of 20, 5 and 16\%, respectively (Scheme 38). 
Scheme 38. The photochemical Fries rearrangement of hydroxyphenyl cinnamate derivatives.

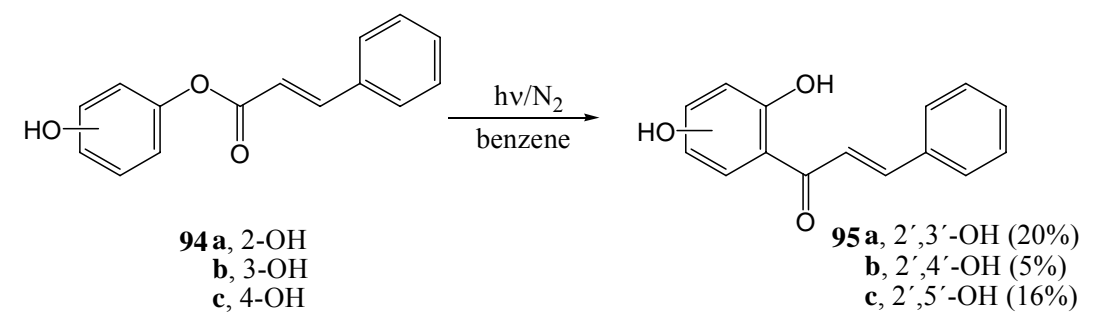

Onodera and Obara [74] extended the work to O-methoxymethyl-protected dihydroxyphenyl cinnamates 96a-c and obtained the corresponding hydroxy-bis $(O$-methoxymethyl)-chalcones 97a-c (Scheme 39).

Scheme 39. The photochemical Fries rearrangement of $O$-methoxymethyl protected dihydroxyphenyl cinnamates to the corresponding hydroxychalcones.

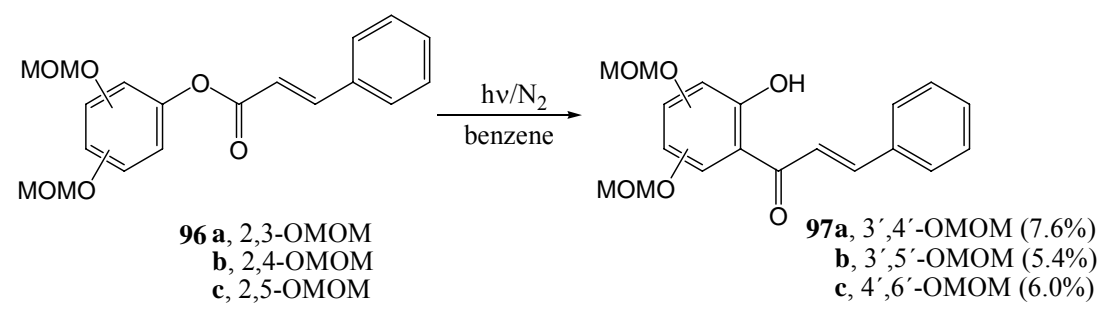

Bhatia and Kagan [75] transformed cinnamate 98 into 2',6'-dihydroxy-4'-methoxychalcone (99a, $7 \%$ ) and 2',4'-dihydroxy-6'-methoxychalcone $(\mathbf{9 9 b}, 12 \%)$ by irradiation in methanol at $250 \mathrm{~nm}$ (Scheme 40).

Scheme 40. The photochemical Fries rearrangement of 3'-hydroxy-5'-methoxycinnamate into 2',6'-dihydroxy-4'-methoxychalcone.

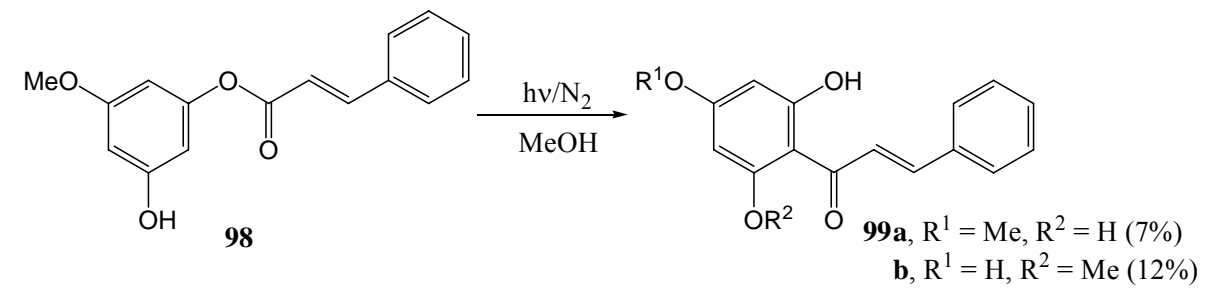

Ramakrishnan and Kagan [76] studied the photo-Fries reaction with the view of obtaining chalcones with the complex substitution patterns found in plants. A variety of chalcone derivatives were irradiated at $254 \mathrm{~nm}$ in different solvents, as given in Scheme 41 and Table 12.

Scheme 41. The photochemical synthesis of 2'-hydroxychalcones from phenyl cinnamates.<smiles>[R]c1cc([R])c([R])c(OC(=O)/C=C/c2ccc([R7])c([R3])c2[R])c1</smiles> 
Table 12. $\mathrm{R}^{1}-\mathrm{R}^{6}$ substituents on structure (100) and (101).

\begin{tabular}{ccc}
\hline Substituent on structure $\mathbf{1 0 0}$ and $\mathbf{1 0 1}$ & Solvent & Irradiation time (h) \\
\hline $\mathbf{a}, \mathrm{R}^{1}=\mathrm{R}^{2}=\mathrm{R}^{3}=\mathrm{R}^{4}=\mathrm{R}^{5}=\mathrm{R}^{6}=\mathrm{H}$ & $\begin{array}{c}\text { MeOH or chloroform } \\
\text { chloroform }\end{array}$ & 20 \\
$\mathbf{b}, \mathrm{R}^{1}=\mathrm{OMe}, \mathrm{R}^{2}=\mathrm{R}^{3}=\mathrm{R}^{4}=\mathrm{R}^{5}=\mathrm{R}^{6}=\mathrm{H}$ & $\mathrm{EtOH}$ & 45 \\
$\mathbf{c}, \mathrm{R}^{2}=\mathrm{OH}, \mathrm{R}^{1}=\mathrm{R}^{3}=\mathrm{R}^{4}=\mathrm{R}^{5}=\mathrm{R}^{6}=\mathrm{H}$ & & \\
$\left.\mathbf{d}, \mathrm{R}^{3}=\mathrm{OH}, \mathrm{R}^{1}=\mathrm{R}^{2}=\mathrm{R}^{4}=\mathrm{R}^{5}=\mathrm{R}^{6}=\mathrm{H}\right)^{*}$ & & 22 \\
$\mathbf{e}, \mathrm{R}^{2}=\mathrm{R}^{3}=\mathrm{OH}, \mathrm{R}^{1}=\mathrm{R}^{4}=\mathrm{R}^{5}=\mathrm{R}^{6}=\mathrm{H}$ & $\mathrm{MeOH}$ & 16 \\
$\mathbf{f}, \mathrm{R}^{2}=\mathrm{R}^{3}=\mathrm{R}^{4}=\mathrm{OH}, \mathrm{R}^{1}=\mathrm{R}^{5}=\mathrm{R}^{6}=\mathrm{H}$ & $\mathrm{MeOH}$ & 22 \\
$\mathbf{g}, \mathrm{R}^{2}=\mathrm{R}^{3}=\mathrm{R}^{6}=\mathrm{OH}, \mathrm{R}^{1}=\mathrm{R}^{4}=\mathrm{R}^{5}=\mathrm{H}$ & $\mathrm{MeOH}$ & 22 \\
$\mathbf{h}, \mathrm{R}^{2}=\mathrm{R}^{3}=\mathrm{OH}, \mathrm{R}^{6}=\mathrm{OMe}, \mathrm{R}^{1}=\mathrm{R}^{4}=\mathrm{R}^{5}=\mathrm{H}$ & $\mathrm{MeOH}$ & 36 \\
$\mathbf{i}, \mathrm{R}^{2}=\mathrm{R}^{3}=\mathrm{R}^{5}=\mathrm{R}^{6}=\mathrm{OH}, \mathrm{R}^{1}=\mathrm{R}^{4}=\mathrm{H}$ & $\mathrm{MeOH}$ & 17 \\
$\mathbf{j}, \mathrm{R}^{2}=\mathrm{R}^{3}=\mathrm{R}^{6}=\mathrm{OH}, \mathrm{R}^{5}=\mathrm{OMe}, \mathrm{R}^{1}=\mathrm{R}^{4}=\mathrm{H}$ & $\mathrm{MeOH}$ & 36 \\
$\mathbf{k}, \mathrm{R}^{2}=\mathrm{R}^{3}=\mathrm{OH}, \mathrm{R}^{5}=\mathrm{R}^{6}=\mathrm{OMe}, \mathrm{R}^{1}=\mathrm{R}^{4}=\mathrm{H}$ & $\mathrm{MeOH}$ & \\
\hline
\end{tabular}

* 101d obtained from 100c.

Yields varied between 20 and 50\% and it was postulated that the forming chalcones acted as internal filters and prevented complete conversion of the cinnamates. No cis-chalcones were isolated. After confirming that the photo-Fries reaction proceeded with the sample ester 100a, which yielded 101a as the major rearrangement product, different substituents were introduced on the A ring and it was found that the 2-methoxy- (compound 100b) and 3-hydroxy- (compound 100c) phenylcinnamates yielded the products of ortho migration, namely 101b from 100b and a mixture of 101c and 101d from 100c. Finally the set of compounds 100e-k was photolysed to get 101e-101k. The photo-Fries reaction of the phloroglucinol mono-ester is particularly simple since, for reasons of symmetry, the two products of ortho migration and that of para migration are identical.

Scheme 42. Proposed mechanism of the photo-oxygenation of chalcones.

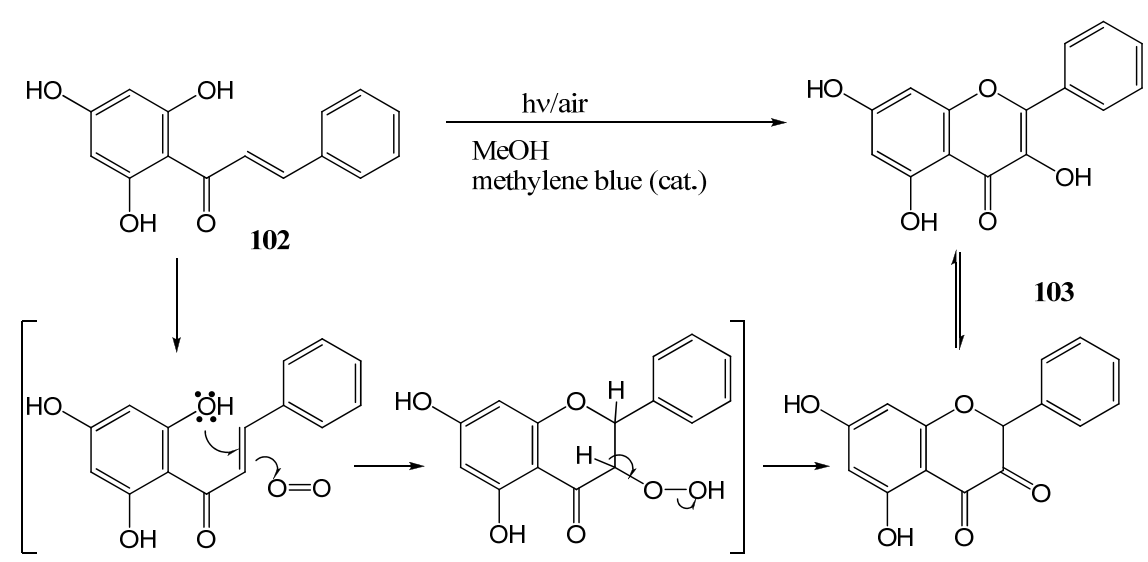

Chawla and Chibber [77] studied the photo-oxygenation of chalcones. Irradiation of 2',4',6'trihydroxychalcone (102) in methanol containing catalytic amounts of methylene blue under air with a $100 \mathrm{~W}$ tungsten lamp yielded the corresponding flavonol 103. The suggested mechanism is given in Scheme 42. No yields were reported. No reaction took place in the absence of methylene blue, suggesting the involvement of singlet molecular oxygen. Replacement of methylene blue with rose bengal gave lower yields, probably due to a lower concentration of ${ }^{1} \Delta_{\mathrm{g}}$ oxygen and the formation of ${ }^{1} E_{g}$ oxygen which leads to the formation of side products [78].

Subsequently Chawla and coworkers [79] studied the conversion of chalcones into dihydroflavonols. Irradiation of 2'-hydroxy-4',6',3,4-tetramethoxychalcone (104) in 4\% aqueous 
methanol and a catalytic amount of methylene blue with a $100 \mathrm{~W}$ tungsten flood lamp yielded the corresponding flavanol 105 (compared to flavonol 103 in previous paper [75]) (Scheme 43), but no 2,3-relative stereochemistry was indicated. No reaction was observed in non-aqueous solvents such as benzene, benzene-methanol mixtures, or absolute methanol. Upon addition of small amounts of water (ca. 5\%) the product was observed. This suggests that water is the source of the 3-OH in the flavanol product. Quinol, a well known radical quencher, inhibited the reaction, suggesting a radical mechanism. No yield was reported. The reaction was compared to the chlorophyll sensitised oxygenation in plants.

Scheme 43. Photochemical conversion of chalcones to flavanols.<smiles>COc1cc(O)c(C(=O)/C=C/c2ccc(OC)c(OC)c2)c(OC)c1</smiles>

Climent and co-workers [80] investigated the electron-transfer dehydrogenation of flavanones. They transformed flavanones 106a-c,e into the corresponding flavones 107a-c,e in yields ranging from 50 to $69 \%$ (Scheme 44, Table 13) using triphenylpyrilium tetrafluoroborate (TPT) in dichloromethane with a Pyrex immersion well and $125 \mathrm{~W}$ medium pressure lamp (potassium chromate solution as filter).

Scheme 44. Photosensitized dehydrogenation of flavanones to flavones with 2,4,6triphenylpyrylium tetrafluoroborate (TPT).<smiles>[R]c1ccc(C2CC(=O)c3cc([R])c([R])c([Y])c3O2)cc1</smiles><smiles>[R]c1ccc(-c2cc(=O)c3cc([R])c([R])c([R])c3o2)cc1</smiles>

107a-f

Table 13. The effect of substituents on the yield of photosensitized dehydrogenation of flavanones to flavones with 2,4,6-triphenylpyrylium tetrafluoroborate (TPT) $\left(\mathrm{R}^{1}-\mathrm{R}^{4}\right.$ substituents on 106 and 107).

\begin{tabular}{lc}
\hline \multicolumn{1}{c}{ Substituent } & Yield (\%) \\
\hline a, $R^{1}=R^{2}=R^{3}=R^{4}=H$ & 59 \\
b, $R^{2}=O M e, R^{1}=R^{3}=R^{4}=H$ & 68 \\
c, $R^{4}=O M e, R^{1}=R^{2}=R^{3}=H$ & 69 \\
d, $R^{4}=\mathrm{NO}_{2}, R^{1}=R^{2}=R^{3}=H$ & 0 \\
e, $R^{1}=R^{3}=M e, R^{2}=R^{4}=H$ & $52^{*}$ \\
\hline$* \mathbf{1 0 7 f}(13 \%)$ was also obtained $\left(R^{1}=C H O, R^{2}=R^{4}=H, R^{3}=M e\right)$.
\end{tabular}


4'-Nitroflavanone 106d was inert under the reaction conditions. The mechanism was rationalised in terms of an initial single electron transfer from the aromatic B-ring of the flavanone to the excited pyrilium salt to give the radical cation $\mathbf{1 0 8}$ or $\mathbf{1 1 0}$ which disproportionated to the flavones. Prevention of the reaction by an electron-withdrawing nitro group and acceleration by electron-donating methoxy substituents supports this mechanism (Scheme 45).

Scheme 45. Proposed single electron transfer mechanism of photosensitized dehydrogenation of flavanones to flavones with 2,4,6-triphenylpyrylium tetrafluoroborate (TPT).<smiles>[R]c1ccc(C2CC(=O)c3cc([R])c([R])c([R])c3OC2c2ccc([R])cc2)cc1</smiles><smiles>Cc1cc(C)c2oc(-c3ccccc3)cc(=O)c2c1</smiles>

\section{Chalcone Epoxides}

Bodforss [81] epimerised 4'-chloro- $\alpha, \beta$-epoxychalcone to the corresponding $\beta$-diketone in benzene with sunlight. A mechanism was proposed by Zimmerman [82] for a non-chlorinated derivative involving $\mathrm{C}_{\alpha}-\mathrm{O}$ ring-opening (Scheme 46).

Scheme 46. Proposed mechanism for photochemical $\beta$-diketone formation from $\alpha, \beta$-epoxychalcone.<smiles>O=C(CC(=O)c1ccccc1C(O)C1OC1C(=O)c1ccccc1)c1ccccc1</smiles> 
Ramakrishnan and Kagan [83] irradiated the phenyl epoxycinnamate 112 at $250 \mathrm{~nm}$ (in benzene under nitrogen) and obtained the 2-hydroxybenzoylacetophenone ( $\beta$-diketone) $\mathbf{1 1 4}$ in $75 \%$ yield. This $\beta$-diketone was readily converted to the corresponding flavone 118 with sodium acetate in acetic acid. The same $\beta$-diketone 114 was obtained upon irradiation of phenyl epoxycinnamate (112). It was postulated that 2'-hydroxyepoxychalcone $\mathbf{1 1 3}$ was an intermediate in this reaction, via a photo-Fries rearrangement. The isolation of small quantities of dihydroflavonol 115 (3.3\%) and flavonol 117 $(0.7 \%)$ was explained in terms of thermal rearrangements and oxidation of 113 (Scheme 47). No 2,3relative stereochemistry was indicated for $\mathbf{1 1 5}$. Phenol $(16 \%)$ and stilbene $(10 \%)$ were also isolated and a carbene mechanism was suggested. Efforts to broaden the scope of this reaction failed because other substituted phenyl cinnamates could not be converted to their corresponding epoxides.

Scheme 47. Photochemical conversion of phenyl epoxycinnamate to flavonoids.

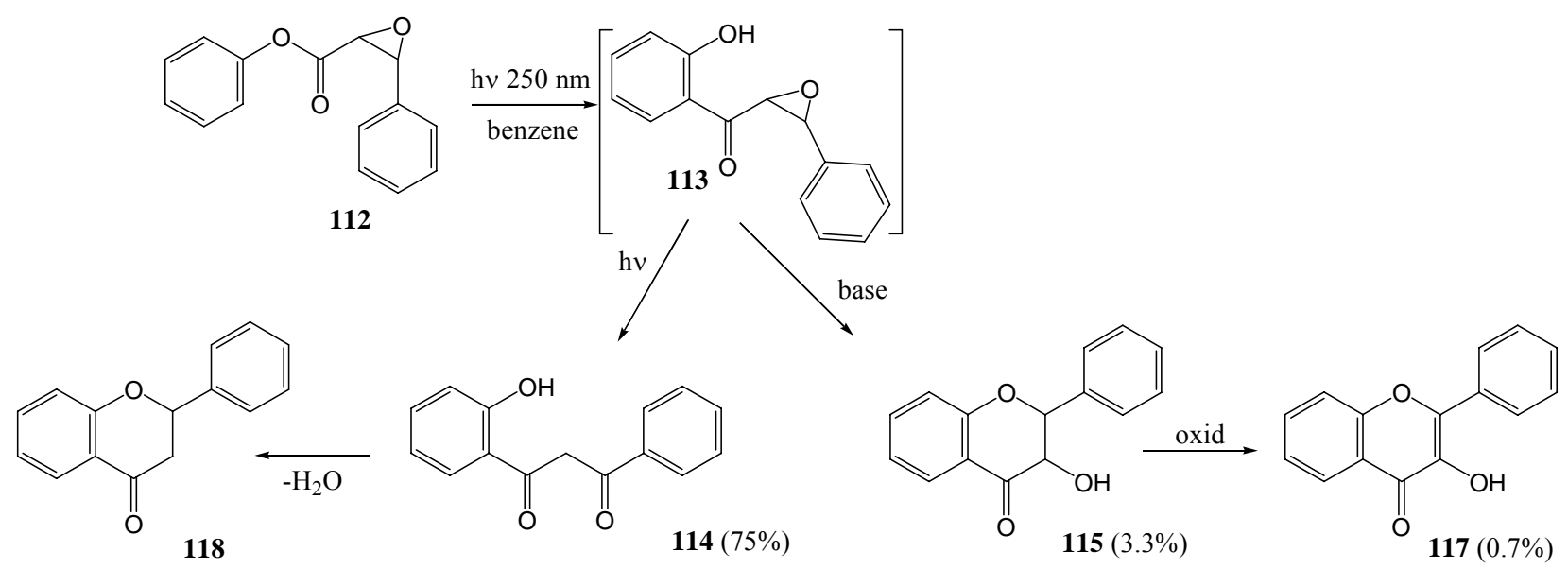

Van der Westhuizen and co-workers [84] irradiated 4,4',6'-trimethoxy-2'-methylmethoxy-trans chalcone-epoxide (119) in benzene at $250 \mathrm{~nm}$ under nitrogen and obtained the anticipated [85] $\beta$ diketone 120 (32\%) via heterocyclic $\mathrm{C}_{\alpha}$-O heterolysis and hydrogen transfer (Scheme 48).

Scheme 48. Photochemical transformation of 4,4',6'-trimethoxy-2'-methylmethoxy-trans chalcone-epoxide to the corresponding $\beta$-diketone.<smiles>COc1ccc(C(=O)CC(=O)c2c(OC)cc(OC)cc2OC)cc1</smiles>

Repetition of the reaction under identical conditions except for the presence of 3,5dimethoxyphenol, afforded a complex mixture (47\% overall yield) and the $\mathrm{C}_{\beta}-\mathrm{C}$ coupled analogues (via $\mathrm{C}_{\beta}-\mathrm{C}$ homolysis) $124,125,127,128$, and $130, \mathrm{C}_{\beta}-\mathrm{O}$ coupled isomer 126 , and a $\mathrm{C}_{\beta}-\mathrm{O}$ linked ester 129 were isolated (Scheme 49). 
Scheme 49. $\mathrm{C}_{\beta}$ coupled analogues obtained from irradiation of 4,4',6'-trimethoxy-2'methylmethoxy-trans chalcone-epoxide.

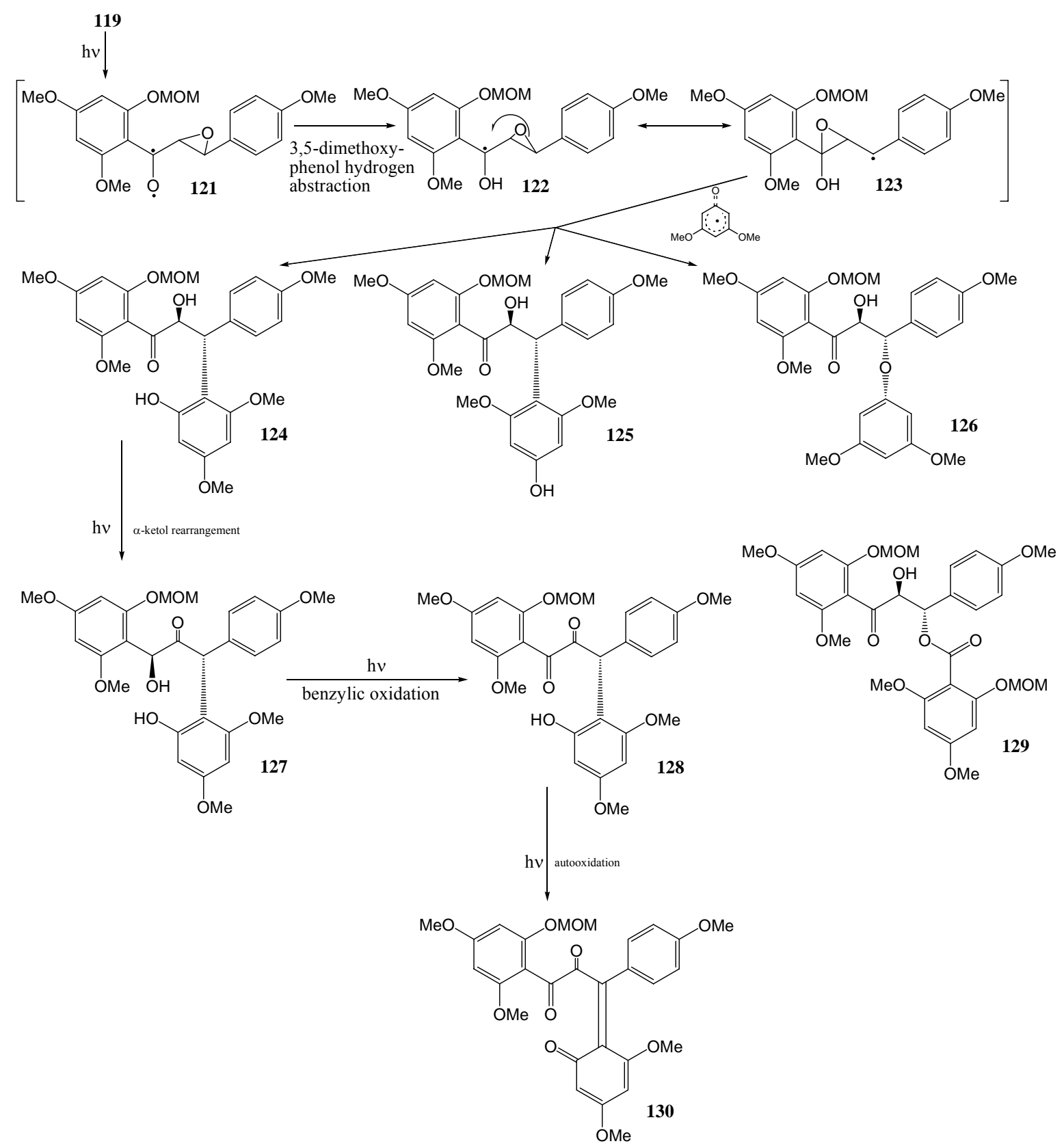

Formation of the $\beta$-coupled products 124 -126 was explained in terms of hydrogen abstraction from the phenol by an $n, \pi^{\star}$-excited carbonyl, rearrangement of the radical 122 to the corresponding benzyl radical 123, and coupling with the associated phenoxy radical (probably in a cage) at the 2-, 4-, or oxygen position. The $\beta$-coupled benzoyl ester 129 has a similar origin and indicates photolytic formation of a benzoic acid analogue. Photochemical $\alpha$-ketol rearrangement via photoenolisation of 124 explained the formation of the propan-2-one 127. Oxidation of 127 yielded structures 128 and 130.

\section{Reactions Initiated via Hydrogen Abstraction by an Excited State Carbonyl}

The excited state carbonyl group, generally assumed to be ${ }^{3}\left(n, \pi^{\star}\right)$, may abstract a suitably positioned hydrogen to form a biradical intermediate that may undergo further rearrangements to novel 
products. Photochemical keto-enol isomerisation and further transformations of the enol is included in hydrogen abstraction by carbonyls.

Scheme 50. Photochemistry of 2,3-trans-flavanols.

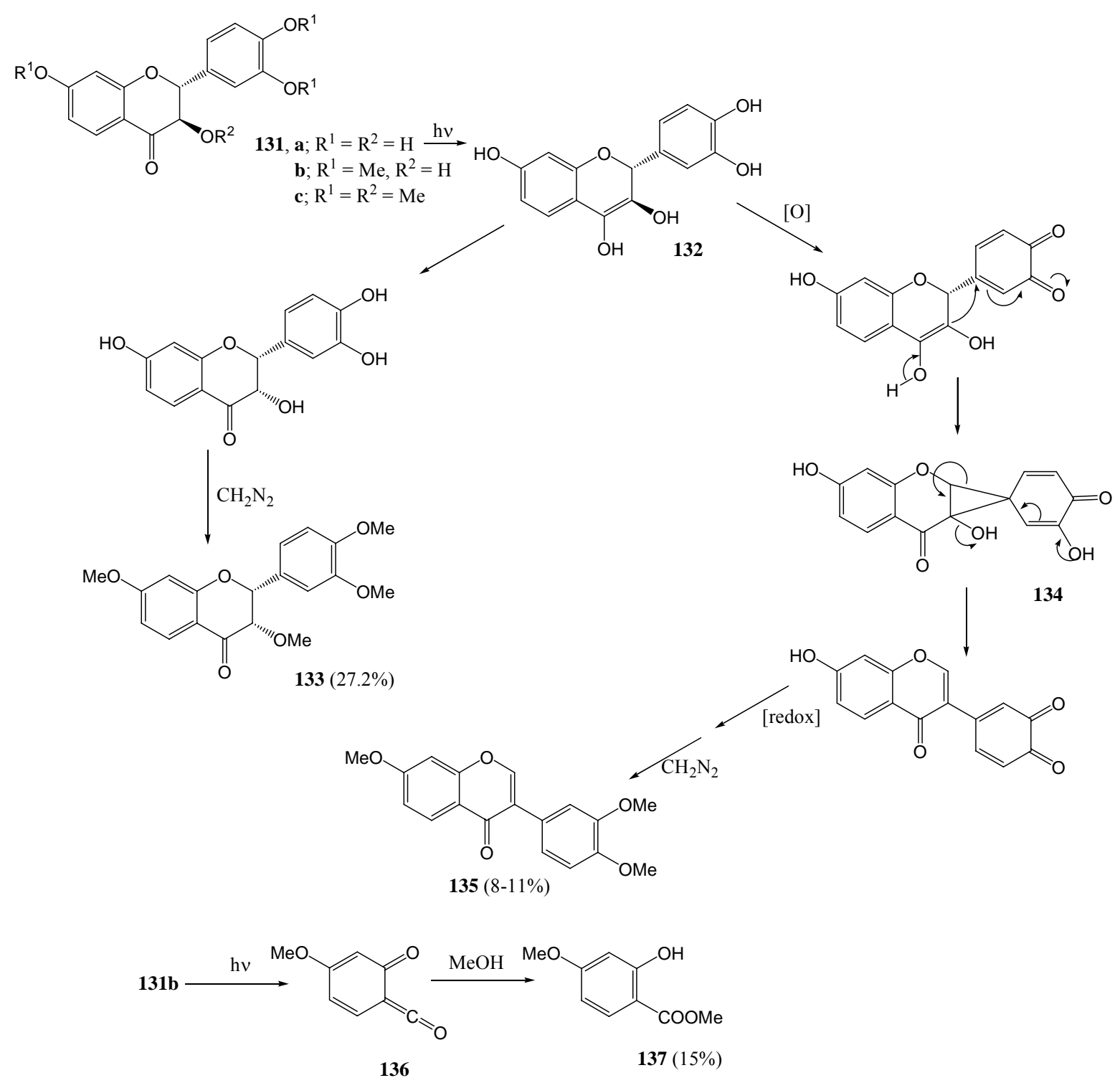

Fourie and co-workers [86] studied the photochemistry of 2,3-trans-flavanols 131a-c. Irradiation of free-phenolic (+/-)-2,3-trans-fustin (131a) at $300 \mathrm{~nm}$ in methanol yielded the thermodynamically less stable 2,3-cis isomer 133 (27\%) after complete methylation, and the isoflavone analogue 135 after final reduction and methylation. Both these products may form via an enol intermediate 132. The triO-methylether 131b gave none of the products obtained from free-phenolic fustin 131a, but instead underwent homolysis of both the heterocyclic O-C and $\alpha$-carbonyl bonds (Norrish type I process) to yield methyl-2-hydroxy-4-methoxybenzoate 137 via trapping of the intermediary ketene 136 (25\%) (Scheme 50). In contrast to the products obtained from free-phenolic and tri-O-methyl fustin, the tetra$O$-methyl analogue 131c gave 2'-hydroxy-3,4,4'-trimethoxy-trans-chalcone (138, 58\%) and tri-Omethylflavanone 139 (34\%), as shown in Scheme 51. The mechanism requires abstraction of a hydrogen atom from the 3-methoxy group by the excited carbonyl chromophore, followed by 
formaldehyde loss. The absence of the cis-chalcone suggested slow trans-cis isomerisation, probably due to inefficient light absorption at $300 \mathrm{~nm}$.

Scheme 51. Photochemistry of tetra-O-methyl fustin (permethylated flavanol).<smiles>C=CC1Oc2cc(OC)ccc2C(=O)CC1c1ccc2c(c1)OC(c1ccc(OC)c(OC)c1)C(O)=C2</smiles>

Van der Westhuizen and co-workers [87] described the photochemical deoxygenation of the series of flavanones depicted in Figure 5.

Figure 5. Flavanones and flavone obtained from flavanols.<smiles>[R10]Oc1cc([R])c2c(c1)O[C@H](c1ccc(O[R1])c([R])c1)[C@@H](O)C2=O</smiles>

a, $\mathrm{R}^{1}=\mathrm{R}^{2}=\mathrm{H}$<smiles>[R2]Oc1cc([R])c2c(c1)O[C@H](c1ccc(O[R1])c(O[R])c1)CC2=O</smiles>

b, $\mathrm{R}^{1}=\mathrm{Me}, \mathrm{R}^{2}=\mathrm{H}$

c, $\mathrm{R}^{1}=\mathrm{H}, \mathrm{R}^{2}=\mathrm{OH}$

d, $\mathrm{R}^{1}=\mathrm{Me}, \mathrm{R}^{2}=\mathrm{OH}$

$\mathrm{e}, \mathrm{R}^{1}=\mathrm{Me}, \mathrm{R}^{2}=\mathrm{OMe}$<smiles>[R2]Oc1cc([R])c2c(=O)cc(-c3ccc(O[R1])c(O[R1])c3)oc2c1</smiles>

Irradiation of (+)-fustin (140a) at $350 \mathrm{~nm}$ in dry ethyl acetate under nitrogen yielded the flavanone (-)-butin (141a) (2S) (37\%). In the case of tri-O-methylfustin (140b) both the corresponding flavanone 141b (21\%) and flavone 142b (15\%) were isolated. (-)-Fustin gave the flavanone with the inverse configuration $(2 R)$. Addition of phloroglucinol as a hydrogen donor increased the yield of 141a to $47 \%$, of $141 \mathbf{b}$ to $45 \%$, and of $142 \mathbf{b}$ to $28 \%$. Naphthalene, as triplet quencher, reduced the yield of 141a to $7 \%$ and increased the yield of the flavone $142 \mathbf{b}$ to $53 \%$. 
Scheme 52. Photochemical deoxygenation of an $\alpha$-ketol to a flavone.<smiles>COc1ccc2c(c1)OC(c1ccc(OC)c(OC)c1)C(O)C2=O</smiles><smiles>COc1ccc2c(c1)O[C@@H](c1ccc(OC)c(OC)c1)C=C2O</smiles><smiles>COc1ccc2c(c1)OC(c1ccc(OC)c(OC)c1)CC2=O</smiles>

These results indicate that deoxygenation takes place from an $\mathrm{n}, \pi^{\star}$-excited state via hydrogen abstraction. Phloroglucinol probably enhances this process. Efforts to transform the flavanone 141b into the flavone photolytically led to only minor transformation to the flavone $142 \mathrm{~b}(6 \%)$. It would appear that the flavanone 141b is not an intermediate in the formation of 142b from 140b. Nascent oxygen liberated during deoxygenation may be responsible for the oxidation of $\mathbf{1 4 1 b}$ to $\mathbf{1 4 2 b}$ (Scheme 52). The low conversion of the flavanone 141b to the isomeric trans-chalcone 143 in ethyl acetate (Scheme 53) contrasts with the results in polar solvents $(\mathrm{MeOH})$ where the equilibrium is towards the chalcone (Scheme 51) [86]. This allows isolation of optically pure flavanone $\mathbf{1 4 1 b}$.

Scheme 53. Photochemical conversion of flavanone to trans-chalcone.<smiles>COc1ccc(C(=O)/C=C/c2ccc(OC)c(OC)c2)c(O)c1</smiles>

(+)-Tri-O-methyldihydroquercetin (140d) has a hydroxyl group at C-5 that may form a hydrogen bond with the carbonyl chromophore thus resisting photo-transformation, and hampering the general applicability of the method. Efforts to overcome the problem with triplet sensitizers gave poor results ( $2 \%$ ), but addition of phloroglucinol increased the yields of the deoxygenated product $141 \mathrm{~d}$ to $23 \%$.

Van der Weshuizen and co-workers [88] investigated the photochemical methoxy-hydroxymethyl isomerization of 4-methoxybenzo[b]furan-3(2H)-ones 144a and 144b. Irradiation of 2-benzyl-2hydroxybenzo[b]furan-3(2H)-one (144a) at $350 \mathrm{~nm}$ in anhydrous ethyl acetate under nitrogen yielded 
$149(21 \%)$ and $150(16 \%)$. Irradiation of $144 \mathrm{~b}$ yielded $147 \mathrm{~b}$. These products require methoxyhydroxymethyl isomerisation of the 4-methoxy substituent (Scheme 54).

Scheme 54. Photochemical methoxy-hydroxymethyl isomerization of 4-methoxybenzo[b]furan-3(2H)-ones.
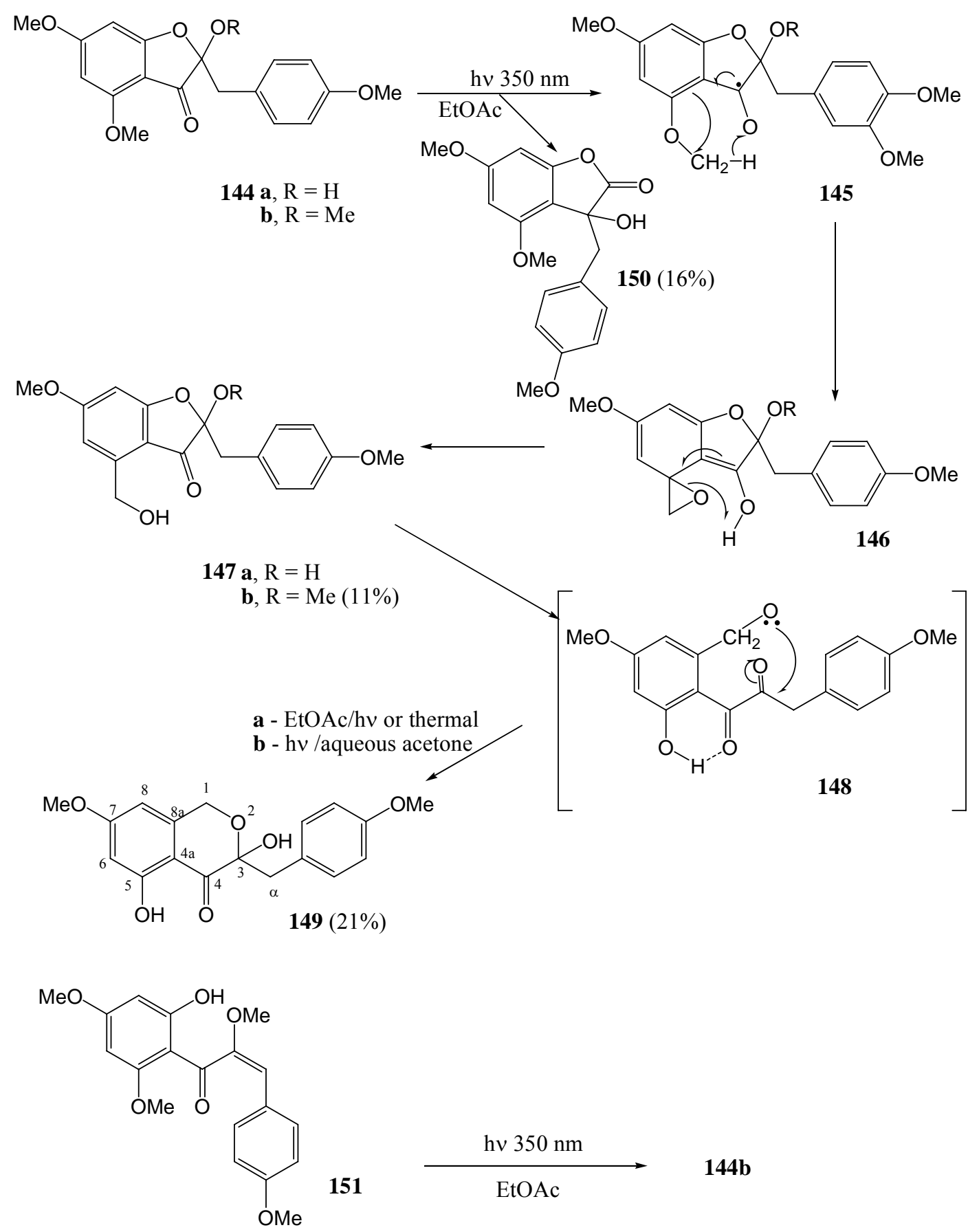<smiles>COc1ccc(CC(C)(OC)[C@](C)(O)C(=O)c2c(O)cc(OC)cc2OC)cc1</smiles> 
In 144a the 2-hydroxy allows incorporation of the aromatic $-\mathrm{CH}_{2} \mathrm{OH}$ group in the heterocyclic ring that changes the five-membered to a six-membered ring. In the case of the fully methylated 2methoxybenzo[b]furan-3(2H)-one (144b), the five-membered ring resisted ring-opening and the product with a free $-\mathrm{CH}_{2} \mathrm{OH}$ (compound 147b) was isolated (11\%). It was postulated that the benzylic acid rearrangement has ionic character and takes place from a $\pi, \pi^{\star}$ excited state which has ionic character and is encouraged by polar solvents [89]. Formation of 150 is described in Scheme 60 [90].

\section{Reactions of Flavonoids with a Fully Saturated C-Ring (no Carbonyl Chromophore). Benzyl Ether Fission}

Benzyl ethers typically undergo photolytic fission of the C-O bond. This is assisted by the stability of the benzylic radical or ionic intermediates. The heterocyclic C-ring of flavonoids contains an intramolecular benzylic ether bond.

Scheme 55. Photochemistry of flavan-3-ols.

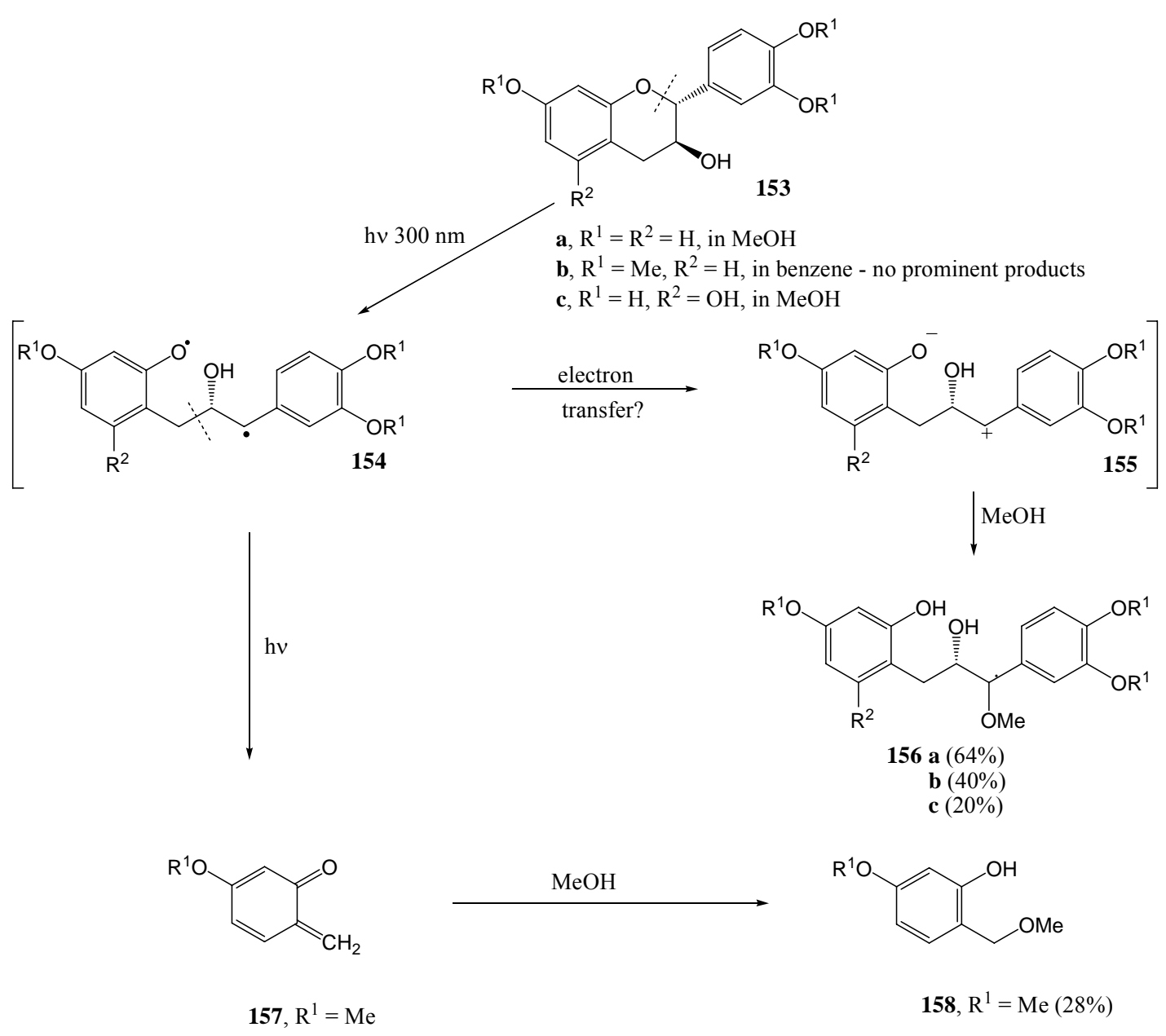

Fourie and co-workers [86] studied the photochemistry of flavan-3-ols. Irradiation of free phenolic flavan-3-ol 153c, fisetinidol (153a) and its tetra-O-methyl ether 153b at $300 \mathrm{~nm}$ in methanol yielded the corresponding optically active 1,3-diarylpropan-2-ols 156a and 156b (in 64 and 40\% yield, respectively). The mechanism involves fission of the heterocyclic benzylic $O-C$ bond and trapping of the resulting intermediary benzylic carbocation 155 with methanol. 
The methyl ether 153b also yielded 5-methoxy-2-methoxymethylphenol (158), via subsequent fission of the $\mathrm{C} 3-\mathrm{C} 4$ bond of radical 154 and trapping of the resulting ortho quinone methide 157 with methanol. The absence of the free phenolic analogue of $\mathbf{1 5 7}$ probably indicates stabilization of the free-phenolic benzylic carbocation as a para-quinone methide. Irradiation of the tetra-O-methyl ether 153b in benzene did not give any product. Benzene is probably not sufficiently polar to stabilise the intermediate carbocation 155 (Scheme 55). Under identical conditions free-phenolic catechin 153c gave the corresponding diarylpropan-2-ol 156c (20\%). Irradiation of flavan-3-ols results in homolysis of the heterocyclic 1,2-(O-C) and 3,4-(C-C) bonds.

Van der Westhuizen and co-workers [91] studied the photochemistry of tannin analogues. Benzophenone sensitized photolysis of free phenolic (2R,3S,4S)-2,3-trans-3,4-trans-4-(2,4,6-trihydroxyphenyl)-flavan-3-ol (159) at $350 \mathrm{~nm}$ in acetone yielded $(2 S, 3 S, 4 S)-2,3-c i s-3,4-c i s-4-(2,4-$ dihydroxyphenyl)-flavan-3-ol (160).

Scheme 56. Synthesis of 2,3-cis-3,4-cis 4-arylflavan-3-ols by photolytic rearrangement.
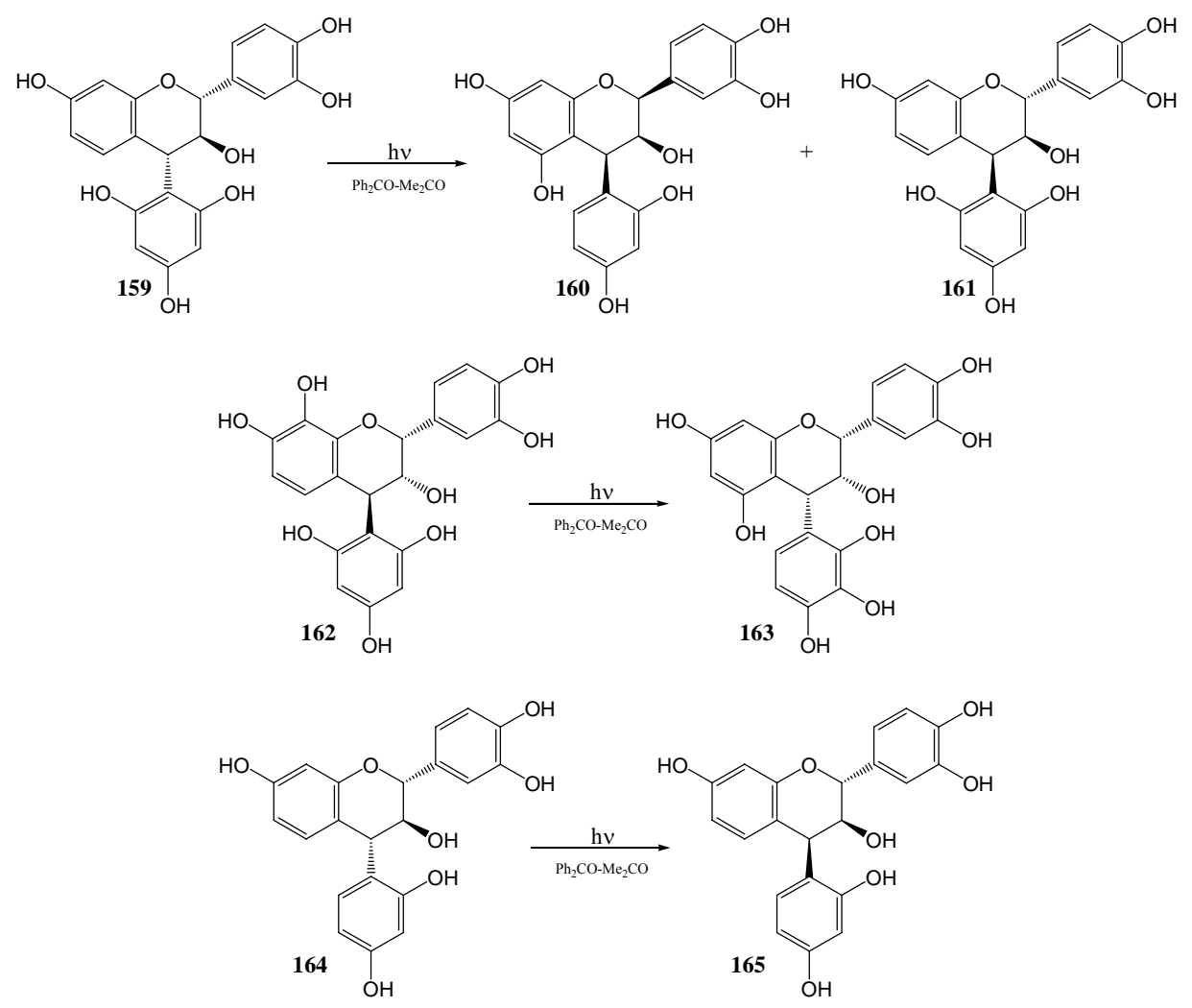

The mechanism involves formal cleavage of the heterocyclic ether bond followed by recyclisation via the quinone methide-stabilized benzylic carbocation 166 involving attack by the more nucleophilic phloroglucinol D-ring (isomerisation of the A-and D-ring) on the $\alpha$-face of C-2 (anti to the 3-hydroxy substituent).

Inversion of configuration at $\mathrm{C} 4$ is thus a result of rotation about the $\mathrm{C} 3-\mathrm{C} 4$ bond and inversion of configuration at $\mathrm{C} 2$ is probably controlled by the orientation of the $3-\mathrm{OH}$ substituent via a protonated oxirane intermediate 169. Traces of the $(2 R, 3 S, 4 R)$ 2,3-trans-3,4-cis-4-(2,4,6-trihydroxyphenyl)flavan-3-ol (163), were also isolated. 
Scheme 57. Proposed mechanism for photochemical inversion of configuration at C-4 of 4-arylflavan-3-ols.

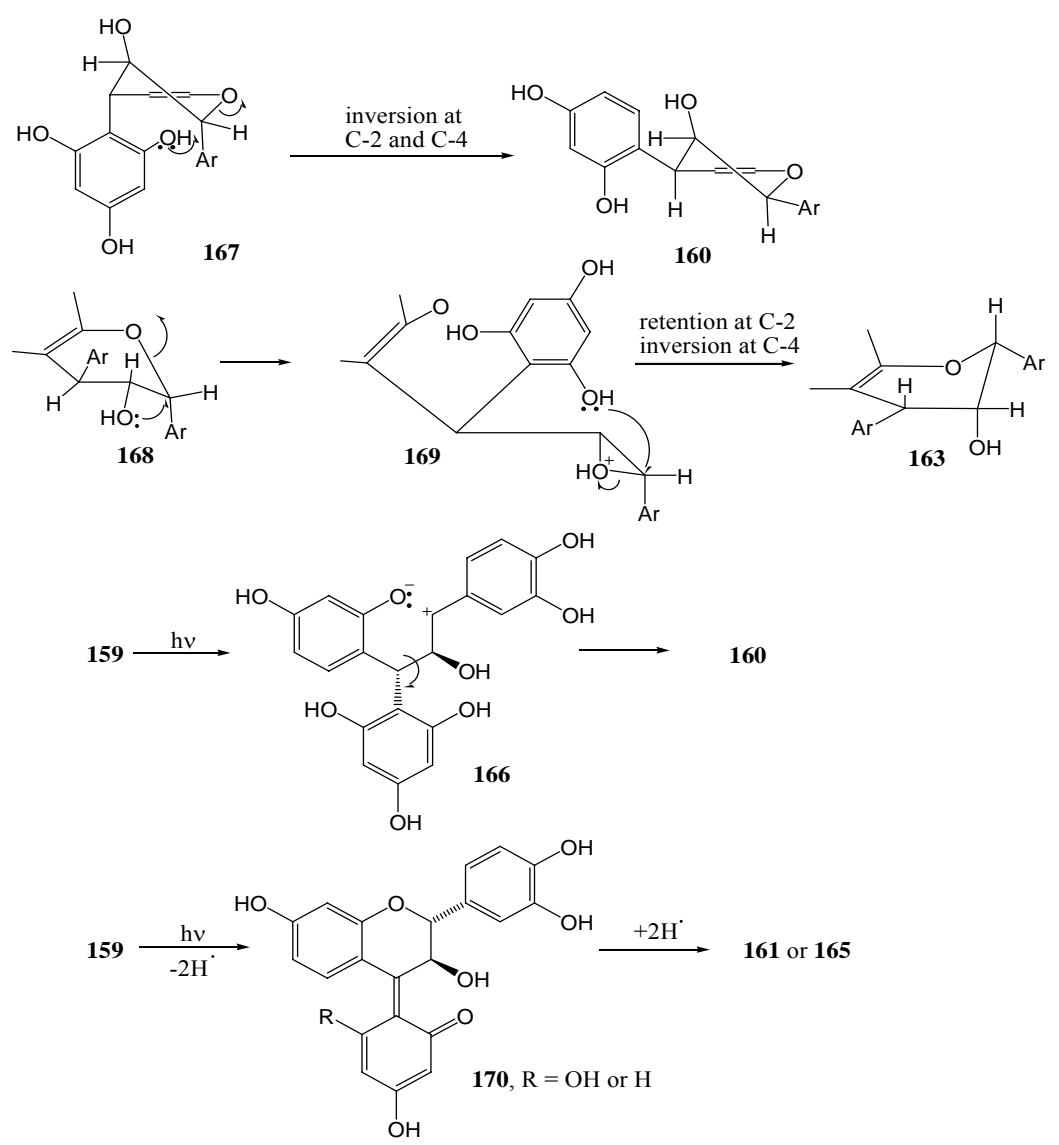

Formation of $\mathbf{1 6 1}$ involves no ring-isomerisation but only inversion of configuration at $\mathrm{C} 4$, probably via an A-ring quinone methide yielded the $(2 R, 3 R, 4 R)$ 2,3-cis-3,4-cis product 163. The stereochemistry at $\mathrm{C} 4$ was determined by rotation about the $\mathrm{C} 3-\mathrm{C} 4$ bond and configuration at $\mathrm{C} 2$ by the orientation of the hydroxy group on C3. With a weak nucleophilic D-ring, isomerisation of the Aand D-ring is not observed. Photolysis of $(2 R, 3 S, 4 R)$ 2,3-trans-3,4-trans-4-(2,4,-dihydroxyphenyl)flavan-3-ol (164) yielded the $(2 R, 3 S, 4 S)$ 2,3-trans-3,4-cis isomer 165. Inversion of configuration at $\mathrm{C} 4$ probably takes place via an A-ring quinone methide, similar to $\mathbf{1 7 0}$ described above. The reactions are given in Scheme 56 and a suggested mechanism provided in Scheme 57.

\section{Photochemistry of 2-Benzylbenzofuranones}

Fourie and co-workers [86] studied the photochemistry of 2-benzylbenzofuranones in methanol at $300 \mathrm{~nm}$ in quartz vessels. Photofragmentation of the heterocyclic $O-C$ and $\alpha$-carbonyl bonds of the tri$O$-methyl-2-benzyl-2-methoxybenzo[b]furan-3 $(2 H)$-one (171a) yielded 2-hydroxy-4-methoxybenzoate $(\mathbf{1 3 7}, 16 \%$ ), similar to tri-O-methylfustin (see also Scheme 51). In contrast, bond fission in the tetra-Omethyl-2-benzyl-2-methoxybenzo[b]furan-3(2H)-one (171b) equivalent is restricted to the $O-C$ bond and the 2,2-dimethoxyacetal $172(69 \%)$ is isolated via solvolysis of the ring-opened intermediate (Scheme 58). 
Scheme 58. Photochemistry of 2-benzylbenzofuranones.

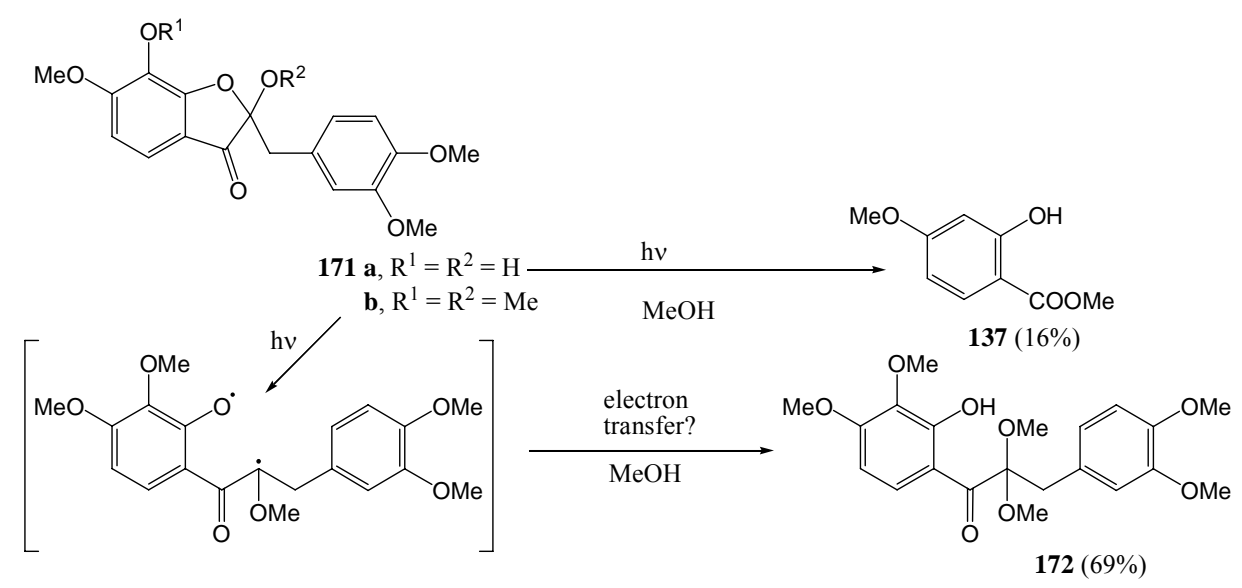

The 2-benzylfuranone (173a) where the B-ring has 4-methoxy- rather than 3,4-dimethoxysubstitution and the A-ring is of the phloroglucinol-type, yielded a cis- $\alpha$-methoxychalcone (174) (21\%) besides the corresponding acetal 175 (52\%). The 2-acetoxy derivative 173b gave the same acetal as the $\alpha$-methoxychalcone while the 2-hydroxy derivative 173c did not react (Scheme 59). By contrast, photofragmentation of 2-benzyloxyfuranones under the same conditions is confined to the heterocyclic C-O bond to form acetals $\mathbf{1 7 2}$ and $\mathbf{1 7 5}$.

Van der Weshuizen and co-workers (1977) [90] found that irradiation of 2-benzyl-2-methoxybenzo[b]furan-3(2H)-one (144b) at $350 \mathrm{~nm}$ in acetone-water, dioxane-water or tetrahydrofuran-water resulted in isolation of the 2-hydroxy derivative 144a (42\%) and small amounts of the corresponding $\alpha$-methoxy-cis-chalcone 151 (15\%). In the absence of water the $\alpha$-methoxy-cis-chalcone $151(60 \%)$ was the only product.

Scheme 59. Photochemistry of 2-benzylbenzofuranones.

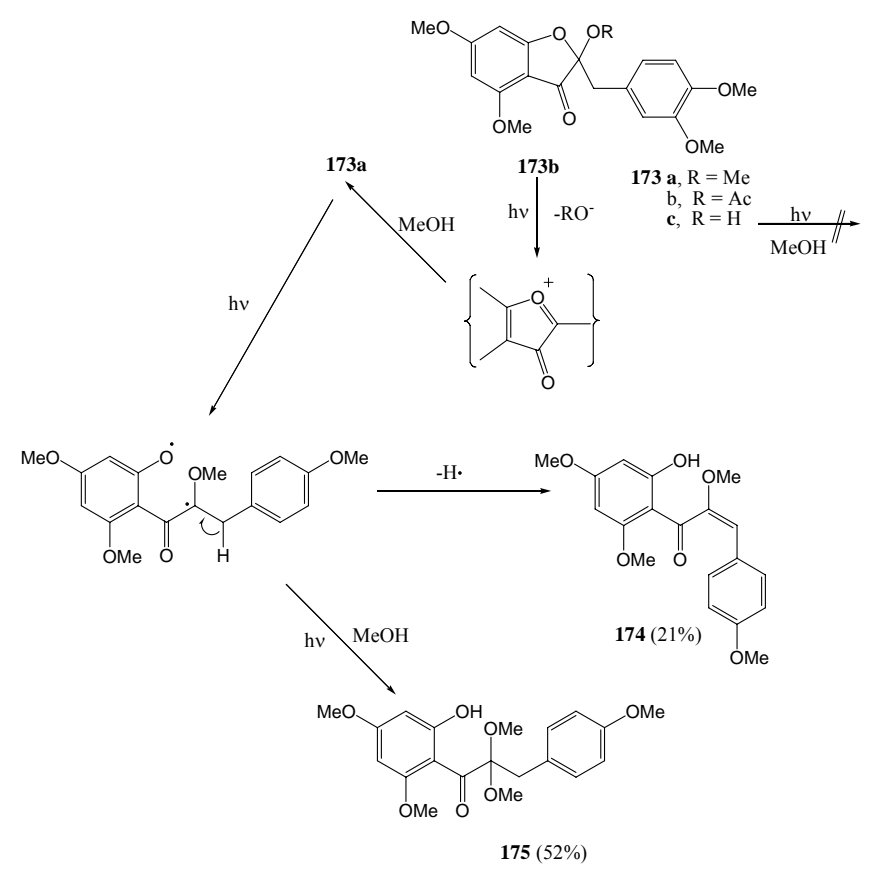


Irradiation of the 2-hydroxy derivative 144a at $350 \mathrm{~nm}$ resulted in a unique photochemical equivalent of the benzilic acid rearrangement to give the 3-benzyl-3-hydroxybenzo[b]furan-2 $(3 H)$-one analogue (150) (15\%). The proposed mechanism involves an $\alpha$-diketone and an 1,2-shift. Irradiation of (150) [88] in anhydrous ethyl acetate results in decarbonylation of the heterocycle via a Norrish type I process, leading to the deoxybenzoin 177 (Scheme 60).

\section{4-Phenylchroman-3-one}

The photochemistry of these compounds is of interest because of the C4 diaryl functionality that appears in all proanthocyanidins. Grover and Anand [92] transformed 4-phenyl-3-chromanone (178) to 4-phenyldihydrocoumarin (179, 35\%) in ethanol using a Hanovia $450 \mathrm{~W}$ mercury lamp (Scheme 61). The proposed mechanism occurs via intramolecular hydrogen abstraction via a five-membered cyclic transition state.

Scheme 60. Photochemical equivalent of benzilic acid rearrangement and related conversions.

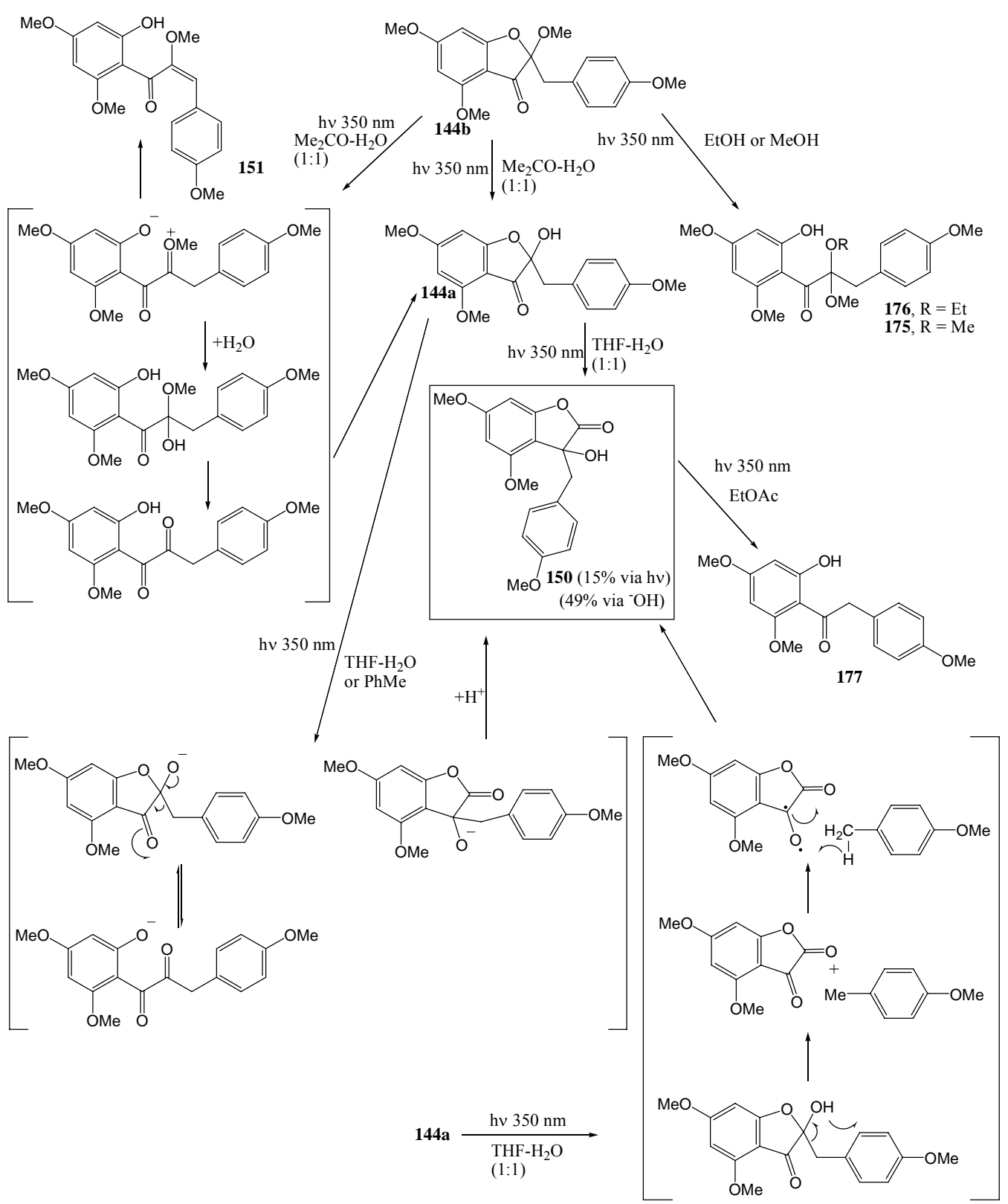


Later Padwa and Lee [93] suggested an alternative mechanism involving an enol tautomer (Scheme 62). Padwa and Au [94], and also Padwa and co-workers [95], subsequently repeated the reaction in benzene or acetonitrile to obtain 2-phenylchroman-3-one (180) in 60\% yield and the proposed mechanism explaining this different product is outlined in Scheme 63. They demonstrated tautomer control via use of the appropriate solvent.

Scheme 61. Proposed mechanism for the photochemical rearrangement of 4-phenyl-3chromanone to 4-phenyldihydrocoumarin.

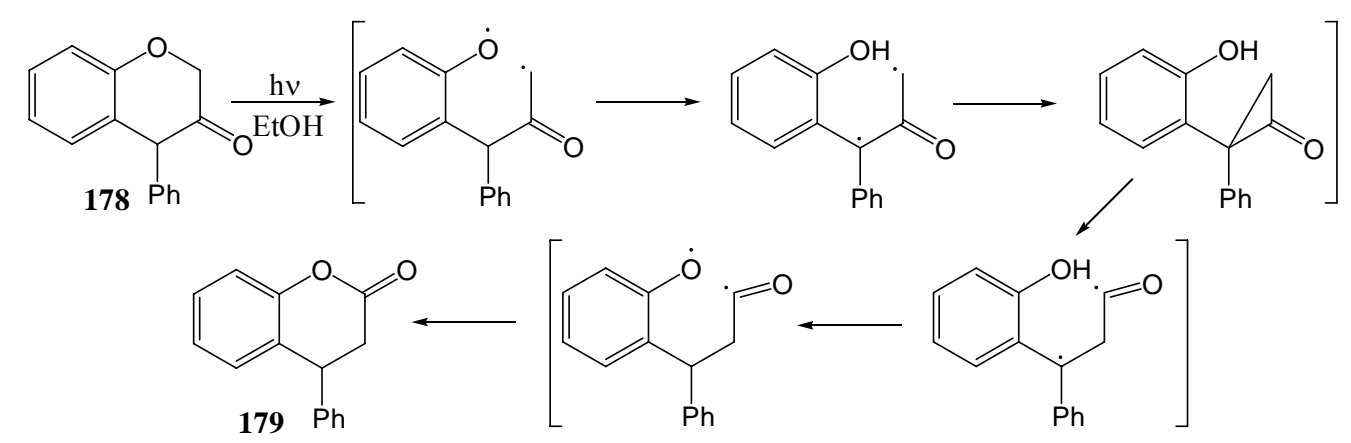

Scheme 62. Alternative mechanism for the photochemical rearrangement of 4-phenyl-3chromonone to 4-phenyldihydrocoumarin (enol tautomer intermediate).

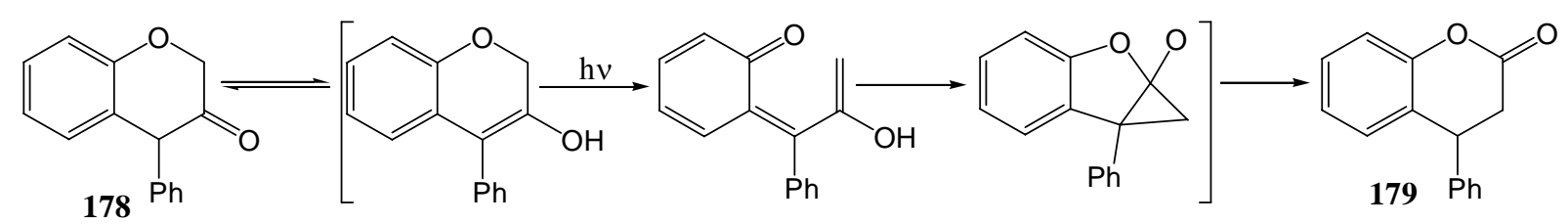

Scheme 63. Proposed mechanism for the photochemistry of 4-phenylchroman-3-one in acetonitrile or benzene.<smiles>C=C(C)C(c1ccccc1)c1cc(C)ccc1[O-]</smiles>

\section{Diverse Reactions}

Sundaryoano and co-workers [29] investigated the photochemistry of 1,7-diphenyl-1,6-heptadiene3,5-dione, a non-phenolic curcuminoid model. Upon irradiation of unsubstituted curcumin (181) with a medium-pressure mercury lamp $(400 \mathrm{~W})$ in an ethanol-ethyl acetate mixture they obtained 2'-hydroxy5',6'-benzochalcone 182 (4\%), the corresponding flavanone 183 (22\%), benzaldehyde, and cinnamaldehyde (Scheme 64).

Formation of the chalcone $\mathbf{1 8 2}$ was postulated to take place via photocyclisation of the excited triplet state of the enol form of $\mathbf{1 8 1}$ followed by a thermal oxidative step. Formation of the flavanone 183 was assumed to be via photochemical cyclisation in agreement with the work by Matshushima and coworkers (1985) [67]. This work represents a unique example of the photochemical conversion of a 
molecule from one important class of natural products (diarylheptanoids) into another important class (flavonoids).

Scheme 64. Photochemistry of 1,7-diphenyl-1,6-heptadiene-3,5-dione.

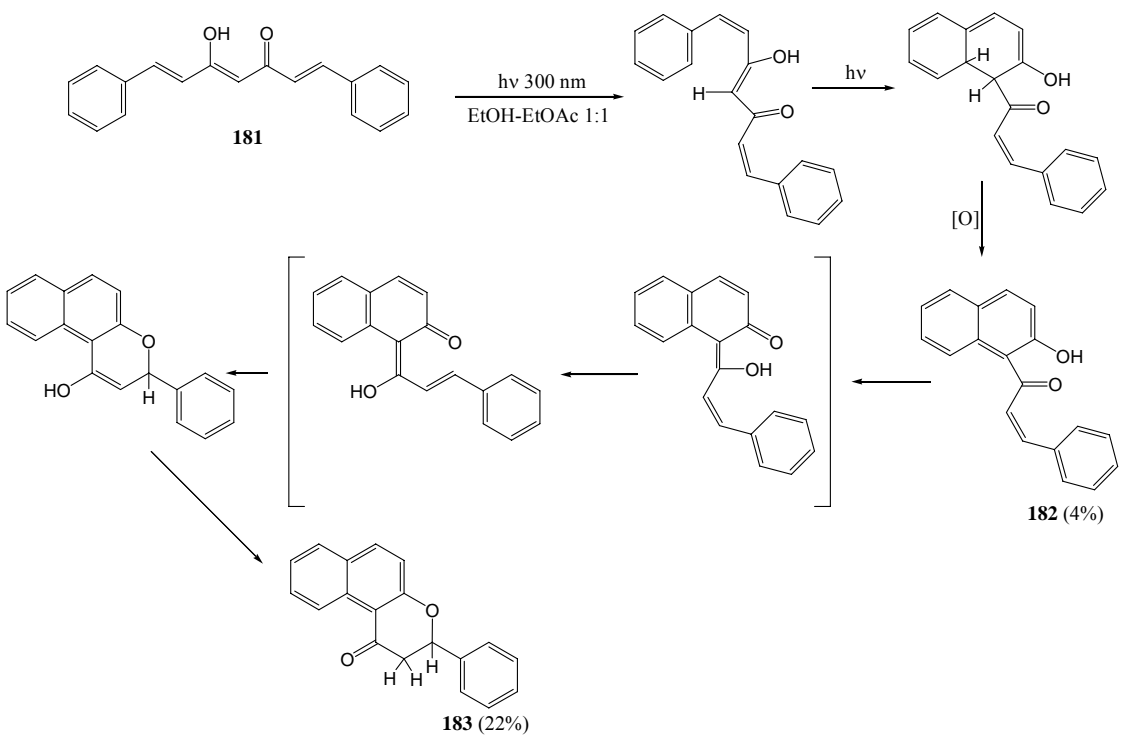

Yokoe and co-workers [96] studied the photochemistry of 2-steryl-4H-chromen-4-ones 184. Irradiation of $\mathbf{1 8 4}$ in benzene with a high-pressure mercury lamp at room temperature under air yielded benzo[a]xanthones 185 (Scheme 65) via cyclization in yields of between 43 and 88\%, depending on the aromatic substituents (Table 14). In the case of $\mathbf{1 8 4 d}$ and 184e, there are two possible directions of cyclization, ortho or para to the methoxy group on the benzene ring. However, the photocyclized products (185d and 185e) each showed a single spot on TLC. This reaction provides a general route to polycyclic xanthene derivatives.

Scheme 65. Photocyclization of 2-styryl-4H-chromen-4-ones.<smiles></smiles><smiles>CC1CCCCC1C</smiles><smiles>[R]c1ccc2c(c1)Oc1c(ccc3c([R])c([R])c([R])cc13)C2</smiles>

Table 14. Effect of substituents on the yield of the photocyclization of 2-styryl-4H-chromen-4-ones.

\begin{tabular}{cccccc}
\hline $\mathbf{1 8 4}$ & $\mathbf{R}^{\mathbf{1}}$ & $\mathbf{R}^{\mathbf{2}}$ & $\mathbf{R}^{\mathbf{3}}$ & $\mathbf{R}^{\mathbf{4}}$ & $\begin{array}{c}\text { Yield (\%) of } \\
\mathbf{1 8 5 a - \mathbf { i }}\end{array}$ \\
\hline $\mathrm{a}$ & $\mathrm{H}$ & $\mathrm{H}$ & $\mathrm{H}$ & $\mathrm{H}$ & 22 \\
$\mathrm{~b}$ & $\mathrm{H}$ & $\mathrm{Me}$ & $\mathrm{H}$ & $\mathrm{H}$ & 23 \\
$\mathrm{c}$ & $\mathrm{H}$ & $\mathrm{OMe}$ & $\mathrm{H}$ & $\mathrm{H}$ & 1 \\
$\mathrm{~d}$ & $\mathrm{H}$ & $\mathrm{H}$ & $\mathrm{OMe}$ & $\mathrm{H}$ & 15 \\
$\mathrm{e}$ & $\mathrm{H}$ & $\mathrm{OMe}$ & $\mathrm{OMe}$ & $\mathrm{H}$ & 7 \\
$\mathrm{f}$ & $\mathrm{He}$ & $\mathrm{H}$ & $\mathrm{H}$ & $\mathrm{H}$ & 11 \\
$\mathrm{~g}$ & $\mathrm{Me}$ & $\mathrm{Me}$ & $\mathrm{H}$ & $\mathrm{H}$ & 13 \\
$\mathrm{~h}$ & $\mathrm{Me}$ & $\mathrm{OMe}$ & $\mathrm{H}$ & $\mathrm{H}$ & 2 \\
$\mathrm{i}$ & $\mathrm{H}$ & $\mathrm{H}$ & $\mathrm{H}$ & $\mathrm{Br}$ & 31 \\
\hline
\end{tabular}


Kamboj and co-workers [97] observed similar results upon irradiation of 3-alkoxy-2-styrylchromones 186a-d with a $125 \mathrm{~W}$ mercury vapour lamp in methanol under nitrogen to afford six different structures 187-192 (Scheme 66, Table 15).

Scheme 66. Photochemistry of some 3-alkoxy-2-sterylchromones.<smiles>[R]COc1c(/C=C(\C)c2ccccc2)oc2ccc(Cl)cc2c1=O</smiles>

$186 \mathrm{a}, \mathrm{R}=\mathrm{H}$ b, $\mathrm{R}=\mathrm{C}_{6} \mathrm{H}_{5}$ c, $\mathrm{R}=\mathrm{CH}=\mathrm{CH}_{2}$ d, $\mathrm{R}=\mathrm{C}\left(\mathrm{CH}_{3}\right)_{2}$<smiles>C=C(C)C=C(C)C12COC1C(=O)c1cc(Cl)ccc1O2</smiles>
187<smiles>[R]COc1c(/C(C)=C/c2ccccc2)oc2ccc(Cl)cc2c1=O</smiles>

188<smiles>COc1c(/C(C)=C\c2ccccc2)oc2ccc(Cl)cc2c1=O</smiles>

189 (trans isomer of 188a)<smiles>[R]C1Oc2c(oc3ccc(Cl)cc3c2=O)[C@@H](C)[C@@H]1c1ccccc1</smiles><smiles>Cc1c(-c2ccccc2)oc2c(=O)c3cc(Cl)ccc3oc12</smiles>

192

Table 15. Effect of substituents on the photochemistry of 3-alkoxy-2-sterylchromones.

\begin{tabular}{|c|c|c|c|c|c|}
\hline \multirow[b]{2}{*}{186} & \multicolumn{5}{|c|}{ Yield (\%) } \\
\hline & 187 & 188 & 190 & 191 & 192 \\
\hline $\mathbf{a}, \mathrm{R}=\mathrm{H}$ & 6 & 54 & 5 & 8 & \\
\hline $\mathbf{b}, \mathrm{R}=\mathrm{C}_{6} \mathrm{H}_{5}$ & 7 & 55 & & 10 & 3.0 \\
\hline c, $\mathrm{R}=\mathrm{CH}=\mathrm{CH}_{2}$ & 8.5 & 56 & & 14 & 10 \\
\hline d, $\mathrm{R}=\mathrm{CH}=\mathrm{C}\left(\mathrm{CH}_{3}\right)_{2}$ & 9 & 58 & & 7 & 19 \\
\hline
\end{tabular}

The suggested mechanism for the formation of the photoproduct through dealkylation and excited state intramolecular proton transfer is given in Scheme 67.

Scheme 67. Suggested mechanism for the formation of the photoproduct from 3-alkoxy-2sterylchromones.

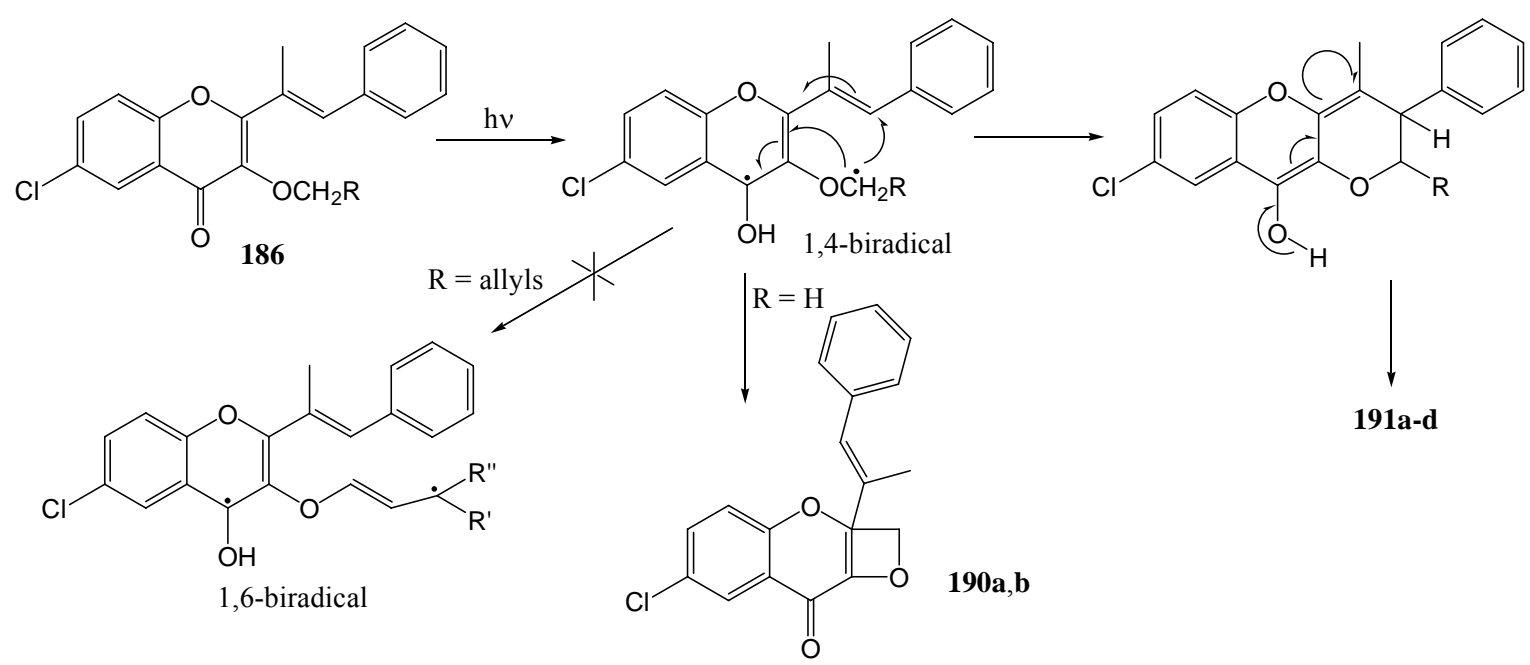


Scheme 68 shows the mechanism via isomerisation and cyclisation and Scheme 69 represents formation of the photoproduct through dealkylation and excited state intramolecular proton transfer.

Scheme 68. Suggested mechanism for the cyclisation of 3-alkoxy-2-styrylchromones.<smiles>[R]Oc1c(/C(C)=C/c2ccccc2)oc2ccc(Cl)cc2c1=O</smiles><smiles>[R]COC1C(=O)c2cc(C(=O)O)cc(C)c2Oc2ccc(Cl)cc21</smiles>

Scheme 69. Suggested mechanism for the dealkylation and excited state intramolecular proton transfer of 3-alkoxy-2-styrylchromones.

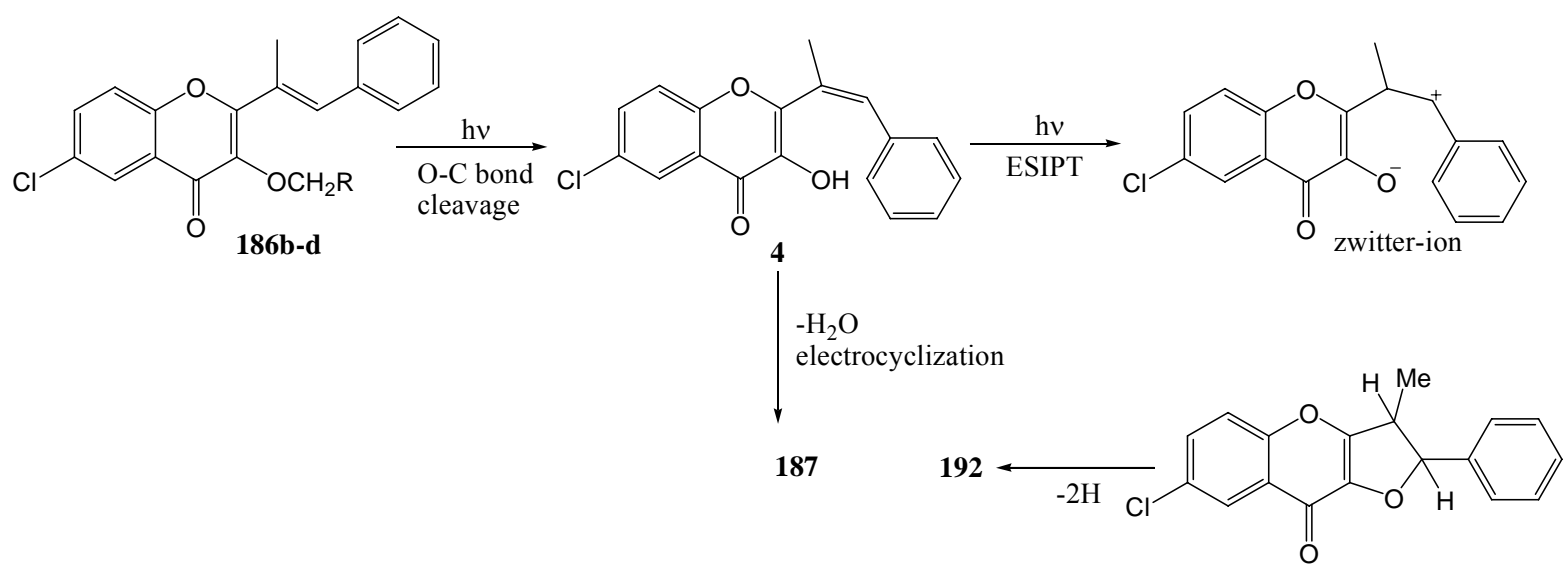

Dhande and co-workers [98] investigated the photochemistry of E-3-benzylideneflavanones 193. Aroylflavone 194 were obtained upon irradiation of compound 193 in dry benzene in the presence of air or oxygen (125 W high-pressure mercury lamp in quartz) as given in Scheme 70. Yields varied between 27 and $90 \%$ depending on the substituent on the aromatic rings. Isomerisation of the double bond to Z-3-benzylideneflavanones 195 was observed in all cases. Under inert atmosphere only the isomerisation product 195 was observed. As the Z-isomer with the C-2 aryl in the equatorial position has the $\mathrm{H}-2$ proton in a suitable axial position for a concerted ene reaction with singlet oxygen, it was suggested that isomerisation to the Z-isomer preceded oxidation to a hydroperoxide intermediate 196. Efforts to increase the reaction rate with rose bengal (a singlet oxygen source), however, failed. In dichloromethane with a phase transfer catalyst and rose bengal or methylene blue, no oxidation and only $E$ to $Z$ isomerisation was observed. Yields for each different derivative are given in Table 16.

Halogen containing solvents (such as chloro-, bromo-, and iodobenzene) or addition of iodoform reduced the isomerisation time under nitrogen. Addition of iodoform to the benzene reaction mixture under air gave 3- $\alpha$-hydroxybenzylflavones 197 upon photolysis using a Pyrex immersion well in yields of between 60 and $88 \%$ depending on the substituent. This represents a general route to these otherwise unavailable compounds. Arylideneflavanones 193 upon UV irradiation using quartz undergo auto-oxidation to 3-aroyl-flavones 194. Photolysis by using a Pyrex filter in the presence of iodoform 
furnishes 3- $\alpha$-hydroxy-benzylflavones indicating the intermediacy of the hydroperoxide 196 and represents a new general method for the synthesis of these compounds not available by other routes. Under the inert conditions the irradiation furnishes the isomerised product 195.

Scheme 70. Phototransformation of 3 -arylideneflavanones to $3 \alpha$-hydroxybenzylflavones.

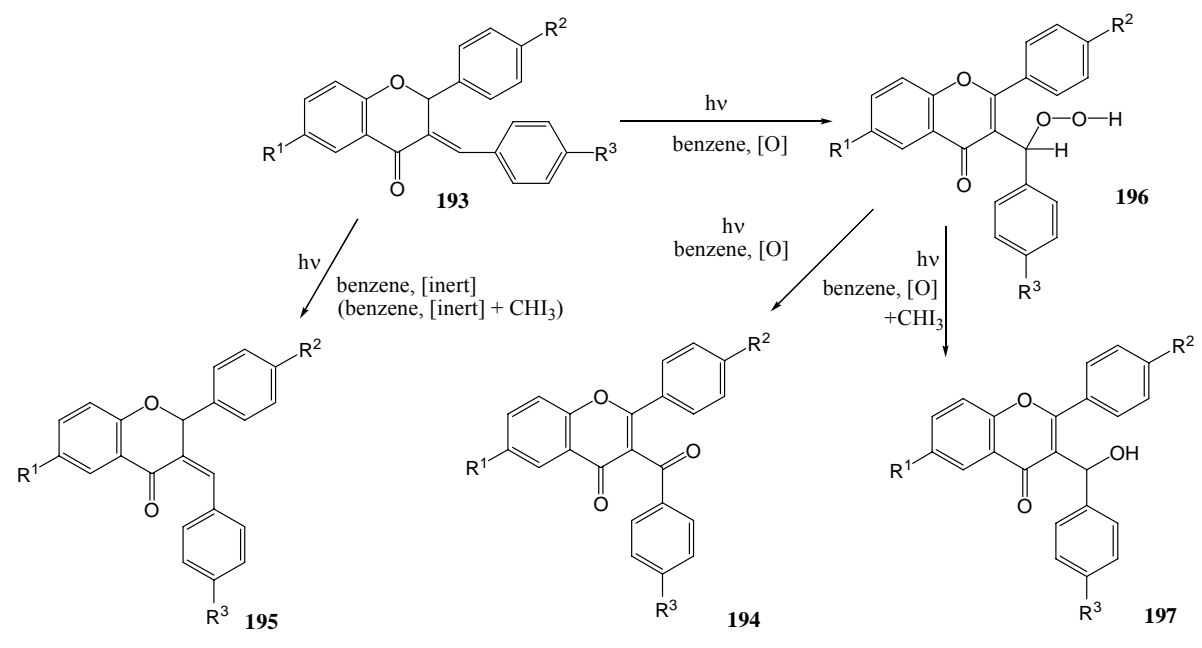

Table 16. Effect of substituents on the yields of phototransformation of 3arylideneflavanones to $3 \alpha$-hydroxybenzylflavones.

\begin{tabular}{cccccccccc}
\hline $\mathbf{1 9 3}, 194,197$ & a & b & c & d & e & f & g & h & i \\
\hline $\mathrm{R}^{1}$ & $\mathrm{Me}$ & $\mathrm{Me}$ & $\mathrm{Me}$ & $\mathrm{H}$ & $\mathrm{H}$ & $\mathrm{H}$ & $\mathrm{H}$ & $\mathrm{H}$ & $\mathrm{H}$ \\
$\mathrm{R}^{2}$ & $\mathrm{OMe}$ & $\mathrm{Cl}$ & $\mathrm{OMe}$ & $\mathrm{H}$ & $\mathrm{H}$ & $\mathrm{H}$ & $\mathrm{H}$ & $\mathrm{H}$ & $\mathrm{H}$ \\
$\mathrm{R}^{3}$ & $\mathrm{Cl}$ & $\mathrm{H}$ & $\mathrm{OMe}$ & $\mathrm{H}$ & $\mathrm{Me}$ & $\mathrm{OMe}$ & $\mathrm{OCH}_{2} \mathrm{Ph}$ & $\mathrm{Cl}$ & $\mathrm{NO}_{2}$ \\
\hline $\mathbf{1 9 4}$ Yield (\%) & 32 & 27 & 31 & 90 & & 81 & 86 & 81 & \\
$\mathbf{1 9 7}$ Yield (\%) & & & & 65 & 66 & 61 & 60 & 70 & 88 \\
\hline
\end{tabular}

Ishibe and co-workers (1975) [99] irradiated 2-phenyl-7-methoxyisoflavone (198a) in methanol with a medium-pressure mercury lamp and a Pyrex filter and obtained the corresponding 3,4-diphenylisocoumarin 199a (10\%) and a pentacyclic structure 200a (42\%), presumably via intermediate 201. 2Phenyl-7-hydroxyisoflavone was unreactive in air but gave (200b) in the presence of iodine. Photoisomerisation was not observed with 2-methyl-7-hydroxyisoflavone and 2-methylisoflavone in methanol, indicating that the presence of a 2-phenyl-substituent was a prerequisite (Scheme 71).

Scheme 71. Photochemistry of 2-phenylisoflavones.

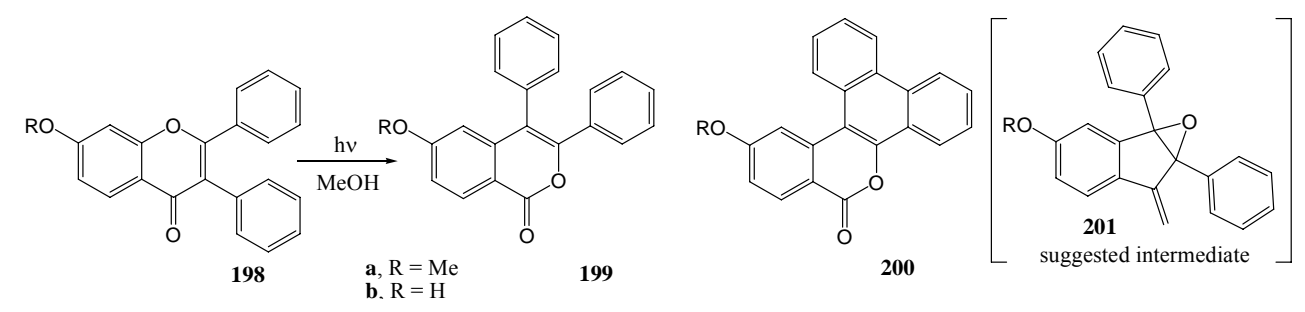

\section{Conclusions}

A plethora of photochemical transformations of flavonoids has been described over the past 50 years [100] and much progress has been made to better understand the reaction mechanisms and the 
associated influence of reaction conditions on yields and products. Yet photochemistry still presents the researcher with many challenges and opportunities. Ephemeral goals like chemical trapping of sunlight energy to replace fossil fuels (derived from sunlight) and industrial feedstocks (also derived from sunlight) will receive considerable attention. More humble goals such as the publication of novel flavonoid photochemical transformations will keep academics active and expand our knowledge of flavonoid chemistry [101]. Photochemistry in chiral environments [102], including the use of chiral light, promises enantiomerically pure products. The use of monochromatic laser light will allow selective excitation of target chromophores. The use of high energy lasers in combination with a flow reactor will reduce the time that reagents are exposed to UV light to minimize unwanted side reactions and increase yields. Low temperature photochemistry should also yield interesting results.

\section{References}

1 Haslam, E. Chemistry and Pharmacology of Natural Products. Plant Polyphenols: Vegetable Tannins Revisited; Cambridge University Press: Sydney, Australia, 1989; p. 8.

2 Smith, M.A.; Perry, G.; Richey, P.L.; Sayre, L.M.; Anderson, V.E.; Beal, M.F.; Kowall, N. Oxidative Damage in Alzheimers. Nature 1996, 382, 120-121.

3 Corder, R.; Mullen, W.; Khan, N.Q.; Marx, S.C.; Woods, E.G.; Carrier, M.J.; Crozier, A. Oenology: Red Wine Procyanidins and Vascular Health. Nature 2006, 444, 566.

4 Jankun, J.; Selman, S.H.; Swiercz, R.; Skrypczak-Jankun, E. Why Drinking Green Tea Could Prevent Cancer. Nature 1997, 387, 561.

5 Garbisa, S.; Biggin, S.; Cavallarin, N.; Sartor, L.; Benelli, R.; Albini, A. Tumor Invasion: Molecular Shears Blunted by Green Tea. Nat. Med. 1999, 5, 1216.

6 Prasain, J.K.; Carlson, S.H.; Wyss, J.M. Flavonoids and Age-related Disease: Risk, Benefits and Critical Windows. Maturitas 2010, in press.

7 Pietta, P.G. Flavonoids as Antioxidants. J. Nat. Prod. 2000, 63, 1035-1042.

8 Schroeter, H.; Heiss, C.; Balzer, J.; Kleinbongard, P.; Keen, C.L.; Hollenberg, K.; Sies, H.; KwikUribe, C.; Schmitz, H.H.; Kelm, M. (-)-Epicatechin Mediates Beneficial Effects of Flavanol-rich Cocoa on Vascular Function in Humans. Proc. Natl. Acad. Sci. USA 2006, 103, 1024-1029.

9 Arai, Y.; Watanabe, S.; Kimira, M.; Shimoi, K.; Mochizuki, R.; Kinae, Naohide. Dietary Intakes of Flavonols, Flavones and Isoflavones by Japanese Women and the Inverse Correlation between Quercetin Intake and Plasma LDL Cholesterol Concentration. J. Nutr. 2000, 130, 2243-2250.

10 Kootstra, A. Protection from UV-B-induced DNA Damage by Flavonoids. Plant Mol. Biol. 1994, 26, 771-774.

11 He, J.; Santos-Buelga, C.; Mateus, N.; de Freitas, V. Isolation and Quantification of Oligomeric Pyranoanthocyanin-flavanol Pigments from Red Wines by Combination of Column Chromatographic Techniques. J. Chromatogr. A 2006, 1134, 215-225.

12 Hergert, H.L. Condensed Tannins in Adhesives: Introduction and Historical Perspectives; Repap Technologies Inc.: Valley Forge, PA, USA, 1989; Volume 385, pp. 155-171.

13 Robertson, A. The Chemistry and Biochemistry of Black Tea Production - the non-volatiles. In Tea: Cultivation to Consumption; Wilson, K.C., Clifford, M.N., Eds.; Kluwer Acad. Publ.: Dordrecht, The Netherlands, 1991; pp. 574-580. 
14 Codorniu-Hernández, E.; Mesa-Ibirico, A.; Montero-Cabrera, L.A.; Martı'nez-Luzardo, F.; Borrmann, T.; Stohrer, W.-D. Theoretical Study of Flavonoids and Proline Interactions. Aqueous and Gas Phases. J. Mol. Struct. (Theochem) 2003, 623, 63-73.

15 Van Andel, T. The Diverse Uses of Fish-Poison Plants in Northwest Guyana. Econ. Bot. 2000, 54, 500-512.

16 Stermitz, F.R.; Adamovics, J.A.; Geigert, J. Synthesis and Photoreactions of Sorbophenones: A Photochemical Synthesis of Flavones. Tetrahedron 1975, 31, 1593-1595.

17 Winkel-Shirley, B. Biosynthesis of Flavonoids and Effects of Stress. Curr. Opin. Plant Biol. 2002, 5, 218-223.

18 Arthur, J.M. Radiation and Anthocyanin Pigments. In Biological Effects of Radiation; Duggar, B.M., Ed.; McGraw-Hill: New York, NY, USA, 1936; Volume 2, pp. 1109-1118.

19 Siegelman, H.W.; Hendricks, S.B. Photocontrol of Anthocyanin Formation in Turnip and Red Cabbage Seedlings. Plant Physiol. 1957, 32, 393-398.

20 Hahlbrock, K.; Ebel, J.; Ortmann, R.; Sutter, A.; Wellmann, E.; Grisebach, H. Regulation of enzyme activities related to the biosynthesis of flavone glycosides in cell suspension cultures of parsley Petroselium hortense. Biochim. Biophys. Acta 1971, 244, 7-15.

21 Wellmann, E.; Hrazdina, G.; Grisebach, H. Induction of Anthocyanin Formation and of Enzymes Related to its Biosynthesis by UV Light in Cell Cultures of Haplopappus gracilis. Phytochemistry 1976, 15, 913-915.

22 Taylor, L.P.; Grotewold, E. Flavonoids as Developmental Regulators. Curr. Opin. Plant Biol. 2005, 8, 317-323.

23 Hernández, I.; Alegre, L.; Van Breusegem, F.; Munné-Bosch, S. Haw Relevant are Flavonoids as Antioxidant in Plants? Trends Plant Sci. 2009, 14, 125-132.

24 Agati, G.; Tattini, M. Multiple Functional Roles of Flavonoids in Photoprotection New Phytol. 2010, 186, 786-793.

25 Roberts, M.R.; paul, N.D. Seduced by the Dark Side: Integrating Molecular and Ecological Perspectives on the Infuence of Light on Plant Defence against Pets and Pathogens. New Phytol. 2006, 170, 677-699.

26 Caldwell, M.M. Solar UV Irradiation and the Growth and Development of Higher Plants. Photophysiology 1971, 6, 131-177.

27 Cavaleri, J.J.; Prater, K.; Bowman, R.M. An Investigation of the Solvent Dependence on the Ultrafast Intersystem Crossing Kinetics of Xanthone. Chem. Phys. Lett. 1996, 259, 495-502.

28 Gupta, R.C.; Jain, A.C.; Saini, H.R. Photochemistry of flavonoids. J. Sci. Ind. Res. 1978, 37, 264-273.

29 Sundaryono, A.; Nourmamode, A.; Gardrat, C.; Grelier, S.; Bravic, G.; Chasseau, D.; Castellan, A. Studies on the Photochemistry of 1,7-diphenyl-1,6-heptadiene-3,5-dione, a Non-phenolic curcuminoid Model. Photochem. Photobiol. Sci. 2003, 2, 914-920.

30 Monici, M.; Mulinacci, N.; Baglioni, P.; Vincieri, F.F. Flavone Photoreactivity. UV-induced Reactions in Organic Solvents and Micellar Systems. J. Photochem. Photobiol. B: Biol. 1993, 20, 167-172.

31 Waiss, A.C., Jr.; Corse, J. Photooxidative Cyclization of Quercetin Pentamethyl Ether. J. Am. Chem. Soc. 1965, 87, 2068-2069. 
32 Waiss, A.C., Jr.; Lundin, A.L.; Lee, A.; Corse J. Photochemistry of Quercetin Pentamethyl Ether. J. Am. Chem. Soc. 1967, 89, 6213-6218.

33 Matsuura, T.; Matsushima, H.; Sakamato, H. Photosensitized Oxygenation of 3-Hydroxyflavones a Possible Model for Biological Oxygenation. J. Am. Chem. Soc. 1967, 89, 6370-6371.

34 Matsuura, T.; Matsushima, H.; Nakashima, R. Photoinduced Reactions-XXXVI: Photosensitized Oxygenation of 3-Hydroxyflavones as a Nonenzymatic Model for Quercetinase. Tetrahedron 1970, 26, 435-443.

35 Matsuura, T.; Matsushima, H. Photoinduced Reactions-XXII: Photooxidative Cyclization of 3Methoxyflavones. Tetrahedron 1968, 24, 6615-6618.

36 Suginome, H.; Yomezawa, T.; Masamune, T. Photoinduced Oxygenation of Dehydrorotenones. Tetrahedron Lett. 1968, 49, 5079-5082.

37 Thakur, M.; Berar, S.; Berar, U.; Arora, S.; Gupta, S.C.; Kamboj, R.C. Phototransformations of 6Chloro-3-propargyloxy-2-aryl-4-oxo-4H-1-benzopyran: 1,4-Hydrogen Abstraction in Propargylethers. Tetrahedron 2008, 64, 5168-5173.

38 Matsuura, T.; Takemoto, T.; Nakashima, R. Photoinduced Reactions LII: Photorearrangement of 3-Hydroxyflavones. Tetrahedron Lett. 1971, 19, 1539-1540.

39 Matsuura, T.; Takemoto, T.; Nakashima, R. Photoinduced Reactions-LXXI*1: Photorearrangement of 3-Hydroxyflavones to 3-Aryl-3-hydroxy-1,2-indandiones. Tetrahedron 1973, 29, 3337-3340.

40 Porter, G.; Suppan, P. Reactivity of Excited States of Aromatic Ketones. Pure Appl. Chem. 1964, 9, 499-506.

41 Porter, G.; Suppan, P. Primary Photochemical Processes in Aromatic Molecules. Part 12.Excited States of Benzophenone Derivatives. Trans. Faraday Soc. 1965, 61, 1664-1673.

42 Hammond, G.S.; Leermakers, P.A. Mechanisms of Photoreactions in Solution. X. Relative Efficiencies of Various Quenchers in the Photoreduction of Benzophenone. J. Phys. Chem. 1962, 66, 1148-1150.

43 Yokoe, I.; Higushi, K.; Shirataki, Y.; Komatsu, M. Photochemistry of Flavonoids. III. Photorearrangement of Flavonols. Chem. Pharm. Bull. 1981, 29, 894-898.

44 Ficarra, R.; Ficarra, P.; Tommasini, S.; Campagna, S.; Guglielmo, G. Photochemistry of Flavonoids. Solvent Effect on Photochemically of 3-Hydroxyflavone. Boll. Chim. Farm. 1994, 133, 665-669.

45 Chen, C.F.; Zhu, Y.; Liu, J.C.; Xu, J.H. Photoinduced Electron Transfer Reactions of Flavone with Amines - The Syntheses of 2,4'- and 2,2'-Biflavanoids. Tetrahedron Lett. 1995, 36, 2835-2838.

46 Yoon, U.C.; Mariano, P.S. Mechanistic and Synthetic Aspects of Amine-enone Single Electron Transfer Photochemistry. Acc. Chem. Res. 1992, 25, 233-240.

47 Chen, A.H.; Kuo, W.B.; Chen, C.W. Photochemical Synthesis of 2,2'-Biflavanones from Flavone. J. Chin. Chem. Soc. 2003, 50, 123-127.

48 Yokoe, I.; Tagushi, M.; Shirataki, Y.; Komatsu, M. Photochemical Dimerization of Flavones. J. Chem. Soc. Commun. 1979, 333-334.

49 Schönberg, A.; Khandelwal, G.D. 1,2-Cycloadditionen von Diphenylacetylen an Flavone. Chem. Ber. 1970, 103, 2780-2863. 
50 Gerard, B; Jones, G.; Porco, J.A., Jr. A Biomimetic Approach to the Rocaglamides Employing Photogeneration of Oxidopyryliums Derived from 3-Hydroxyflavones. J. Am. Chem. Soc. 2004, 126, 13620-13621.

51 Gerard, B.; Sangji, S.; O'Leary, D.J.; Porco, J.A., Jr. Enantioselective Photocycloaddition Mediated by Chiral Bronsted Acids: Asymmetric Synthesis of the Rocaglamides. J. Am. Chem. Soc. 2006, 128, 7754-7755.

52 Bhattacharyya, K.; Ramaiah, D.; Das, P.K.; Goerge, M.V. A Laser Flas Photolysis Study of 2,6Dimethyl-3,5-Diphenyl-4-pyrone and Related Chromones. Evidence for Triplet State Structural Relaxation from Quenching Behaviors. J. Phys. Chem. 1986, 90, 5984-5989.

53 Schuster, D.I.; Bonneau, R.; Dunn, D.A.; Rao, J.M.; Joussot-Dubien. Photochemistry of ketones in solution. 72. Characterization of transient intermediates in the photochemistry of cyclohexenones J. J. Am. Chem. Soc. 1984, 106, 2706-2707.

54 Schuster, D.I.; Dunn, D.A.; Bonneau, R. Kinetic properties of the triplet excited state of a linearly conjugated steroid dienone studied by laser flash photolysis. J. Photochem. 1985, 28, 413-418.

55 Christoff, M.; Toscano, V.G.; Baader, W.J. Influence of Methoxy Substitution on Flavonoid Photophysics: a Steady State and Laser Flash Photolysis Study. J. Photochem. Photobiol. A: Chem. 1996, 101, 11-20.

56 Lutz, R.E.; Jordan, R.H. Cis-benzalacetophenone. J. Am. Chem. Soc. 1950, 72, 4090-4091.

57 Du R. Volsteedt, F.; Rall, G.J.H.; Roux, D.G. Cis-Trans Isomerism of a New $\alpha$-Hydroxychalcone from Berchemia Zeyheri Sond. (Red Ivory). Tetrahedron Lett. 1973, 12, 1001-1004.

58 Ferreira, D.; Roux, D.G. Novel Conversion and Coupling Reactions of Chalcones and their Epoxides. J. Chem. Soc., Perkin Trans. I 1977, 134-138.

59 Dewar, D.; Sutherland, G. The Photolysis of 2-Hydroxychalcone and Its Possible Implication in Flavonoid Biosynthesis. Chem. Commun. 1970, 272-273.

60 Mack, P.O.; Pinhey, J.T. The Photochemistry of Flavanone. J. Chem. Soc. Chem. Commun. 1972, 451-452.

61 Stermitz, F.R.; Adamovic, J.A.; Geigert, J. Synthesis and Photoreactions of Sorbophenones. A Photochemical Synthesis of Flavone. Tetrahedron 1975, 37, 1593-1595.

62 Becker, R.S. Theory and Interpretation of Fluorescence and Phosphorescence; WileyInterscience: New York, NY, USA, 1969; p. 240.

63 Matsushima, R.; Kishimoto, T.; Suzuki, M. Photoreactions via $\pi-\pi^{*}$ and $n-\pi^{*}$ Triplet States of Flavanones. Chem. Lett. 1976, 579-580.

64 Nakashima, R.; Okamoto, K.; Matsuura, T. Photoreactions of Flavanones. Bull. Chem. Soc. Jpn. 1976, 49, 3355-3356.

65 Matsushima, R.; Hirao, I. Photocyclization of 2'-Hydroxyflavones to 4-Flavanones. Bull. Chem. Soc. Jpn. 1980, 53, 518-522.

66 Padwa, A.; Au, A.; Lee, G.A.; Owens, W. Carbonyl Group Photochemistry via the Enol Form. Photoisomerization of 4-Substituted 3-Chromanones. J. Am. Chem. Soc. 1976, 98, 3555-3564.

67 Matsushima, R.; Kageyama, H. Photochemical Cyclization of 2'Hydroxychalcones. J. Chem. Soc., Perkin Trans. II 1985, 743-748.

68 Gresh, O.L.; Markovits, Y.; Shani, A. On the Mechanism of Intramolecular Photocycloaddition of Substituted o-Allylphenols to Cyclic Ethers. Tetrahedron 1975, 31, 2803-2807. 
69 Smith, K.K.; Kaufmann, K.J. Solvent Dependence of the Nonradiative Decay Rate of Methyl Salicylate. J. Phys. Chem. 1981, 85, 2895-2897.

70 Nagaoka, S.; Hirota, N.; Sumitani, M.; Yoshirama, K. Investigation of the Dynamic Processes of the Excited States of o-Hydroxybenzaldehyde and o-Hydroxyacetophenone by Emission and Picosecond Spectroscopy. J. Am. Chem. Soc. 1983, 105, 4220-4226.

71 Jain, S. Photolysis of some Flavanones by Ultraviolet Irradiations. Nat. Acad. Sci. Lett. 1997, 20, 130-132.

72 Obara, H.; Takahashi, H. The Photochemical Fries Rearrangement of Phenyl Cinnamate. Bull. Chem. Soc. Jpn. 1967, 40, 1012-1012.

73 Obara, H.; Takahashi, H.; Hirano, H. The Photo-Fries Rearrangement of Hydroxyphenyl Cinnamates. Bull. Chem. Soc. Jpn. 1969, 42, 560-561.

74 Onodera, J.; Obara, H. The Photo-Frie Rearrangement of Bis(methoxy)-phenyl Cinnamates. Bull. Chem. Soc. Jpn. 1974, 47, 240-241.

75 Bhatia, V.K.; Kagan, J. A Photochemical Synthesis of 2',6'-Dihydroxy-4'-methoxy- and 2',4'Dihydroxy-6'-methoxychalcones. Chem. Ind. 1970, 1203-1204.

76 Ramakrishnan, V.T.; Kagan, J. The Photochemical Synthesis of 2'-Hydroxychalcones from Phenyl Cinnamates. J. Org. Chem. 1970, 35, 2901-2904.

77 Chawla, H.M.; Chibber, S.S. Biologically Patterned Sensitized Photooxygenation of Chalcones. Tetrahedron Lett. 1976, 25, 2171-2172.

78 Kearns, D.R.; Hollins, R.A.; Khan, A.U.; Chambers, R.W.; Radlick, P. Evidence for the Participation of $1 \mathrm{G}+$ and 1.DELTA.g Oxygen in Dye-sensitized Photooxygenation reactions. II. J. Am. Chem. Soc. 1967, 89, 5456-5457.

79 Chawla, H.M.; Chibber, S.S.; Sharma, A. Novel Photochemical Conversion of Chalcones to Flavanonols. Tetrahedron Lett. 1978, 30, 2713-2714.

80 Climent, M.J.; García, H.; Iborra, S.; Miranda, M.A.; Primo, J. Photosensitized Dehydrogenation of Flavanones to Flavones Using 2,4,6-Triphenylpyrylium tetrafluoroborate (TPT). Heterocycles 1989, 29, 115-121.

81 Badforss, S. Über die Einwirkung des Lichts auf Ketoxidovebindungen. Chem. Ber. 1918, 51, 214-219.

82 Zimmerman, H.E.; Cowley, B.R.; Tseng, C.Y; Wilson, J.W. A General Theory of Photochemical Reactions. VII. Mechanisms of Epoxy Reactions. J. Am. Chem. Soc. 1964, 86, 947-948.

83 Ramakrishnan, V.T.; Kagan, J. The Photochemical Conversion of Phenyl Epoxycinnamate to Flavonoids and Synthesis of 2'-Hydroxyepoxychalcone. J. Org. Chem. 1970, 35, 2898-2900.

84 Van der Westhuizen, J.H.; Ferreira, D.; Roux, D.G. Some Novel Photochemical and Related Aryl Couplings and Migrations in Flavonoid Synthesis. J. Chem. Soc., Perkin Trans. I 1980, 2856-2865.

85 Jeger, O.; Schafner, K.; Wehrli, H. Photochemical Transformation of $\alpha, \alpha$-Epoxyketones and Related Carbonyl Systems. Pure Appl. Chem. 1964, 9, 555-565.

86 Fourie, T.G.; Ferreira, D.; Roux, D.G. Flavonoid Synthesis based on Photolysis of Flavan-3-ols, 3-Hydroxyflavanones, and 2-Benzylbenzofuranones. J. Chem. Soc., Perkin Trans. I 1977, 2125-133. 
87 Van der Westhuizen, J.H.; Ferreira, D.; Roux, D.G. Photochemical Deoxygenation of an $\alpha$-Ketol: The Dihydroflavonol-Flavanone Conversion. J. Chem. Soc., Perkin Trans. I 1980, 1003-1006.

88 Van der Westhuizen, J.H.; Ferreira, D.; Roux, D.G. A Novel Photochemical Structural Inversion: The first Methoxy-hydroxymethyl Isomerization. J. Chem. Soc., Perkin Trans. I 1980, 1540-1543.

89 Van der Westhuizen, J.H.; Ferreira, D.; Roux, D.G. Photochemical Equivalent of Benzilic Acid Rearrangement and Related Conversions. J. Chem. Soc., Perkin Trans. I 1977, 1517-1522.

90 Turro, N.J. Modern Molecular Photochemistry; Benjamin/Cummings Publishing Co.: Menlo Park, CA, USA, 1978; p. 377.

91 Van der Westhuizen, J.H.; Ferreira, D.; Roux, D.G. Synthesis of Condensed Tannins. Part 2. Synthesis by Photolytic Rearrangement, Stereochemistry, and Circular Dichroism of the First 2,3-cis-3,4-cis-4-Arykflavan-3-ols. J. Chem. Soc., Perkin Trans. I 1981, 1220-1226.

92 Grover, P.K.; Anand, N. Photochemical Rearrangement of 4-Phenyl-3-chromanone. Chem. Commun. 1969, 982.

93 Padwa, A.; Lee, G.A. Involvement of an Enol Tautomer in the Photoisomerization of 4-Phenyl3-chromonone to 4-Phenyldihydrocoumarin. J. Am. Chem. Soc. 1974, 96, 1634-1636.

94 Padwa, A.; Au, A. Tautomeric Control of the Photochemistry of 4-Phenylchroman-3-one. J. Chem. Soc., Chem. Commun. 1975, 58-59.

95 Padwa, A.; Au, A.; Owens, W. Photochemistry of the Chroman and 3-Chromanone Ring Systems. An Example of Tautomeric Control of Excited-State Chemistry. J. Org. Chem. 1978, 43, 303-310.

96 Yokoe, I.; Higushi, K.; Shirataki, Y.; Komatsu, M. Photochemistry of Flavonoids. V. Photocyclization of 2-Styryl-4H-chromen-4-ones. Chem. Pharm. Bull. 1981, 29, 2670-2674.

97 Kamboj, R.C.; Berar, S.; Berar, U.; Thakur, M., Gupta, S.C. Phototransformations of some 3Alkoxy-6-chloro-2-\{(E)-1'-methyl-2'-phenylvinyl $\}$ chromones: A study of Type-II and Triene Bichromophoric System. J. Photochem. Photobiol. A: Chem. 2009, 204, 122-128.

98 Dhande, V.P.; Thakwani, P.; Marathe, K.G. Flavonoid Part 7: A Novel Photosythesis of 3aHydroxybenzylflavones from 3-Arylideneflavanones. Tetrahedron 1988, 44, 3015-3023.

99 Ishibe, N.; Yutaka, S.; Masui, J.; Ishida, Y. Photorearrangement of Isoflavones. J. Chem. Soc., Chem. Commun. 1975, 241.

100 Griesbeck, A.G.; Mattay, J. Synthetic Organic Photochemistry. In Molecular and Supramolecular Photochemsitry; Ramamurthy, V., Schanze, K.S., Eds.; Marcel-Dekker: New York, NY, USA, 2005; Volume 12.

101 Grotewold, E. The Science of Flavonoids; Springer: New York, NY, USA, 2006.

102 Inoue, Y.; Ramamurthy, V. Chiral Photochemistry. In Molecular and Supramolecular Photochemsitry; Ramamurthy, V., Schanze, K.S., Eds.; Marcel-Dekker: New York, NY, USA, 2004; Volume 11.

(C) 2010 by the authors; licensee MDPI, Basel, Switzerland. This article is an Open Access article distributed under the terms and conditions of the Creative Commons Attribution license (http://creativecommons.org/licenses/by/3.0/). 